\title{
A TECHNOLOGY ASSESSMENT AND FEASIBILITY EVALUATION OF NATURAL GAS ENERGY FLOW MEASUREMENT ALTERNATIVES
}

\section{Final Report, Tasks A and B}

(August 1998 - January 1999)

\author{
by \\ Kendricks A. Behring II \\ Eric Kelner \\ Ali Minachi \\ Cecil R. Sparks \\ Thomas B. Morrow \\ Steven J. Svedeman
}

Southwest Research Institute

P.O. Drawer 28510

San Antonio, Texas 78228-0510

for

U.S. Department of Energy

Federal Energy Technology Center

P.O. Box 880

Morgantown, West Virginia 26507-0880

under

DOE Cooperative Agreement No. DE-FC21-96MC33033--02

January 1999 


\section{A TECHNOLOGY ASSESSMENT AND FEASIBILITY EVALUATION OF NATURAL GAS ENERGY FLOW MEASUREMENT ALTERNATIVES}

Final Report, Tasks A and B

(August 1998- January 1999)

by

Kendricks A. Behring II

Eric Kelner

Ali Minachi

Cecil R. Sparks

Thomas B. Morrow

Steven J. Svedeman

Southwest Research Institute

P.O. Drawer 28510

San Antonio, Texas 78228-0510

for

U.S. Department of Energy

Federal Energy Technology Center

P.O. Box 880

Morgantown, West Virginia 26507-0880

under

DOE Cooperative Agreement No. DE-FC21-96MC33033

January 1999

Approved by

Danny M. Deffenbaugh, Director

Department of Fluids Engineering

SOUTHWEST RESEARCH INSTITUTE
SANANTONIO
DETROIT
WOUSTON
WASHGTON, DC




\section{Disclaimer}

This report was prepared as an account of work sponsored by an agency of the United States Government. Neither the United States Government nor any agency thereof, nor any of their employees, makes any warranty, express or implied, or assumes any legal liability or responsibility for the accuracy, completeness, or usefulness of any information, apparatus, product, of process disclosed, or represents that its use would not infringe privately owned rights. Reference herein to any specific commercial product, process, or service by trade name, trademark, manufacturer, or otherwise does not necessarily constitute or imply its endorsement, recommendation, or favoring of the United States Government or any agency thereof. The views and opinions expressed herein do not necessarily reflect those of the United States Government or any agency thereof. 


\section{Abstract}

Deregulation and open access in the natural gas pipeline industry has changed the gas business environment towards greater reliance on local energy flow rate measurement. What was once a large, stable, and well-defined source of natural gas is now a composite from many small suppliers with greatly varying gas compositions. Unfortunately, the traditional approach to energy flow measurement [using a gas chromatograph (GC) for composition assay in conjunction with a flow meter] is only cost effective for large capacity supplies (typically greater than 1 to 30 million scfd). A less costly approach will encourage more widespread use of energy measurement technology. In turn, the United States will benefit from tighter gas inventory control, more efficient pipeline and industrial plant operations, and ultimately lower costs to the consumer.

An assessment of the state and direction of technology for natural gas energy flow rate measurement is presented. The alternative technologies were ranked according to their potential to dramatically reduce capital and "operating and maintenance" (O\&M) costs, while improving reliability and accuracy. The top-ranked technologies take an unconventional "inference" approach to the energy measurement problem. Because of that approach, they will not satisfy the fundamental need for composition assay, but have great potential to reduce industry reliance on the GC.

Technological feasibility of the inference approach was demonstrated through the successful development of data correlations that relate energy measurement properties (molecular weight, mass-based heating value, standard density, molar ideal gross heating value, standard volumetric heating value, density, and volume-based heating value) to three inferential properties: standard sound speed, carbon dioxide concentration, and nitrogen concentration (temperature and pressure are also required for the last two). The key advantage of this approach is that inexpensive on-line sensors may be used to measure the inferential variables, which can then be applied (through the data correlations) to convert existing flow meters (ultrasonic, orifice, turbine, rotary, Coriolis, diaphragm, etc.) for on-line energy measurement. The practical issues for field development were evaluated using two transducers extracted from a \$100 ultrasonic domestic gas meter, and a \$400 infrared sensor. 


\section{Table of Contents}

Page

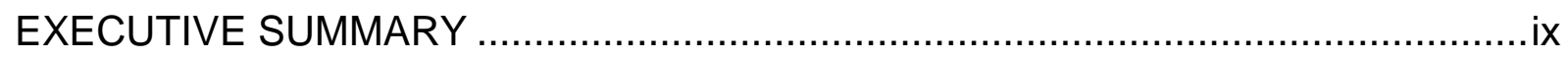

TASK A: TECHNOLOGY ASSESSMENT OF NATURAL GAS ENERGY FLOW MEASUREMENT ALTERNATIVES ................................................ 1

1.0 INTRODUCTION AND BACKGROUND - Industry Needs and Desires for Energy Flow Measurement Technology ...................................................... 1

2.0 FUNDAMENTAL TECHNOLOGY CLASSIFICATIONS .............................. 5

2.1 Traditional Approach with Standard Volumetric (Mass) Reference ……..................... 5

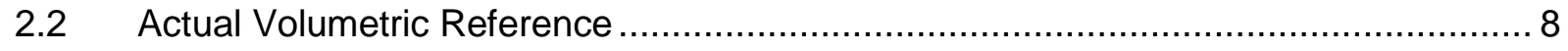

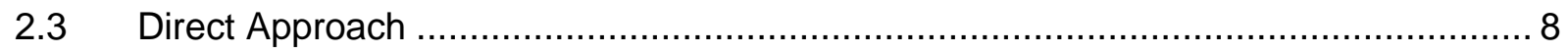

3.0 COMMERCIALLY AVAILABLE EQUIPMENT - Accuracy, Operational, and Economic Performance ................................................................... 9

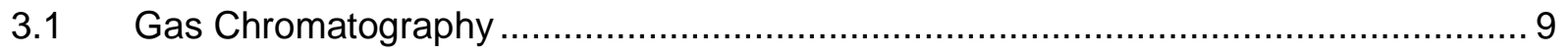

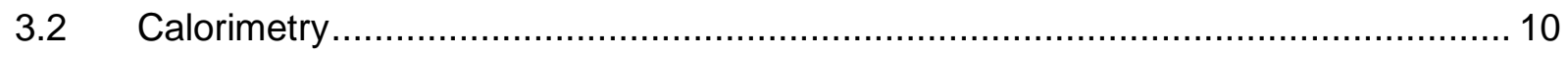

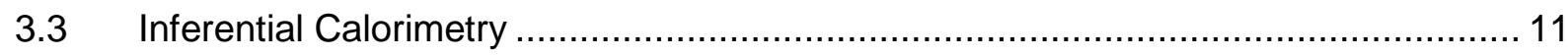

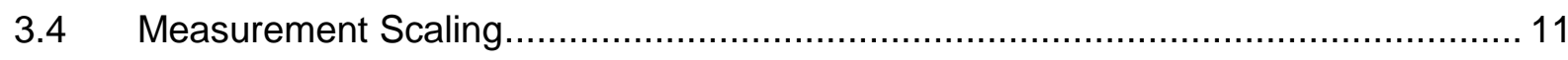

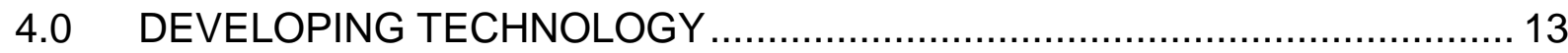

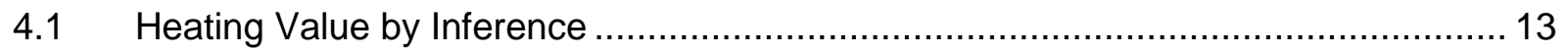

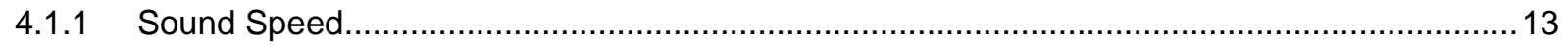

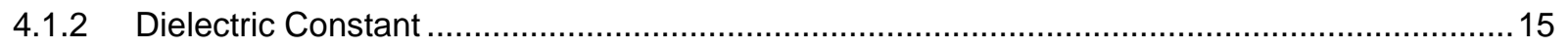

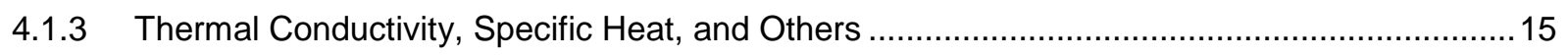

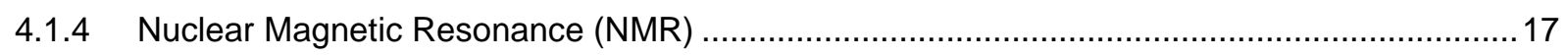

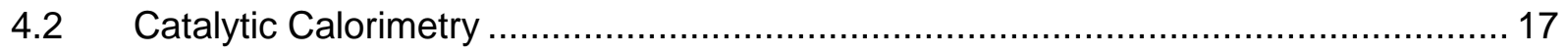




\section{Table of Contents (continued)}

Page

$5.0 \quad$ INDUSTRY ACCEPTANCE REQUIREMENTS .................................... 19

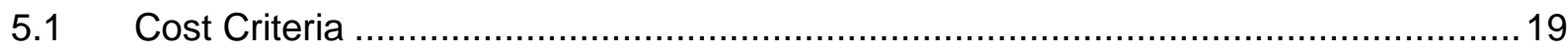

5.2 Performance Criteria and Market Potential ...........................................................20

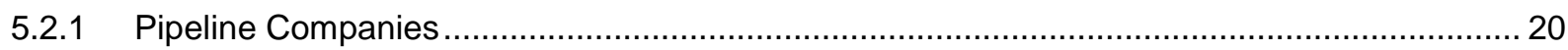

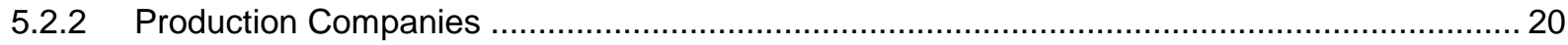

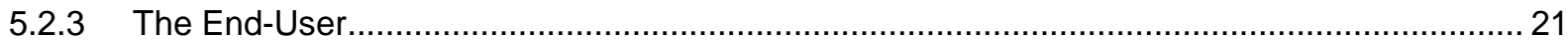

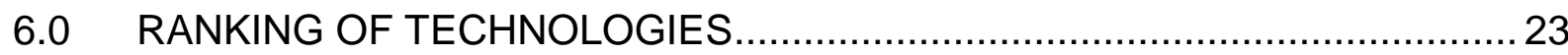

6.1 \#1 Ranking: Heating Value Inference from Speed of Sound Measurements ............23

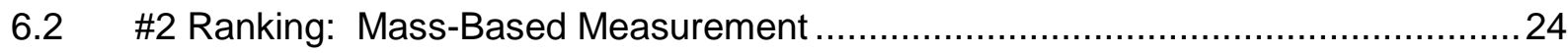

6.3 \#3 Ranking: Thermal Microbridge and Crystal Resonator .....................................25

6.4 \#4 Ranking: Heating Value Inference from Dielectric Constant Measurements........25

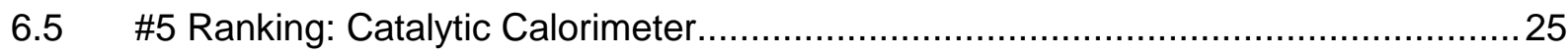

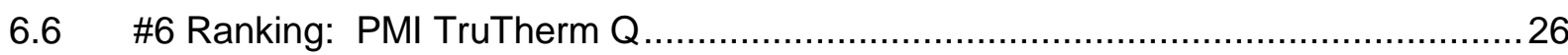

TASK B: FEASIBILITY EVALUATION OF PROMISING ALTERNATIVES ..............27

7.0 THE VISION OF LESS EXPENSIVE AND MORE ACCURATE NATURAL GAS ENERGY MEASUREMENT ….....................................2 27

8.0 CHARACTERIZING NATURAL GAS PROPERTIES BY INFERENCE ..........29

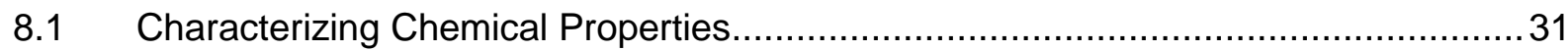

8.1.1 Inferential Correlation for Mixture Molecular Weight, M ................................................... 31

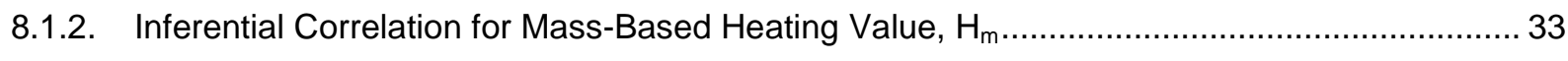

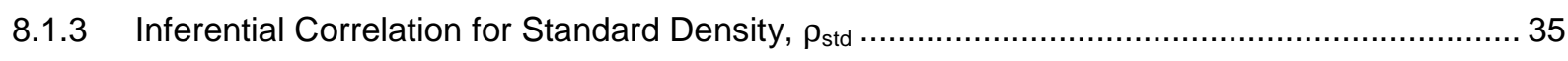

8.1.4 Inferential Correlation for the Mixture Molar Ideal Gross Heating Value, $\mathrm{H}_{\mathrm{n}, \text { ref }}[\mathrm{kJ} / \mathrm{mol}$, with

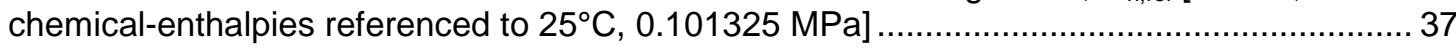

$8.2 \quad$ Characterizing Thermodynamic Properties .................................................. 39 


\section{Table of Contents (continued)}

Page

9.0 FEASIBILITY EVALUATION OF INFERENTIAL PROPERTY-SENSING

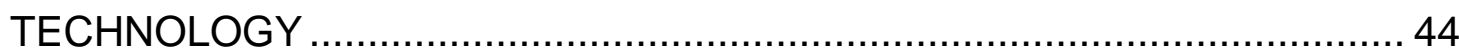

9.1 Uncertainty Specifications of Inferential Variables ................................................ 44

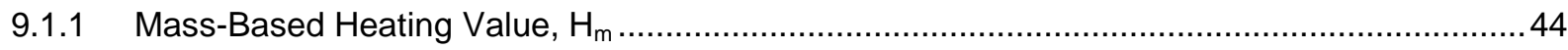

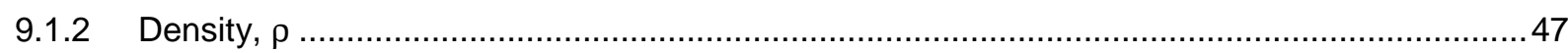

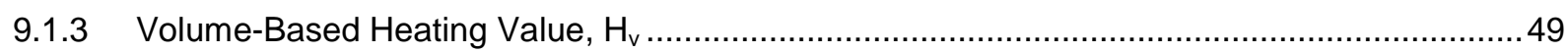

9.2 Feasibility Evaluation of Sound Speed Measurement............................................ 50

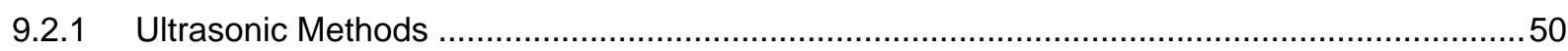

9.2.2 Exploratory Tests of Ultrasonic Technology .................................................................. 52

9.3 Feasibility Evaluation of Diluent (Carbon Dioxide and Nitrogen) Concentration

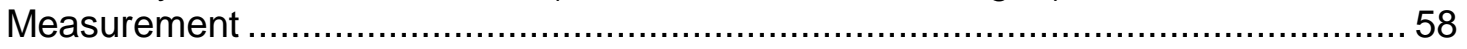

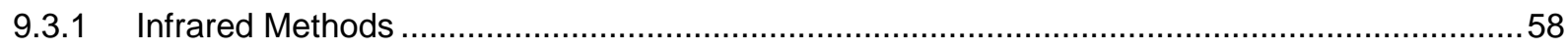

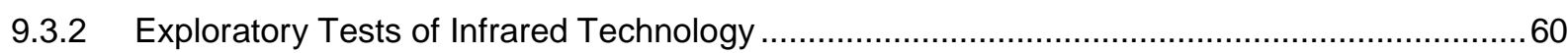

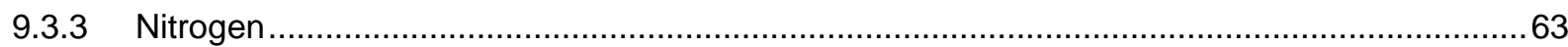

10.0 CONCLUSIONS AND RECOMMENDATIONS $\ldots \ldots \ldots \ldots \ldots \ldots \ldots \ldots \ldots \ldots \ldots \ldots . \ldots \ldots$

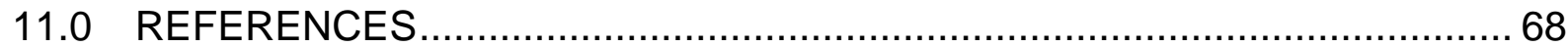

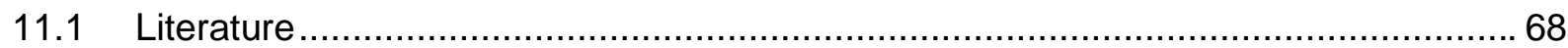

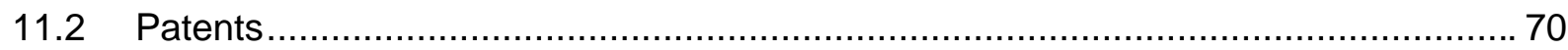

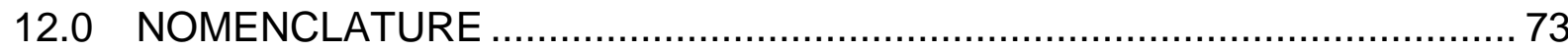

APPENDIX A: NATURAL GAS COMPOSITION DATABASE $\ldots \ldots \ldots \ldots \ldots \ldots \ldots \ldots \ldots . . . \ldots \ldots$

APPENDIX B: FORTRAN PROGRAM TO MODIFY A.G.A. 8 (1994) SUBROUTINES FOR GENERAL INFERENTIAL CHARACTERIZATION 


\section{EXECUTIVE SUMMARY}

\section{Background:}

Natural gas value is determined by measuring the energy flow rate delivered to the customer. The natural gas industry in the United States has historically determined energy flow rate by combining independent measurements of flow rate (delivery rate) and heating value (combustible energy). A composition assay by gas chromatography (GC) is often performed to calculate heating value and gas properties (e.g., density) required to determine flow rate. Composition assay is, in general, a tedious process that requires the collection of representative gas samples and analysis of those samples using complex and expensive measurement equipment. As a result, the cost-effective application of such equipment has been limited by flowing natural gas capacity (typically at least 1 to 30 million scfd).

The need to apply local energy measurement equipment throughout gas networks has increased as a result of deregulation. Gas supplies are no longer uniform and stable, but are a composite from a greater number of sources. Because of the composition variations within a typical pipeline today, inequities may occur if the supply is assumed to be stable, or if periodic sampling is done infrequently. There is greater need in the open market to measure energy flow rate on-line, even at sites with capacities below 1 to 30 million scfd. If simpler and less expensive energy measurement technology can be implemented, the United States will benefit from better gas inventory control, more efficient pipeline and industrial plant operations, and ultimately lower costs to the consumer.

A non-traditional, and more promising, approach to natural gas energy flow rate measurement has been identified and found to be technologically feasible. Natural gas composition may be accurately characterized by the measurement of three inferential variables (standard sound speed, carbon dioxide concentration, and nitrogen concentration) rather than a detailed GC composition assay. Feasibility was demonstrated using two ultrasonic transducers extracted from a \$100 ultrasonic domestic gas meter, and one \$400 infrared sensor.

\section{Objective:}

The objective of this work was to assess the state and direction of technology for the measurement of natural gas energy flow rate, and evaluate the feasibility of promising alternatives. The assessment was performed in light of industry acceptance requirements, which largely depend on a reduction in capital and "operating and maintenance" (O\&M) costs. The technological feasibility evaluation was performed with inexpensive, commercially available equipment.

\section{Results:}

Existing technology is capable of fulfilling technical measurement performance requirements in the industry. However, traditional energy measurement technology is cost prohibitive for widespread application. A different technological approach is required to improve cost and reliability, while maintaining (if not improving) accuracy. 
Promising technologies were ranked according to their potential to lower costs (relative to a GC installation) and make use of technically viable technologies. The top three rankings related to the use of inexpensive instrumentation to measure gross characterization properties of natural gas, avoiding a detailed composition assay. The project, therefore, proceeded to further evaluate the feasibility of such an approach.

For an exploratory range of 102 different natural gas compositions $(987-1,150 \mathrm{Btu} / \mathrm{scf}$, 16.3 - $19.5 \mathrm{lbm} / \mathrm{lb}-$ mole, 83.4 - 98.3 mole\% methane, 0.97 - 7.4 mole\% total diluent concentration, and $0.001-0.1$ mole $\% \mathrm{C}_{6}+$ ), successful gross inferential natural gas property correlations were developed. These requisite properties include molecular weight, mass-based heating value, standard density, molar ideal gross heating value, standard volumetric heating value, density, and volume-based heating value. The correlations may be applied to determine flow rate or energy flow rate from flow meters of all kinds (ultrasonic, orifice, turbine, rotary, Coriolis, diaphragm, etc.) with knowledge of only standard sound speed, $S_{s t d}$, carbon dioxide concentration, $X_{\mathrm{CO} 2}$, nitrogen concentration, $X_{N 2}$, temperature, $T$, and pressure, $P$. The feasibility of such an approach was demonstrated using two ultrasonic transducers extracted from a $\$ 100$ ultrasonic domestic gas meter (to measure standard sound speed), and one $\$ 400$ infrared sensor (to measure carbon dioxide concentration). No sensor has yet been identified to directly measure nitrogen concentration, but indirect measurement approaches have been identified.

Despite the successful demonstration of general technological feasibility, the inexpensive inferential sensor designs require refinement, packaging for field application, and prototype testing (as a package) under flowing natural gas conditions.

It is recommended that the 1999 project focus on:

(1) Extension of the data correlations to a broader range of gas compositions, and determine if sound speed, measured at line conditions, can be easily related to sound speed at standard conditions. This would make a sound speed retrofit sensor unnecessary for ultrasonic meters,

(2) Refinement of the performance of the speed of sound sensor,

(3) Refinement of the performance of the infrared carbon dioxide sensor,

(4) Development of a workable indirect approach to nitrogen measurement,

(5) Design and construction of a prototype retrofit instrument module for testing purposes,

(6) Conduction of tests with the prototype retrofit module in the GRI Metering Research Facility at varied natural gas operating conditions. 


\section{TASK A: TECHNOLOGY ASSESSMENT OF NATURAL GAS ENERGY FLOW MEASUREMENT ALTERNATIVES}

\subsection{INTRODUCTION AND BACKGROUND - Industry Needs and Desires for Energy Flow Measurement Technology}

Virtually all natural gas produced in the U.S. is used as fuel. As such, its intrinsic value lies in the combustible chemical energy stored in hydrocarbon molecules (heating value). The delivery rate (flow rate) of such a commodity is also a critical value measurement for custody transfer. Unfortunately, there is presently no practical means for measuring energy flow rate (the simultaneous product of heating value and flow rate) directly and instantaneously, so the problem has been historically subdivided into more tenable measurement pieces.

Energy flow rate has traditionally been determined by independent measurements of flow rate and heating value. Flow meters are based on a number of different measurement technologies, each of which has different measurement sensitivities and implementation cost. Heating value is commonly determined by composition assay. Composition assay is, in general, a tedious process that requires collection of a representative gas sample, and gas chromatographic (GC) analysis. Gas samples can either be automatically collected and analyzed using a field GC every few minutes, or collected much less frequently using manual labor, and transported to a central laboratory for GC analysis. In the absence of low cost instrumentation, the application of such automated equipment, especially field gas chromatographs, has been limited.

With the advent of deregulation and open access in the gas pipeline industry (FERC Orders 436, 500, 636, etc.), substantial changes were experienced in the natural gas business environment. Large volume, long-term commodity gas contracts (usually supplying gas from fixed, well-defined gas sources) gave way to a proliferation of small volume, short-term transportation contracts, taking numerous gas "packages" from a multiplicity of supply (and/or storage) fields with widely varying gas qualities. These short-term gas packages lose their identity when mixed (commingled) in the pipeline, and the purchaser receives whatever is in the pipeline at his time of need. Without a convenient and low-cost means for continuously measuring the quality of gas entering and exiting the pipeline, neither the supplier nor the enduser can assure quality of the commodity exchanged, nor can gas supplies be blended to assure conformity to a quality standard (as, for example, that quality required for optimizing the efficiency of a furnace burner). End-users withdraw gas on the basis of energy needs. If energy content is low, they simply withdraw (and pay for) more gas than anticipated.

Because of the composition variations within a typical pipeline today, the assumption of a fixed energy content based on infrequent periodic sampling can lead to energy exchange inequities. For example, typical pipeline-quality gas has a heating value between 1,010 to $1,030 \mathrm{Btu} / \mathrm{scf}$, but content variations from 980 to $1,250 \mathrm{Btu} / \mathrm{scf}$ are seen in some cases. Wellhead gas normally ranges from about 980 to $1,300 \mathrm{Btu} / \mathrm{scf}$ for naturally flowing wells. Some West Texas wells produce 1,200 to 1,300 Btu/scf gas at high pressure, while vacuum recovery processes can produce even higher energy gas because of high saturation limits, sometimes up to 2,000 Btu/scf. 
For these reasons, the gas industry is in great need of accurate, reliable, and low-cost equipment that will measure instantaneous (or near-instantaneous) energy flow rate. Low cost is a critical factor because price will determine the extent to which any new technology will be accepted and implemented.

Gas producers and end-users have been the primary drivers behind the push for energy measurement.

- Gas producers seek reimbursement for the full intrinsic value of the commodity (energy) they provide, not just the volume of gas delivered. For example, much of the low-pressure Appalachian gas produced has heating value near 1,240 Btu/scf. Because heavy hydrocarbons can be stripped out (and sold separately) and still leave pipeline quality gas, this rich gas is more valuable than a lower quality (e.g., 1,010 Btu/scf) gas.

- Most large end-users use the gas for fuel. In such cases, energy content is very important, and a few percent change in heating value can have a large economic impact. It is important to these consumers that full value is received for the dollars spent. Low heating value means more gas volume must be purchased. In addition, variations greater than $50 \mathrm{Btu} / \mathrm{scf}$ can adversely affect burner efficiencies in furnaces and engines, resulting in reduced operational efficiency.

- To small residential users, on the other hand, energy content is a trivial issue, so long as gas appliances perform satisfactorily. They rely on the local distribution companies (LDC's) to meet their needs and protect their interests.

- Pipeline companies (gas transporters) are caught in the middle of the energy measurement controversy. The pipeline itself is designed and operated on the basis of pressure, volume flow rate, and gas density. Compressor head curves, pipeline pressure drop, and line pack are not direct functions of heating value. Nevertheless, many (if not most) pipeline companies now provide energy measurement and energy-based transportation rates in recognition of their custodial responsibilities to their customers. It has become necessary for accounting purposes to balance pipelines on the basis of energy (rather than volume) and balance again (for operational purposes) on the basis of volume. Without well-defined energy content, it is impossible to keep both balanced. With an energy imbalance, the pipeline company may be required to supply make-up energy from its own pocket at a purchase price per cubic foot much higher than delivery charges. Conversely, the pipeline might deliver less energy than the customer has contracted for. An incorrect energy balance can also have a direct impact on line pack (pipeline inventory) and gas deliverability.

In summary, the general consensus among all segments of the industry is that accounting should reflect the value of the product, whether the gas is being bought, sold, transported, or processed. Traditional energy measurement technology, however, is cost prohibitive for widespread application. A different technological approach is required to maintain (if not improve) accuracy, operational reliability, and cost. Such an improvement will benefit the U.S. gas industry through:

(1) better gas inventory control,

(2) lower capital, operating and maintenance costs for custody transfer, 
(3) tighter controls over natural gas emissions,

(4) more efficient operation of large industrial combustors, lowering polluting combustion emissions,

(5) more precise control over gas deliverability,

(6) lower costs to the consumer. 


\subsection{FUNDAMENTAL TECHNOLOGY CLASSIFICATIONS}

Natural gas energy flow measurement is, fundamentally, a count of combustible molecular bonds that pass a given location in time. Such a direct approach, however, is not the traditional approach, nor necessarily the most feasible approach based on modern technology. Energy flow rate may also be represented as the product of flow rate (mass or volume per unit time) and heating value (combustible value per unit mass or volume).

\subsection{Traditional Approach with Standard Volumetric (Mass) Reference}

The natural gas industry has historically measured the value of gas for custody transfer by referencing flow rate and heating value to arbitrary standard volume flow conditions (14.73 psia and $60^{\circ} \mathrm{F}$, for example). Ultimately, when energy flow rate is computed, this arbitrary reference condition cancels, leaving the product of mass-based flow rate and heating value:

$$
Q_{\text {energy }}=Q_{v, s t d} H_{v, s t d}=\left(\frac{Q_{m}}{\rho_{\text {std }}}\right)\left(\rho_{\text {std }} H_{m}\right)=Q_{m} H_{m}
$$

The standard gas density (density calculated at a standard reference pressure and temperature), $\rho_{s t d}$, is a function of the flowing gas composition only, and is strictly not a thermodynamic property. Arbitrary standard reference conditions have traditionally been used to balance gas networks and bill customers, even though more direct mass or energy quantities could be used.

Examination of the fundamental energy flow rate equations for different meter types can reveal more direct strategies for measuring what ultimately determines value of the product delivered, i.e., energy flow rate. Volume-based meters, for example, include ultrasonic, turbine, rotary, or diaphragm meters. Mass flow rate through a volume-based meter is the product of measured volume flow rate and gas density:

$$
\underset{\substack{\text { energy, } \\ \text { volume-based }}}{Q_{m}}=\left(Q_{m}\right)=\left(\rho Q_{v}\right)\left(H_{m}\right)
$$

If a differential-pressure producer like an orifice meter is used, then mass flow rate is nominally proportional to the square root of gas density:

$$
\underset{\substack{Q_{\text {energy, }} \text { differential-based } \\ \text { end }}}{ }=\left(Q_{m}\right)\left(H_{m}\right)=(C \sqrt{\rho})\left(H_{m}\right)
$$


where $C$ is a factor that includes the dependence of all other orifice measurement variables (pressure drop, orifice bore diameter, meter-tube diameter, isentropic exponent (secondary importance, compared to density), and viscosity (secondary importance, compared to density).

Finally, if a mass-based meter such as a Coriolis meter is used, then mass flow rate is determined without reference to gas density:

$$
Q_{\substack{\text { energy, } \\ \text { mass-based }}}=\left(Q_{m}\right)\left(H_{m}\right)
$$

Such classifications are important because of the primary dependence of gas density on composition. Gas composition is traditionally measured through the collection of gas samples (using either spot, on-line, or composite sampling techniques) that are analyzed by gas chromatography (GC). This extended process of gas property determination provides multiple sources of potential error, and such errors are propagated primarily through the application of gas density to determine flow rate.

The propagation of composition uncertainty through gas density makes volume-based meters most sensitive to composition measurement errors because mass flow rate through a volume-based meter is proportional to density. Differential-pressure producers are half as sensitive to composition errors because mass flow rate is nominally proportional to the square root of density. Mass-based meters are least sensitive because no thermodynamic properties must be measured to determine energy flow rate. Mass-based meters only require knowledge of the mass-based heating value, which is a chemical property (depends only on gas composition), and is a very weak function of hydrocarbon composition.

The mass-based heating value, $H_{m}[\mathrm{Btu} / \mathrm{lbm}]$, is a weak function of hydrocarbon composition because the energy released per unit mass is nearly equivalent to the energy released per unit molecular bond. Energy released by combustion of a carbon-hydrogen bond from methane $\left(\mathrm{C}_{1}\right)$, is similar to the energy released by combustion of a carbon-hydrogen bond from $n$-decane $\left(\mathrm{C}_{10}\right)$, so there is little variation in heating value of natural gas hydrocarbons (mostly normal paraffins) on a mass basis. This point is demonstrated by two vastly different gas mixture compositions shown in Table 2-1.

As seen in Table 2-1, even though the standard volumetric heating values of the mixtures differ by $53 \%(1,566 \mathrm{Btu} / \mathrm{scf}$ compared to $1,025 \mathrm{Btu} / \mathrm{scf})$, the mass-based heating value varies by only $4 \%(21,960 \mathrm{Btu} / \mathrm{lbm}$ compared to $22,910 \mathrm{Btu} / \mathrm{lbm})$. In this particular example, the mass-based heating value is thirteen times less sensitive than the standard volumetric heating value to the variations in hydrocarbon composition. This effect is due to the physical reality that normal paraffin hydrocarbon bonds are nearly identical in energy content, regardless of the size of their parent molecule. Larger molecules have more bonds available, but on a mass basis the contribution is not much different.

The diluent concentrations (carbon dioxide and nitrogen) are kept constant in the example of Table 2-1, while the hydrocarbon concentrations were varied. That is an important qualifier because the diluents contribute mass to the mixture, but provide no heating value. If the diluent concentrations had varied, greater differences might have been seen. Whereas diluent gases dilute $H_{v, s t d}$ directly, their impact on $H_{m}$ varies, depending on their proximity to the mixture molecular weight. For example, a natural gas mixture with 1 mole\% helium has a 
higher heating value, per unit mass, than a gas mixture with 1 mole $\%$ nitrogen; the mixture containing helium has a smaller mass fraction of diluents. In other words, if the diluents remain constant, as in Table 2-1, the heating value per unit mass changes very little, even when the hydrocarbon composition varies significantly.

Table 2-1. The weak composition dependence of mass-based heating value is demonstrated relative to the strong composition dependence of standard volumetric heating value, for two vastly different natural gas composition mixtures.

\begin{tabular}{|l|c|c|}
\hline Gas Component & $\begin{array}{c}\text { Gas Mixture \#1 } \\
{[\mathbf{m o l e \%}]}\end{array}$ & $\begin{array}{c}\text { Gas Mixture \#2 } \\
{[\mathbf{m o l e \%}]}\end{array}$ \\
\hline Methane & 95.58 & 65.97 \\
\hline Ethane & 2.037 & 10.16 \\
\hline Propane & 0.381 & 8.32 \\
\hline i-butane & 0.0728 & 2.21 \\
\hline n-butane & 0.0652 & 6.53 \\
\hline i-pentane & 0.0343 & 1.90 \\
\hline n-pentane & 0.0265 & 2.32 \\
\hline n-hexane & 0.0216 & 0.534 \\
\hline n-heptane & 0.0153 & 0.190 \\
\hline n-octane & 0.0112 & 0.084 \\
\hline n-nonane & 0.0051 & 0.021 \\
\hline n-decane & 0.000 & 0.011 \\
\hline Carbon Dioxide & 0.750 & 0.750 \\
\hline Nitrogen & 1.00 & 1.00 \\
\hline Total & $\mathbf{1 0 0 . 0 0}$ & $\mathbf{1 0 0 . 0 0}$ \\
\hline & & \\
\hline $\boldsymbol{H}_{\boldsymbol{v}, \text { std }}[$ Btu/scf] & $\mathbf{1 , 0 2 5}$ & $\mathbf{1 , 5 6 6 ( + 5 3 \% )}$ \\
\hline $\boldsymbol{\rho}_{\text {std }}[$ [lbm/scf] & $\mathbf{0 . 0 4 4 7 4}$ & $\mathbf{0 . 0 7 1 3 0}$ \\
\hline $\boldsymbol{H}_{\boldsymbol{m}}[$ Btu/lbm] & $\mathbf{2 2 , 9 1 0}$ & $\mathbf{2 1 , 9 6 0 ( - 4 \% )}$ \\
\hline
\end{tabular}

* Standard temperature and pressure are taken to be $60^{\circ} \mathrm{F}$ and 14.73 psia.

If a mass-based flow meter (such as a Coriolis meter) is used to measure energy flow rate, then the only remaining measurement requirement would be $H_{m}$, which is principally a function of the diluent concentration of the natural gas. As long as the diluent concentration remained relatively constant, then $H_{m}$ could likely be measured very infrequently, using a spot 
sampling and analysis approach. Greater confidence could be gained if the diluent concentrations were measured on-line, or were inferred by measurement of some other property. A full composition assay would likely be unnecessary, since $H_{m}$ is a weak function of hydrocarbon composition. If any other flow meter (orifice, ultrasonic, turbine, rotary, diaphragm, etc.) is used to measure energy flow rate, then thermodynamic property measurement (principally gas density) becomes a critical issue.

\subsection{Actual Volumetric Reference}

A non-traditional approach to energy flow rate measurement involves application of a non-traditional reference condition for combining flow rate and heating value - the actual flowing condition in the pipe. This unique reference condition only has useful application for the very common volume-based meters, such as ultrasonic, turbine, rotary, or diaphragm meters. Combining actual volumetric flow rate [acfh, for example] and actual volumetric heating value [Btu/acf, for example] eliminates the need for arbitrary standard volumetric reference conditions. Gas networks could then be balanced on energy alone, the ultimate gas value quantity, rather than standard volumetric flow rate. Knowledge of other pipeline flow properties (e.g., composition) may still be desirable, but would not be required at every metering site.

Application of the actual volumetric reference creates a unique perspective on energy measurement requirements. Equation (2-2) may be re-written:

$$
Q_{\substack{\text { energy, } \\ \text { volume-based }}}=\left(Q_{v}\right)\left(\rho H_{m}\right)=\left(Q_{v}\right)\left(H_{v}\right)
$$

Note that whereas the mass-based heating value, $H_{m}$, is a chemical property (a function of gas composition only), the actual volumetric heating value, $H_{v}$, is a thermodynamic property (a function of flowing temperature, pressure, and gas composition). As seen from Equation (25), $H_{v}$ can be calculated as the product of gas density and mass-based heating value, or it could be measured directly. Direct measurement of actual volumetric heating value, $H_{v}$, could eliminate the need for gas sampling, composition analysis, and an equation of state to calculate gas density [A.G.A. Report No. 8 (1994) being the industry standard] - all processes that add expense, time delay, and uncertainty to the energy measurement process. No such device is currently available.

\subsection{Direct Approach}

Energy flow rate, by definition, is the combustible energy in molecular bonds that pass a given location in time. The ultimate energy flow meter would be able to identify and count gas molecules that pass a pipe cross-section at any given time. Reference conditions and density calculations would have no relevance to this energy measurement viewpoint for custody transfer of natural gas. If the type and number of gas molecules is known, then more traditional properties, such as standard volume flow rate, could be derived as a byproduct for pipeline operations purposes. 


\subsection{COMMERCIALLY AVAILABLE EQUIPMENT - Accuracy, Operational, and Economic Performance}

Commercially available technology has traditionally provided two approaches to energy flow rate measurement. The first requires a composition assay in addition to a flow rate measurement. The composition assay not only allows for the calculation of heating value, it is also required to calculate gas properties (primarily gas density) that are needed to determine flow rate. The second approach does not require composition assay. Instead, gas density and heating value can be measured more directly with instrumentation that targets those properties themselves, rather than measuring composition to calculate those properties.

Papers on total energy flow measurement have been presented at industry conferences and training schools. One popular source of fundamental information is the International School of Hydrocarbon Measurement held each year in Oklahoma. Dodds (1991) reviewed the state of the art for energy measurement and identified three types of equipment currently used for heating value determination in natural gas. These are the gas chromatograph, the CutlerHammer recording calorimeter, and the inferential calorimeter.

Calorimetry is a traditional energy measurement alternative to gas chromatography (GC). Unfortunately, the traditional calorimeter makes no effort towards the measurement of gas density, an essential requirement of energy measurement. Additional equipment, such as a densitometer or GC, is also required to complete the calorimeter energy flow rate measurement package. GCs have replaced calorimeters in a number of applications because a composition assay may be used to compute both required properties, heating value and density (with the addition of pressure and temperature measurements).

\subsection{Gas Chromatography}

Gas chromatographs (GCs) measure composition by first separating a natural gas into its pure gas components, and then detecting the concentration of those pure gas components. A gas sample is first collected from the pipeline and injected into one or more columns. The columns are constructed from tubing that is packed or coated with adsorbent material. When a carrier gas such as helium "carries" the natural gas sample through the columns, the adsorbent material adsorbs gas components (causes sample gas molecules to stick), then desorbs (releases) gas components at different rates, depending on molecular structure of the pure gas components. The net result is that the inlet gas mixture is separated such that the various pure gas components are eluted from the columns with different residence times. Once the columns separate the gas mixture, the magnitudes of pure gas component concentrations are sensed at detectors. Field GCs typically use thermal conductivity detectors (TCDs), whereas laboratory units may also use flame ionization detectors (FIDs) due to their increased sensitivity to hydrocarbons in low concentration.

A trend in the GC market is towards smaller columns and detectors to reduce analysis time and instrument size. A detailed extended natural gas analysis (through $\mathrm{C}_{10}$ ) may require 45 minutes to complete. However, HP/MTI and Daniel Industries have developed instruments that can determine hydrocarbon concentrations through $\mathrm{C}_{9}+$ in 3-5 minutes, although many isomers (gas components with the same molecular weight, but different molecular structure and energy content) elute from the columns unseparated. This is not a critical issue in energy flow 
rate measurement, however, because industry standards for calculating density (A.G.A. Report No. 8) and heating value (GPA Standard 2172 and GPA Standard 2145) are designed for groupings of $\mathrm{C}_{6}$ isomers, $\mathrm{C}_{7}$ isomers, etc.

Most field GCs measure separated hydrocarbon (and diluent concentrations) through $\mathrm{C}_{5}$, then flush $\mathrm{C}_{6}$ and heavier hydrocarbons to the detector as a single $\mathrm{C}_{6}+$ concentration. It is then left to the user to characterize the concentration breakdown of the $\mathrm{C}_{6}+$ group, e.g., $50 \%$ $n-C_{6}, 30 \% n-C_{7}, 20 \% n-C_{8}$, or some other relative concentration distribution. Most field units require ac electrical power, containment structures for hazardous environments, and the use of specially prepared gas composition standards (natural gas mixtures of known composition) to calibrate detectors for each targeted pure gas component. In the field, calibration gas standards may require temperature control equipment if ambient temperatures can fall below the hydrocarbon dew point of the gas mixture.

Purchase price for a GC may vary from $\$ 15,000$ to $\$ 60,000$, depending on the separation, detection, and analysis quality of the unit. A typical $\mathrm{C}_{6}+$ field unit costs around $\$ 25,000$ to $\$ 30,000$. A typical laboratory-grade machine costs around $\$ 40,000$ to $\$ 50,000$. Housing, utilities, calibration gas standards, sampling systems, data communication systems, etc. can easily double the purchase price of a unit. Unfortunately, GCs also require regular attention by a highly trained technician or scientist, to ensure that columns, detectors, and switching valves are properly tuned.

Several papers have addressed the use of on-line gas chromatographs (to measure the gas composition for gas property calculations) and a gas flow rate measurement by a turbine meter, rotary meter, orifice meter, or ultrasonic meter. Examples include Haas (1984), Foundos et al. (1985), Kizer (1998), and Price (1998). Kizer (1998) notes that GCs with modern micropacked columns provide faster analysis times, but are not nearly as instantaneous as calorimeters. Care must be taken in the analysis of the $\mathrm{C}_{6}{ }^{+}$lumped components that contain hexanes $\left(\mathrm{C}_{6}\right)$ and heavier hydrocarbons. Kizer (1998) claims that a properly calibrated and operated on-line GC can obtain a repeatability of $\pm 1 \mathrm{Btu} / \mathrm{scf}$ for a natural gas with a nominal heating value of $1,000 \mathrm{Btu} / \mathrm{scf}$.

\subsection{Calorimetry}

A calorimeter provides a very direct way to measure heating value because it burns a gas sample and measures the heat generated. That, in essence, is the definition of heating value. Commercially available calorimetry equipment, however, needs to be considered together with densitometry because gas density is still needed for energy measurement. Commercial calorimeters currently measure standard volumetric heating value at low pressure conditions. Gas density is still needed to calculate energy flow rate from most installed meters, and may be measured either from a densitometer or a GC composition analysis (along with flowing gas temperature and pressure measurements). Note that if a calorimeter could measure actual volumetric heating value (at flowing temperature and pressure), then the additional density measurement would be unnecessary for volume-based meters (see Equation 2-5).

Van Meter (1985) states that the Cutler-Hammer instrument is the "most familiar calorimeter in the gas industry." Stern (1984) reports that this device burns a stream of gas taken from the pipeline at a constant rate with a fixed air/gas ratio. The heat of combustion is transferred to a flow of "heat absorbing air." The temperature change of the "heat absorbing 
air" is related to the heating value of the gas. A tank of water serves to saturate and provide temperature stability for the gas and air. Stern (1984) states, “....as long as the manufacturer's installation and operational guidelines are followed, accuracy of $0.25 \%$ (approximately 2.5 Btu/scf for a typical pipeline gas) or better can be maintained."

The Cutler-Hammer technology now belongs to Fluid Data. It has been discontinued and is no longer available as a new commercial item. Reconditioned Cutler-Hammer calorimeters can be purchased for about $\$ 7,000$. A companion vibrating element densitometer will cost approximately $\$ 10,000$ (reported accuracy on the order of $0.15 \%$ ).

\subsection{Inferential Calorimetry}

An inferential calorimeter also burns a sample of gas in air, but instead of measuring the heat released by combustion, it infers heating value from stoichiometric (just enough air to completely oxidize all of the fuel) combustion properties. Because heating value is inferred from on-line combustion properties, this approach is characterized by a relatively fast response time, as compared to a GC. Like the standard calorimeter, commercial inferential calorimeters also measure standard volumetric heating value $(\mathrm{Btu} / \mathrm{scf})$, and require the additional use of a densitometer to determine energy flow rate at a volume-based meter. They may also be suited to measure the mass-based heating value (Btu/lbm), since it is an even less sensitive property of the fuel composition.

PMI sells an inferential calorimeter that (per ASTM D-4891) fixes the air flow rate delivered to the burner, then correlates fuel (natural gas sample) flow rate to heating value at the stoichiometric condition. A flame temperature sensor is used to provide feedback to regulate fuel flow rate to the flame. Since the stoichiometric condition occurs near a peak flame temperature condition, the fuel flow rate is varied until a peak flame temperature is reached. A rich gas (high heating value) will require a lower fuel flow rate than a lean gas (lower heating value) to reach the stoichiometric condition. The instrument is calibrated periodically with pure methane gas having a known heating value.

Another design maintains the exhaust gas temperature at a fixed level by regulating the air supply to the flame, which is then correlated to heating value. Still another fixes the airflow rate and infers fuel-heating value from exhaust gas temperature. Discontinued products from other manufacturers have found the stoichiometric condition by using an exhaust gas sensor to minimize oxygen concentration or to maximize carbon dioxide concentration.

Stern (1984) reports that the accuracy of the inferential calorimeter is comparable to the Cutler-Hammer calorimeter and that the reproducibility is approximately $\pm 3.2 \mathrm{Btu} / \mathrm{scf}$. The cost of these devices can range from $\$ 10,000$ to $\$ 50,000$. The higher-cost equipment tends to be enclosed for placement in hazardous areas. A companion vibrating element densitometer will cost approximately $\$ 10,000$ (reported accuracy on the order of $0.15 \%$ ).

\subsection{Measurement Scaling}

The first three devices, described in Sections 3.1-3.3, measure only the energy content of the gas. Vander Heyden (1991) and Sowell (1995) have described the PMI, Badger Meter, Inc. system for real-time, direct measurement of natural gas energy flow. Vander Heyden (1991) notes that the PMI system does not separately measure the flow rate and the heating 
value, but it is used in conjunction with a flow meter (such as an orifice meter) that registers the flow rate of gas through the pipeline.

The PMI TruTherm Q system measures the flow rate of natural gas in a sample line, which is then combined with heating value measured by inferential calorimetry, to determine the energy flow rate of natural gas in the sampling line. That value is then scaled up to the pipeline rate by the use of differential pressure measurements across the pipeline and sampleline orifices, and by exploiting thermodynamic similarity (the gas composition, temperature, and pressure is nearly identical in the pipeline and mini orifices). The sample line "miniorifice" is not geometrically similar to a pipeline orifice. In reality, it is a tortuous path component whose flow characteristics may be different than the pipeline orifice.

Site tracking results from field tests of the PMI system are reported by the manufacturer in Vander Heyden (1991) and Sowell (1995). This particular measurement system is priced at $\$ 15,000$ to $\$ 20,000$, depending on peripheral items selected. 


\subsection{DEVELOPING TECHNOLOGY}

New technology has focused on either the measurement of the gas mixture heating value or the total energy flow rate. Many of these approaches avoid a full characterization of the composition of the gas mixture [i.e., by gas chromatography (GC)], or a direct determination of heating value by combustion. Some new technologies seek to correlate (infer) the gas mixture heating value by measuring one or more related intermediate properties of the gas mixture (such as sound speed, thermal conductivity, etc.) in real time.

Some of these developing technologies offer potential for very inexpensive commercial products that may promote widespread application. In addition to low cost, however, they must also be capable of measuring actual volumetric heating value (Btu/acf), to reduce the dependence on GCs in volume-based measurement applications.

A principal difficulty with developing suitable inferential technology involves the need to correct for the presence of diluent gases. The diluents tend to affect intermediate property measurement(s), but do not contribute to the heating value of the gas. Therefore, new inferential approaches have to consider the impact of diluent gases on the accuracy of heating value measurement. Bonne (1995) stated that for approaches "based on measuring one property, the achievable accuracy is acceptable only if the combined volumetric concentration of inert gases $\left(\mathrm{N}_{2}, \mathrm{CO}_{2}, \mathrm{H}_{2} \mathrm{O}, \mathrm{He}\right.$, etc.), in percent, is about equal to or less than the desired accuracy, also in percent."

\subsection{Heating Value by Inference}

\subsubsection{Sound Speed}

In recent years, transit-time ultrasonic flow meters have become popular due to their non-intrusive nature and their demonstrated performance for flow measurement. In some cases, a single multi-path meter is replacing entire orifice metering stations. Compact ultrasonic flow meters are revolutionizing the residential market as well, particularly in Europe, due to the ability of an electronic meter to provide value-added features beyond traditional mechanical meters.

A hidden benefit, arising from the use of ultrasonic meters, is the measurement of sound speed (a thermodynamic property) as a by-product of the transit-time measurements. This additional information may be exploited to indirectly determine other thermodynamic properties, including heating value, of a natural gas stream. There is evidence to suggest that sound speed can be accurately correlated to actual volumetric heating value (Btu/acf), which would convert ultrasonic meters to on-line energy measurement devices (see Section 2.2). For new installations, the ultrasonic meter could serve as a stand-alone energy flow meter. At existing meter stations, any other volume-based meter (such as a turbine, rotary, or diaphragm meter) could then be retrofitted with an inexpensive ultrasonic transit-time device, to achieve real-time energy flow measurement.

Lueptow and Phillips (1994) note that the speed of sound has been used to determine the composition of binary gas mixtures successfully. Phillips and Lueptow (U.S. Patent $5,537,854)$ describe an acoustic natural gas fuel sensor that has a flow-through chamber with a 
sound-producing emitter at one end and a sound receiver at opposite end. A gas fuel flows through the chamber and the speed of sound in the fuel is measured by time-of-flight through the gas. The Phillips and Lueptow patent claims a means for numerically relating sound speed of the gaseous fuel to a combustion property of the gaseous fuel. Lueptow and Phillips (1994) demonstrate the relation between higher heating value and sound speed. For a given sound speed, a range of heating values was obtained that was a function of the combined quantity of "inerts" in the gas stream. Mixtures with low quantities of inert constituents had a greater heating value than those with high levels of inert constituents at a particular sound speed. Using 12 natural gas blends, the spread of data for heating value at a constant value of sound speed is of the order of $7 \%$ for gases with inert concentrations ranging from 0 to $5 \%$. No attempt was made to compensate for the diluent concentrations.

Watson and White (1981) also recognized the ambiguity that diluent gases can generate when correlating heating value to sound speed. However, they demonstrated that low cost piezoelectric sensors can be used to infer heating value by transit-time measurement with a repeatability (precision, not accuracy) of $0.02 \%$.

The tests described above were all attempts to correlate standard volumetric heating value $[\mathrm{Btu} / \mathrm{scf}]$ to acoustic speed. Standard volumetric heating value is the product of standard density and mass-based heating value, and is a function of the gas composition only, i.e., not a thermodynamic property:

$$
H_{v, s t d}=\rho_{\text {std }} H_{m}
$$

There is no published evidence of attempts to correlate sound speed with actual volumetric heating value [Btu/acf], which can be represented as the product of flowing density and massbased heating value:

$$
H_{v}=\rho H_{m}
$$

In contrast to $H_{v, s t d}, H_{v}$ is a true thermodynamic property that depends on gas composition and flowing temperature and pressure. An examination of Equation (2-5) reveals that $H_{v}$ is the correct variable needed to determine energy flow rate.

Kristensen et al. (1998) have developed a proprietary thermodynamic correlation between flowing gas density and sound speed. The correlation requires the use of known diluent concentrations and has predicted density from sound speed (measured from a multi-path ultrasonic meter) to within an accuracy of $1 \%$ over several different natural gas compositions. This work provides encouragement that an accurate sound speed correlation may be drawn between another thermodynamic property, actual volumetric heating value, and sound speed.

Unlike a GC, the transit-time ultrasonic transducer approach has the inherent advantage of not requiring analog calibration with a natural gas of known composition. The ultrasonic transducers are simply used to measure the transit-time of an ultrasonic pulse between two fixed locations. The cost of such a conversion unit could potentially be very low, as evidenced by the cost of residential transit-time ultrasonic flow meters. Residential ultrasonic flow meters may be purchased commercially for about $\$ 100$. A technological hurdle, that could add cost, appears to be the detection and quantification of diluent gases (primarily carbon dioxide and 
nitrogen), whose known concentrations would improve the accuracy of this approach. There are existing instruments capable of detecting such gas component concentrations, but they will only be viable in this application if they can do so inexpensively. Fortunately, the diluent sensor(s) would not need to be extremely accurate, since the diluent concentrations would be used to apply small corrections to the mixture heating value. The diluent sensors would not even necessarily need to measure the diluent concentrations directly, but provide some means to infer their presence.

\subsubsection{Dielectric Constant}

Johnson et al. (U.S. Patent 4,845,976) describe a different method and apparatus to infer the energy content of natural gas. The method relies on relating the mixture dielectric constant to the mixture density by the Clausius-Mosotti equation, and relating the density of the hydrocarbon mixture to the standard volumetric heating value [Btu/scf]. The method claimed in patent $4,845,976$ is to:

(1) measure the dielectric constant of the natural gas mixture (including the diluents);

(2) pass the natural gas mixture through a separation column to extract a mixture of diluent gases and methane;

(3) measure the dielectric constant of the methane and diluent gas mixture;

(4) use the dielectric constant measurements to calculate the standard volumetric heating value of the natural gas mixture.

The Johnson et al. patent assumes that the concentration of diluent gas in the methane/diluent gas binary mixture is approximately the same as the concentration in the hydrocarbon gas mixture.

The development effort was conducted with sponsorship from the Gas Research Institute (GRI). The final GRI project report (Johnson et al., 1984) states that an uncorrected accuracy of $+2.5 \%$ was achieved in measuring the standard volumetric heating value [Btu/scf] of natural gas mixtures containing diluents. The diluents caused an overestimation of the heating value. The approach to correct for the presence of the diluents, outlined in the patent, was apparently never implemented. Johnson et al. reported (1984) that the prototype cost $\$ 2,000$ to produce.

\subsubsection{Thermal Conductivity, Specific Heat, and Others}

Bonne (1995) claims that more accurate heating value determinations are possible if two or more properties of the natural gas mixture are measured. While several combinations of properties are possible, Bonne prefers to measure the thermal conductivity and the specific heat of the gas mixture and to relate these measurements to heating value. Bonne (1992) described the operation of a gas property sensor that is identical in structure to a hot-element anemometer fabricated and marketed by Honeywell in 1987. When the sensor is not exposed to forced convection, the sensor output is believed to indicate the average thermophysical properties of the surrounding fluid. According to Bonne (1992), a heater element is energized and a nearby temperature sensing element registers the time-dependent increase in gas temperature. Then, the thermal conductivity is determined from the steady-state sensor element output, and the 
volumetric specific heat is determined from the transient sensor output and the thermal conductivity. U.S. Patent 5,486,107 provides many of the details concerning the method and apparatus for the gas property sensing system.

Bonne (1992) advocates calibration of the gas property sensor using pure gases such as methane, ethane, and nitrogen at constant temperature and pressure. In operation, the sensor will see a natural gas mixture containing several hydrocarbon gases and diluents. Subsequent research has focused on the calculation of mixture properties for gas mixtures of arbitrary composition. Bonne et al. (1995a,b) indicate that a consistent set of values of thermal conductivity, $\mathrm{k}_{\mathrm{j}}$, and specific heat, $\mathrm{cp}_{\mathrm{j}}$, are needed for a chosen set of pure calibration gases and an accurate procedure to compute the $\mathrm{k}$ and $\mathrm{cp}$ values for gas mixtures. Bonne and Kubisiak (1996) state, "....we have chosen to calibrate our sensors with two to three pure fluids and to rely on predictive thermophysical equations for the data needed to establish universal (sensor independent) correlations to secondary properties..."

Bonne (1995) reports a "std. compute error" of $0.46 \%$ (4.6 Btu/scf) for the heating value using a set of 78 natural gases and 23 test gases at $15^{\circ} \mathrm{C}$. However, Bonne and Kubisiak (1996) provide a more thorough discussion of gas property sensor accuracy. After calibrating a sensor's measure of thermal conductivity for nitrogen, methane, and natural gas, they found that the sensor output for the thermal conductivity of argon and for the thermal conductivity of natural gas was within fractions of $1 \%$ of the correct value. A further comparison was made between predicted and measured values of heating value for 117 natural and test gases having a range of heating value from $810 \mathrm{Btu} / \mathrm{scf}$ to $1,250 \mathrm{Btu} / \mathrm{scf}$. Using two sensed properties, the maximum error was $3.5 \%$ and the majority of data points were within $1 \%$ of the true value. The maximum error was reduced to $2.8 \%$ and to $2.0 \%$ by using 3 sensed properties and 4 sensed properties, respectively. Apparently no attempt was made to measure or predict actual volumetric heating value [Btu/acf] from sensed properties at various operating pressures.

Reynolds Equipment Company is under contract to Niagara Mohawk Power Corporation to develop a low-cost heating value instrument for commercial introduction by the year 2000. According to Curry (1998), the technology is based on U.S. Patents 5,311,447, $5,235,844$ and 4,501,144. The development goal is a maximum reading error of less than \pm 2 Btu/scf and an end-user cost of under $\$ 3,000$. The device yields values for specific gravity, $\%$ inerts (diluents), standard volumetric heating value, and static pressure.

A Honeywell microbridge sensor is used to measure thermal conductivity and specific heat of the gas mixture. A tuning fork crystal resonator is used to measure the product of viscosity and density. Tests have been performed using nitrogen, methane, propane, n-butane, and mixed gases. Regression analysis was performed to create equations to predict heating value, specific gravity, and percent inerts. Additional work is in progress to use Genetic Algorithms and Neural Networks to predict results with even greater accuracy. Curry states, "The sample data taken to construct the regression equations have the potential through Artificial Intelligence techniques to improve over time. Theoretically, within some yet unknown limits, the degree of accuracy attained depends on the number of normal samples used for training. With these methods, we expect to exceed our initial accuracy requirements." 


\subsubsection{Nuclear Magnetic Resonance (NMR)}

The results of NMR measurements of natural gas properties, including heating value, are reported by King et al. (1988), King and Nicholls (1990), and by King and Ni (1996). The NMR method uses radio frequency power to excite hydrogen nuclei, which resonate in a magnetic field. The nuclei re-emit radio frequency signals that can be used to characterize a flow field.

When applied to characterize a natural gas flow field, NMR measures the total concentration of hydrogen nuclei within the sensor. In a mixture of hydrocarbon gases and diluents, the NMR sensor responds only to gases containing hydrogen atoms, so it essentially counts the number of combustible hydrocarbon molecules that pass a certain location in time. This has the strong advantage that it may be applied in multi-phase flows to measure energy flow rate. Nitrogen, carbon dioxide, or other diluent gases would be ignored.

Even though an NMR sensor is non-intrusive and can directly measure combustible gas value under multi-phase conditions, it is presently limited by cost. The material costs in making these instruments are driven by the need for sophisticated electronics and the production of a magnetic field. Highly qualified individuals are currently required to construct these devices on a job basis, so labor costs are also high. In general, an NMR instrument for natural gas energy measurement can cost $\$ 100,000$ to $\$ 300,000$. The high manufacturing expense will severely limit its application, as compared to traditional technology.

\subsection{Catalytic Calorimetry}

A catalysis-based calorimeter is being developed by Ametek Corporation [see Jeffrey et al. (1995)]. The instrument uses a catalytic bead sensor made from a platinum filament that is coated with a catalyst material. The sensor is heated to approximately $670^{\circ} \mathrm{C}$ by applying an electrical current to the filament, then a natural gas sample is introduced to the sensor, with air, for oxidation. Oxidation of the natural gas sample produces a temperature rise at the sensor, whose magnitude is related to the heat released. The platinum filament resistance changes with temperature and allows for electrical detection of the temperature change.

The Ametek catalytic calorimeter is not yet commercially available. Ametek has successfully demonstrated a prototype device to determine the standard volumetric heating value of natural gases from 930 to $1,140 \mathrm{Btu} / \mathrm{scf}$, "to a precision of several tenths of a percent" (Jeffrey et al., 1995). Ten developmental meters are currently being tested in the field. Based on the success of those tests, the unit may be commercially released in mid-1999. The target purchase price for the calorimeter is $\$ 3,000$ to $\$ 4,000$.

This calorimeter is designed to measure standard volumetric heating value, with samples introduced to the sensor at reduced pressure. Gas density is still required to determine energy flow rate from volume-based meters. The technology may, however, be suited to measure actual volumetric heating value [Btu/acf]. If a gas sample is collected at pipeline conditions instead of reduced pressure, then the heat generated by catalytic oxidation would be related to actual volumetric heating value, and auxiliary instrumentation such as a gas chromatograph or densitometer would not be required to measure energy flow rate from volume-based meters. Some additional development and testing would likely be required to redesign the unit for such application. 
Note also that since standard volumetric heating value (Btu/scf) and mass-based heating value $(\mathrm{Btu} / \mathrm{lbm})$ are both properties of the gas composition only, Ametek may be able to use the device, as currently configured, to predict mass-based heating value. That feature would make it uniquely suited to complement a mass-based meter such as a Coriolis meter for energy measurement. 


\subsection{INDUSTRY ACCEPTANCE REQUIREMENTS}

Industry's acceptance of new energy measurement equipment will principally depend on cost and performance. Assuming such equipment meets existing safety and environmental standards, the fundamental basis for its acceptance will be capital and "operating and maintenance" (O\&M) costs, and its technical performance relative to that of existing equipment. Economic issues associated with present energy measurement alternatives limit the application of existing chromatographic equipment, and undermine industry's attempts to provide energy measurement at all custody transfer points.

\subsection{Cost Criteria}

In order to overcome present economic and performance deficiencies, industry has indicated that the greatest single need for an improved energy measurement technology is to reduce equipment costs-whether the answer lies in the refinement of existing technology or in a totally new metering concept. The lower the cost, the more widely new equipment can be applied. A system that has been improved technically, but does not produce a cost reduction, will have very little impact on (or benefit to) industry.

The approach normally used to measure energy content in the field is to add a gas chromatograph (GC) to an existing flow meter, along with the necessary electronics to compute energy flow rate. A survey of the user industry indicates that the purchase price of a dedicated GC typically runs about $\$ 30,000$. Another $\$ 30,000$ is typically required to add the electronic systems needed for data processing and telemetry. When housing and installation costs are included, the total expense ranges between $\$ 60,000$ to $\$ 100,000$ to upgrade an existing flow meter to energy measurement. This does not include periodic costs to tune and maintain units.

With this prohibitive cost structure, the use of dedicated and automated near-real-time GC data systems can be justified only at large measurement sites-typically those handling at least 1 to 10 million SCFD. For smaller meter sites, any of several alternative approaches are pursued. These include:

1. Use of "area GCs" for groups of smaller meters that share a common gas supply, and/or

2. The collection of gas samples periodically for analysis in a central laboratory or meter shop.

The problems with these alternatives are both economic and technical:

1. The equipment is still costly, in terms of both capital outlays and O\&M costs required for maintaining and operating specialized equipment by specially trained personnel.

2. The cost penalties associated with dedicated equipment often means that heating values are estimated at many meter sites on the basis of periodic sample analyses, and substantial errors can result if techniques are inadequate or sampling intervals are infrequent. 


\subsection{Performance Criteria and Market Potential}

\subsubsection{Pipeline Companies}

For gas transporters [transmission companies and local distribution companies (LDCs)], the primary issue is cost. Pipelines provide energy measurement as a service to their customers. Energy measurement is not a major factor in pipeline operation and control, and the cost of buying, operating and maintaining such equipment is an added operational cost provided for the benefit of their customers. Its value, therefore, is strategic rather than operational, as such measurement is deemed necessary for maintaining and expanding their transportation market.

For pipeline quality gas (normally dry, with an energy content between 900 and 1,050 $\mathrm{Btu} / \mathrm{scf}$ ) the performance of existing equipment is adequate. If properly maintained and used, it will do the job intended and provide the accuracy needed. It is, however, expensive to purchase and maintain, and usually requires special skills to operate. The primary acceptance issue for pipelines, therefore, is cost. Unless new technology provides a cost advantage over existing equipment, it will have little if any impact on the transportation industry. There are, however, some operational advantages provided to the transporter in his role as custodian of his client's commodity, and in minimizing the time and costs associated with settling billing disputes.

\subsubsection{Production Companies}

The intrinsic value of natural gas lies almost exclusively in its energy content, i.e., the heat produced from its combustion as fuel. Gas producers, therefore, place more emphasis on "performance" of energy measurement equipment (accuracy, range of hydrocarbons analyzed, etc.) than do pipelines. Capital and O\&M costs are still important, however, because high costs limit the application of such equipment at field measurement installations. Dedicated chromatographs, for example, can be justified for only large-volume production wells or custody transfer points. Lower costs relate specifically, therefore, to expanding the use of energy measurement to a wider range of (smaller) field applications. Accurate, low-cost energy measurement would, therefore, be of advantage both to the producer and to the end-user in better defining value of the product exchanged.

Most of the domestic natural gas is produced wet; i.e., it is saturated with hydrocarbon and/or other liquids that may appear as entrained droplets or liquids on the pipe wall. Measuring the quality (composition) of such gas is difficult because present sampling technology cannot reliably collect representative samples of the gas and liquid mixture when multiphase flow exists. Producers want new measurement equipment to circumvent both sampling and analysis problems when wet gas is flowing.

Even dry gas, if it has high heating value ${ }^{1}$, presents potential sampling problems if ambient temperatures fall below the gas dew point, or if equipment cleanliness is a problem. In such cases, special care is required in selecting appropriate sample collection procedures and

\footnotetext{
${ }^{1}$ About $1,050 \mathrm{Btu} / \mathrm{scf}$ or higher, depending on the specific gas composition and operating condition within the pipeline.
} 
equipment to avoid distorting the gas sample in the collection, transportation, or analysis processes.

Most field GCs accommodate compositions from methane $\left(\mathrm{C}_{1}\right)$ to hexane $\left(\mathrm{C}_{5}\right)$. Typically, the $\mathrm{C}_{6}$ and heavier hydrocarbons are lumped into a single $\mathrm{C}_{6}{ }^{+}$concentration. This range is adequate for most pipeline quality gas because heavier hydrocarbons (plus some of the lighter ones) have been stripped out for separate sale or blending. Wellhead gas, however, and some high-energy pipeline gas often contain higher energy constituents up to about $\mathrm{C}_{9}$ or $\mathrm{C}_{10}$. Some production companies, therefore, require extended range chromatographs that can accommodate heavier hydrocarbons (up to at least $\mathrm{C}_{8}$ or $\mathrm{C}_{9}$ ), along with analysis of diluents such as nitrogen and carbon dioxide. Some field GCs have these extended capabilities, but are even more complex and expensive than the more common $\mathrm{C}_{6}{ }^{+}$units. Expanded use of such existing equipment can only result in higher cost to the end-user.

\subsubsection{The End-User}

While end-users of natural gas align with production companies in stressing the need for energy measurement, their acceptance criteria are more nearly that of the transporter (transmission companies and LDCs). Technical performance of existing equipment is generally adequate, but cost considerations largely preclude the use of even existing equipment for measuring heating value or flow rate. End-users normally rely on the pipeline or LDC to provide accurate flow and/or energy measurement and to maintain a gas quality compatible with their needs. While they stress the need for energy accountability, end-users are also extremely sensitive to any increase in purchase or transportation costs. The final evaluation of cost/accuracy options will typically depend on their past experiences with energy variations in the gas received from various suppliers. A large end-user, such as a power plant, is extremely sensitive to cost/accuracy issues because small variations in measured energy flow rate have a large impact on their accumulated costs. 


\subsection{RANKING OF TECHNOLOGIES}

A comparative ranking of energy measurement technologies requires a standard for comparison. The standard in the natural gas industry is currently the gas chromatograph (GC) installation, which is applied together with any flow meter to determine energy flow rate. The GC measures the detailed gas composition, which is used to calculate heating value, and gas properties needed for flow rate.

The primary acceptance criteria for replacement of the GC are cost and performance. The GC installation can cost between $\$ 60,000$ and $\$ 100,000$, as previously described, and is normally justified only for locations that flow at least 1 to 10 million SCFD. The most promising technological alternatives for reducing the cost of energy flow measurement do not, however, directly measure the composition of a gas stream. In these alternative approaches, energy content of the gas is inferred from bulk properties, rather than a detailed assay of the composition. The alternatives, therefore, do not have the inherent capability to replace all GCs, but may reduce the number of GCs required in a gas network, and make energy measurement cost-effective for more metering locations.

Promising technologies have been ranked according to their potential to revolutionize the measurement of natural gas energy by lowering costs (relative to a GC installation) and making use of technically viable technologies. These technologies may still require some developmental effort, but show promise for extensive application in industry. Only technologies with such potential have been ranked. Technologies without such potential, have not been considered for ranking. For example, the NMR technology appears to be cost prohibitive for general-purpose use, and is therefore not considered in the ranking. All the ranked technologies have potential to improve general-purpose operations, and ultimately reduce costs to the consumer.

\section{1 \#1 Ranking: Heating Value Inference from Speed of Sound Measurements}

Since volume-based meters (ultrasonic, turbine, rotary, diaphragm, etc.) measure actual volume flow rate directly, energy flow rate may be determined with such meters by the additional measurement of actual volumetric heating value [Btu/acf] (see Section 2.2). The increased utilization of ultrasonic meters in production, transmission, and distributions systems creates an opportunity to exploit their unique characteristics to measure more than flow rate, and ultimately reduce costs to the consumer. As a byproduct of transit-time flow rate measurements, ultrasonic meters measure sound speed, a thermodynamic property of the gas. While the desired thermodynamic property (actual volumetric heating value) is not measured directly, it may be inferred from other thermodynamic properties such as sound speed, temperature, pressure, etc.

Lueptow and Phillips (1994) correlated standard volumetric heating value [Btu/scf] (which is not a thermodynamic property, but a property of the gas composition only) to sound speed measurements with an accuracy roughly equivalent to the concentration of diluents present in the gas. Kristensen et al. (1998) have applied sound speed measurements from multi-path ultrasonic meters, with known diluent concentrations, to correlate gas density within $1 \%$ over several natural gas compositions. While neither has attempted to correlate the actual 
volumetric heating value [Btu/acf], it is clear that such a correlation is possible. It is also clear that, for custody transfer applications, such a correlation will require additional information about the gas (diluent concentrations in particular, if not another property measurement such as thermal conductivity) to differentiate gas components that alter sound speed magnitude, but contribute no heating value.

Watson and White (1981) demonstrated that low cost piezoelectric sensors may be used to measure sound transit time and infer standard volumetric heating value [Btu/scf] with a precision (not accuracy) of $0.02 \%$. Such sensor pairs could be used to retrofit volume-based meters that do not inherently measure sound speed (turbine, rotary, diaphragm, etc.). The cost of such a retrofit module can be inferred by the cost of compact residential ultrasonic meters, which may currently be purchased for about $\$ 100$. Additional costs will likely be incurred by the need to differentiate diluent effects, but the base capital costs to measure sound speed are negligible as compared to the GC installation.

An additional benefit of this technological approach is the inherent potential as a calibration-free device. Transit time sound speed measurements reduce to the timing of an ultrasound pulse across a known length. Analog sensors may be required to infer diluent effects, but these corrections are expected to be a small fraction of the final result, so calibration of those sensors will not need to be extremely accurate or frequent.

Because ultrasonic meters are being widely accepted by the gas industry, and they have the inherent potential to be converted to on-line energy flow meters with minimal additional expense, this technology is given the \#1 ranking. Inexpensive transit-time retrofit modules also have the potential to convert any volume-based meter (turbine, rotary, diaphragm, etc.) into an on-line energy flow meter.

\section{2 \#2 Ranking: Mass-Based Measurement}

Mass-based measurement is also uniquely suited to determine energy flow rate without much additional equipment, if any. Coriolis meters, however, have not been as widely accepted in the gas industry as ultrasonic meters, but are seeing renewed consideration in small to medium pipe sizes (at or below 6 inch pipe diameters). Mass-based measurement is given the \#2 ranking because a tremendous advantage may be gained by directly measuring mass flow rate, instead of actual volume flow rate. As demonstrated in Section 2.1, the only additional property required to convert mass flow meters to energy flow meters is the massbased heating value $[\mathrm{Btu} / \mathrm{lbm}]$, which is not a thermodynamic property, and is nearly constant for all paraffin hydrocarbons found in natural gas.

If the diluent concentration of a natural gas stream does not vary significantly over time, then a mass-based meter could be set up as an energy flow meter by an initial measurement of gas composition. That initial measurement could be used to calculate mass-based heating value, which should vary more with changes in diluent concentrations than changes in hydrocarbon concentrations. This technology would benefit (like the \#1 ranked sound speed inference approach) from the development of inexpensive equipment to track diluent concentrations either directly, or by inference. Such an add-on feature could eliminate the need for initial or periodic composition analyses, and would make mass-based meters capable of tracking larger variations in energy flow rate. 


\section{3 \#3 Ranking: Thermal Microbridge and Crystal Resonator}

The Reynolds/Niagara Mohawk/Honeywell instrument, under proprietary development by Reynolds Equipment Company, seeks to measure multiple bulk properties of the gas (thermal conductivity, specific heat, product of viscosity and density, etc.) to infer standard volumetric heating value and gas density. A gas sample is delivered to the sensors (a thermal microbridge and a tuning fork crystal oscillator) at line conditions, so it may be suited to measure actual volumetric heating value [Btu/acf] (the property needed for volume-based measurement of energy flow rate), even though the unit will be indicating standard volumetric heating value [Btu/scf]. The target sales price is under $\$ 3,000$, which would make it competitive to reduce reliance on field GCs. Field tests will be conducted with alpha units in 1999. Demonstration tests will be critical to industry acceptance of this new approach.

\section{4 \#4 Ranking: Heating Value Inference from Dielectric Constant Measurements}

The prototype capacitor developed by Johnson et al. (1984) showed promise in predicting standard volumetric heating value [Btu/scf], but showed difficulty with polar molecules, such as water vapor, and other diluent concentrations. This technology, as with others mentioned, would benefit from an independent measure of the diluent concentrations, or some inferential sensing of their presence.

If the capacitor housing were made sufficiently strong, it may be capable of measuring the more desirable quantity of actual volumetric heating value [Btu/acf]. This technology, however, does not have the advantage of a close technological relationship with some flow measurement approach (there are no capacitance flow meters), as in the case of the ultrasonic transit time sensor. The prototype device was reported by Johnson et al. (1984) to cost approximately $\$ 2,000$.

\section{5 \#5 Ranking: Catalytic Calorimeter}

The Ametek catalytic calorimeter technology is used to measure the standard volumetric heating value [Btu/scf], by catalytically oxidizing a natural gas sample (delivered to the sensor by pressure reduction), and measuring the heat generated. As with other calorimeters, it is a very direct means to measure heating value. However, the device does not measure the actual volumetric heating value [Btu/acf] (a thermodynamic property), and therefore suffers from the same limitation as other calorimeters - density (a thermodynamic property) is still needed to calculate energy flow rate from all meters except the mass-based type (see Section 2.1). Coriolis meters, for example, require knowledge of mass-based heating value $[\mathrm{Btu} / \mathrm{lbm}]$, which is a chemical property (not a thermodynamic property) that is even less sensitive than standard volumetric heating value [Btu/scf] (also not a thermodynamic property) to chemical composition.

The catalytic calorimeter, therefore, may be a useful partner with the Coriolis meter to measure energy flow rate. It may also be possible to modify the device to measure actual volumetric heating value [Btu/acf], by purging its sample loop at pipeline conditions (flowing pressure, temperature, and composition), and measuring the heat generated by catalytic oxidation of the higher density sample. If such a modification were successful, it could be used 
with any volume-based meter to measure energy flow rate without the need to determine gas density.

Ametek is currently performing field tests, and plans to commercially release the product, measuring standard volumetric heating value [Btu/scf], in mid-1999. The target selling price is $\$ 3,000-\$ 4,000$.

\section{6 \#6 Ranking: PMI TruTherm Q}

The PMI TruTherm Q is a unique combination of equipment for energy flow measurement through an orifice meter run. The package includes an inferential calorimeter to measure standard volumetric heating value from a sampling line, and a mini-orifice assembly that is placed in a thermowell downstream of the pipeline orifice meter. The energy flow rate of natural gas in the sampling line is measured, and is then scaled up to the pipeline with pressure drop measurements that are made across both the pipeline and mini orifice meters.

While the technology shows potential to address the specific needs of the widely used orifice meter, the scale-ability of the mini-orifice (which is in reality a tortuous gas path that produces a pressure drop) needs to be demonstrated to the industry. Furthermore, the use of an open flame (for the inferential calorimeter) can be a deterrent to widespread use in the industry. The system sells for $\$ 15,000-\$ 20,000$, and requires that the inferential calorimeter be installed in an electrically unclassified location, protected from the weather. 


\section{TASK B: FEASIBILITY EVALUATION OF PROMISING ALTERNATIVES}

\subsection{THE VISION OF LESS EXPENSIVE AND MORE ACCURATE NATURAL GAS ENERGY MEASUREMENT}

The goal of improving energy measurement technology may be approached either by refining the traditional gas chromatograph $(\mathrm{GC})$, or by exploiting a different approach that overcomes inherent disadvantages of GC composition assay. The cost of traditional GCs will decrease only if major components, such as detectors, injectors, switching valves, ovens, peak detection/integration software, etc., could be produced less expensively. Such comprehensive renovation is unlikely. Even if accomplished, the process of gas mixture separation and component concentration measurement would still remain complex. That is why the topranked alternative Task A technologies offer great promise. Rather than refining traditional and complicated technology, a different path is followed.

Natural gas is largely composed of paraffin hydrocarbons, whose properties are interdependent because of similar molecular structure. That inter-dependence may be exploited to characterize the hydrocarbon energy without a detailed composition assay. The process is simple. First, the diluent concentrations (predominantly nitrogen and carbon dioxide) are quantified because they have no energy content, yet they add mass and change gas characterization properties. They can be measured with instrumentation of lesser accuracy because they account for a small fraction of the whole natural gas mixture. Second, the remaining hydrocarbon gas components (the majority of the gas mixture) can be characterized by inferential properties, without species differentiation. If only one diluent component concentration is known (carbon dioxide, for example), then a second diluent-sensitive inferential property may be needed.

There is precedence for such inferential characterization of natural gas. The Gross Characterization Method of A.G.A. 8 (1994) is an equation of state for calculating natural gas density (compressibility factor), where the composition is characterized by one of two methods. The first assumes that volumetric gross heating value, relative density (specific gravity), and carbon dioxide concentration are known. The second assumes that relative density (specific gravity), carbon dioxide concentration, and nitrogen concentration are known.

The Gross Characterization Method of A.G.A. 8 (1994) addresses the determination of only gas density (compressibility factor). However, the general characterization approach may be applied to other gas properties, required for energy measurement, such as mass-based heating value, $\mathrm{H}_{\mathrm{m}}$ [Btu/lbm], and volume-based heating value, $\mathrm{H}_{\mathrm{v}}$ [Btu/acf]. The Gross Characterization Method of A.G.A. 8 (1994) may, itself, be modified to calculate gas density (compressibility factor) using other characterization parameters that can be measured more easily and less expensively than those of the two A.G.A. 8 (1994) methods.

Dramatic cost savings over the traditional GC installation can therefore be achieved by determining new natural gas characterization correlations between properties that are required for energy measurement, and inferential properties that are measured with less costly sensors. Task B of this project was initiated with the intent to explore the feasibility of such correlations, and simultaneously explore some of the more promising sensors. The two project tasks are dependent but, due to time constraints, it was necessary to choose a common starting 
point. Therefore, three inferential properties were pre-selected so both project tasks could proceed simultaneously. The pre-selected Task B inferential properties are

(1) sound speed at $60^{\circ} \mathrm{F}$ and 14.73 psia,

(2) carbon dioxide concentration, and

(3) nitrogen concentration.

Sound speed was chosen because of the increasing popularity of ultrasonic flow meters, which can measure sound speed as a by-product of the flow rate transit-time measurements. One such meter, the Siemens meter, was produced for residential applications in the British gas market. The Siemens ultrasonic meter, which contains ultrasonic transducers and signal processing electronics, sells for about $\$ 100$.

Carbon dioxide and nitrogen concentrations were also pre-selected as inferential properties because they are the major gas components that dilute natural gas hydrocarbons. If they can be quantified separately, then the sound speed property may be used to characterize the hydrocarbon components as a whole. Infrared absorption technology may be used to measure carbon dioxide concentration because carbon dioxide absorbs infrared energy at a unique fundamental wavelength. Hydrocarbons and nitrogen tend to pass infrared energy without absorption at that wavelength. Commercial non-dispersive infrared (NDIR) sensors are available. One such sensor, the Vaisala Model GMM11C, is a complete NDIR package (not necessarily field ready) which sells for about $\$ 400$.

No commercially available and inexpensive nitrogen gas sensors have yet been identified. Nitrogen gas is infrared-inactive (does not absorb infrared energy at significant levels), and is chemically stable. Both characteristics make it difficult to directly sense. That does not imply impossibility or impracticality, just that there is currently no commercially available sensor that exploits its unique features compared to other natural gas components. Even if no inexpensive sensor is found or developed for measuring nitrogen concentration directly, indirect methods are possible, or another nitrogen-dependent gas property may be substituted as the third inferential property. Task B of this project, however, has proceeded to investigate the feasibility of the gross property characterization approach on the basis that nitrogen concentration is known.

An additional benefit of gross characterization, although by no means minimal, is the reduction in uncertainty sources over detailed composition characterization. If natural gas is characterized with fewer measured properties, then there are fewer sources of uncertainty to compound, and fewer controls needed to maintain a particular level of overall measurement uncertainty. 


\subsection{CHARACTERIZING NATURAL GAS PROPERTIES BY INFERENCE}

As described in Section 2.0, natural gas flow meters may be generally classified as volume-based (ultrasonic, turbine, rotary, diaphragm, etc.), differential-based (orifice, annubar, $\mathrm{V}$-cone, etc.), and mass-based (Coriolis, thermal-mass, etc.). Any of these flow meters may be used for energy measurement, but each meter classification requires different properties to complete the energy measurement. For example, volume-based meters require:

$$
Q_{\substack{\text { energy, } \\ \text { volume-based }}}=Q_{v, \text { std }} H_{v, \text { std }}=\left(\frac{\rho Q_{v}}{\rho_{\text {std }}}\right)\left(\rho_{\text {std }} H_{m}\right)=Q_{v}\left(\rho H_{m}\right)=Q_{v} H_{v}
$$

To complete the energy flow rate measurement, volume-based meters fundamentally require only the volume-based heating value, $H_{v}$ [Btu/acf], which is the product of flowing density, $\rho$ $\left[\mathrm{lbm} / \mathrm{ft}^{3}\right]$, and mass-based heating value, $H_{m}[\mathrm{Btu} / \mathrm{lbm}]$. If the traditional formulations of standard volumetric flow rate, $Q_{v, s t d}\left[\mathrm{scf} / \mathrm{h}\right.$ ], and heating value, $H_{v, s t d}[\mathrm{Btu} / \mathrm{scf}]$, are desired, then standard density, $\rho_{\text {std }}$ [typically $\mathrm{lbm} / \mathrm{ft}^{3}$ at $60^{\circ} \mathrm{F}, 14.73 \mathrm{psia}$, and the flowing composition], is also needed.

Energy flow rate through a differential (pressure)-based meter requires:

$$
\underbrace{}_{\begin{array}{c}
\text { energy, } \\
\text { differential-based }
\end{array}}=Q_{v, \text { std }} H_{v, \text { std }}=\left(\frac{C \sqrt{\rho}}{\rho_{\text {std }}}\right)\left(\rho_{\text {std }} H_{m}\right)=C\left(\sqrt{\rho} H_{m}\right)
$$

Note that differential-based meters fundamentally require the flowing gas density, $\rho\left[1 \mathrm{bm} / \mathrm{ft}^{3}\right]$, and the mass-based heating value, $H_{m}[\mathrm{Btu} / \mathrm{lbm}]$. If the traditional formulations of standard volumetric flow rate, $Q_{v, s t d}[\mathrm{scf} / \mathrm{h}]$, and heating value, $H_{v, s t d}[\mathrm{Btu} / \mathrm{scf}]$, are desired, then standard density, $\rho_{\text {std }}$ [typically $\mathrm{lbm} / \mathrm{ft}^{3}$ at $60^{\circ} \mathrm{F}, 14.73$ psia, and the flowing composition], is also needed. Note that the catch-all $C$ factor contains some property dependence for viscosity, $\mu$ (through the discharge coefficient), and isentropic exponent, $\kappa$ (through the expansion factor), but these are of lesser importance.

Energy flow rate through a mass-based meter requires:

$$
Q_{\substack{\text { energy }, \\ \text { mass-based }}}=Q_{v, \text { std }} H_{v, \text { std }}=\left(\frac{Q_{m}}{\rho_{\text {std }}}\right)\left(\rho_{\text {std }} H_{m}\right)=Q_{m} H_{m}
$$


Only the addition of mass-based heating value, $H_{m}[\mathrm{Btu} / \mathrm{lbm}]$, is required to determine energy flow rate through a mass-based meter. If the traditional formulations of standard volumetric flow rate, $Q_{v, s t d}[\mathrm{scf} / \mathrm{h}]$, and heating value, $H_{v, s t d}[\mathrm{Btu} / \mathrm{scf}]$, are desired, then standard density, $\rho_{\text {std }}$ [typically $\mathrm{lbm} / \mathrm{ft}^{3}$ at $60^{\circ} \mathrm{F}, 14.73 \mathrm{psia}$, and the flowing composition], is also needed to convert from a mass-basis to a standard-volume basis.

Equations (8-1) to (8-3) describe the property dependence of different meter classes to energy measurement, but all properties are not equally difficult to measure. The chemical properties depend only on gas composition (chemical characterization). Thermodynamic properties depend on gas composition, temperature and pressure. Furthermore, thermodynamic properties can become chemical properties (dependent only on gas composition) at fixed temperature and pressure, although the chemical dependence will vary at different temperature and pressure conditions.

Table 8-1 summarizes the energy measurement property requirements of the different natural gas flow meter classes.

Table 8-1. The chemical and thermodynamic property dependence of different flow meter classes.

\begin{tabular}{|c|c|c|}
\hline Flow Meter Class & $\begin{array}{c}\text { Chemical Property } \\
\text { Dependence for Energy } \\
\text { Measurement } \\
\end{array}$ & $\begin{array}{c}\text { Thermodynamic Property } \\
\text { Dependence for Energy } \\
\text { Measurement }\end{array}$ \\
\hline $\begin{array}{l}\text { Volume-Based } \\
\text { (Eqn. 9-1) } \\
\text { (ultrasonic, turbine, } \\
\text { rotary, diaphragm, etc.) }\end{array}$ & $\begin{array}{c}H_{m} \\
\rho_{s t d} \\
H_{v, s t d}\left(\text { product of } \rho_{s t d} \text { and } H_{m}\right)\end{array}$ & $\begin{array}{c}H_{v}\left(\text { product of } \rho \text { and } H_{m}\right) \\
\rho\end{array}$ \\
\hline $\begin{array}{l}\text { Differential-Based } \\
\text { (Eqn. 9-2) } \\
\text { (orifice, annubar, } \\
\text { V-cone, etc.) }\end{array}$ & $\begin{array}{c}H_{m} \\
\rho_{s t d} \\
H_{v, s t d}\left(\text { product of } \rho_{s t d} \text { and } H_{m}\right)\end{array}$ & $\begin{array}{c}\rho \\
\mu, \kappa \\
\text { (lesser importance, buried in } C \text { ) }\end{array}$ \\
\hline $\begin{array}{l}\text { Mass-Based } \\
\text { (Eqn. 9-3) } \\
\text { (Coriolis, thermal- } \\
\text { mass, etc.) }\end{array}$ & $\begin{array}{c}H_{m} \\
\rho_{s t d} \\
H_{v, s t d}\left(\text { product of } \rho_{s t d} \text { and } H_{m}\right)\end{array}$ & None \\
\hline
\end{tabular}

It is clear from Table 8-1 that three natural gas properties are critical to energy measurement. Two chemical properties, $H_{m}$ and $\rho_{s t d}$, are required by all three meter classes, and an additional thermodynamic property $(\rho)$ is required by the volume- and differential-based meters. Mass-based meters are uniquely independent of thermodynamic properties, which is an 
important advantage that makes flowing gas temperature and pressure irrelevant for that class of meters.

It will become clear in the following sections that two additional chemical properties, in addition to $H_{m}$ and $\rho_{s t d}$, are also very useful. Mixture molecular weight, $M$ [lbm/lb-mol], is useful as a data correlation intermediary to characterize gas composition, and may also be used to calculate ideal specific gravity. Mixture molar ideal gross heating value, $H_{n, \text { ref }}[\mathrm{kJ} / \mathrm{mol}$, with chemical-enthalpies referenced to $25^{\circ} \mathrm{C}, 0.101325 \mathrm{MPa}$, is also a useful intermediary to characterize gas composition, especially gas density, $\rho$, from an existing equation of state.

\subsection{Characterizing Chemical Properties}

The basis of all inferential property determination is chemical characterization. Chemical properties are constant at all gas-phase temperature and pressure conditions. In contrast, thermodynamic properties must be chemically characterized for all temperature and pressure conditions of interest. This section details semi-empirical data correlations for the important chemical properties identified in Section 9.0, including $M, H_{m}, \rho_{s t d}$, and $H_{n, r e f}$.

As discussed in Section 8.0, three inferential gas characterization properties are assumed known, namely, speed of sound at $60^{\circ} \mathrm{F}$ and $14.73 \mathrm{psia}, S_{s t d}[\mathrm{ft} / \mathrm{s}$ ], carbon dioxide concentration, $X_{\mathrm{CO} 2}$ [mol\%], and nitrogen concentration, $X_{N 2}$ [mol\%]. For the purpose of developing the data correlations, a database of 102 different natural gas compositions was developed. The first 51 compositions are unique. The remaining 51 compositions were obtained by reversing the carbon dioxide and nitrogen concentrations of the first 51 compositions. The database composition range is summarized in Table 8-2. The complete gas compositions are presented in Appendix A.

The inferential properties of carbon dioxide and nitrogen concentration were determined directly from the database. For the purposes of data correlation, speed of sound was calculated from the detailed gas composition database using the GRI Extended Thermodynamic Properties code (1989) at $60^{\circ} \mathrm{F}$ and 14.73 psia. By fixing the temperature and pressure, the speed of sound becomes a function of chemical composition only (a chemical property), although it is inherently a thermodynamic property. The standard-condition speed of sound calculations were checked against the Lomic SonicWare (1997) calculations (also using detailed composition input), and they agreed to within $\pm 0.002 \%$.

\subsubsection{Inferential Correlation for Mixture Molecular Weight, M}

Mixture molecular weight was calculated, for correlation purposes, for each natural gas composition in the database using the mixing model:

$$
M=\sum_{i=1}^{N}\left(\frac{X_{i}}{100} M_{i}\right)
$$


where $\mathrm{N}$ is the number of pure gas components in the mixture, $X_{i}$ is the mole percentage of each component, and $M_{i}$ is the molecular weight of each component (from GPA Standard 2145 (1994)).

Table 8-2. Range of correlation database characteristics.

\begin{tabular}{|l|c|}
\hline \multicolumn{1}{|c|}{ Gas Mixture Characteristic } & $\begin{array}{c}\text { Range of Gas } \\
\text { Mixture Characteristic }\end{array}$ \\
\hline Molecular Weight, $\boldsymbol{M}$ [lbm/lb-mol] & $16.33-19.52$ \\
\hline Ideal Specific Gravity, $\boldsymbol{G}_{\text {id }}[\mathbf{M} / \mathbf{2 8 . 9 6 2 5 ]}$ & $0.564-0.674$ \\
\hline $\begin{array}{l}\text { Standard Volumetric Heating Value, } \boldsymbol{H}_{\boldsymbol{v}, \text { std }} \\
\text { [Btu/real scf at 60} \mathbf{F}, \mathbf{1 4 . 7 3} \text { psia] }\end{array}$ & $987-1,150$ \\
\hline $\mathbf{C}_{\mathbf{6}}+$ Concentration [mol\%] & $0.0009-0.100$ \\
\hline Total Diluent Concentration [mol\%) & $0.968-7.40$ \\
\hline Methane [mol\%] & $83.42-98.27$ \\
\hline Ethane [mol\%] & $0.516-9.53$ \\
\hline Propane [mol\%] & $0.161-3.57$ \\
\hline Iso-butane [mol\%] & $0.0355-0.647$ \\
\hline N-butane [mol\%] & $0.0237-0.432$ \\
\hline Iso-pentane [mol\%] & $0.0094-0.167$ \\
\hline N-pentane [mol\%] & $0.0063-0.112$ \\
\hline N-hexane [mol\%] & $0.0003-0.0654$ \\
\hline N-heptane [mol\%] & $0.0000-0.0260$ \\
\hline N-octane [mol\%] & $0.0000-0.0235$ \\
\hline Carbon Dioxide [mol\%] & $0.0330-6.00$ \\
\hline Nitrogen [mol\%] & $0.0330-6.00$ \\
\hline
\end{tabular}

Mixture molecular weight, $M$, plots semi-linear with standard sound speed, $S_{\text {std }}$, where the scatter in the data (about 1\%) is a function of the diluent concentrations. The form of the inferential correlation is therefore chosen to be: 


$$
M=A+B S_{s t d}+C S_{s t d}^{2}
$$

where

$$
\begin{aligned}
& A=A_{0}+A_{1} X_{N 2}+A_{2} X_{C O 2} \\
& B=B_{0}+B_{1} X_{N 2}+B_{2} X_{C O 2} \\
& C=C_{0}+C_{1} X_{N 2}+C_{2} X_{C O 2}
\end{aligned}
$$

A least squares curve fit of the data in the database produced the following values for the unknown constants:

$$
\begin{aligned}
& \mathrm{A}_{0}=89.599,87 \\
& \mathrm{~A}_{1}=0.259,561,6 \\
& \mathrm{~A}_{2}=0.842,011,2 \\
& \mathrm{~B}_{0}=-0.083,035,39 \\
& \mathrm{~B}_{1}=-3.576,14 \mathrm{e}^{-4} \\
& \mathrm{~B}_{2}=-1.201,99 \mathrm{e}^{-3} \\
& \mathrm{C}_{0}=2.227,87 \mathrm{e}^{-5} \\
& \mathrm{C}_{1}=1.373,42 \mathrm{e}^{-7} \\
& \mathrm{C}_{2}=4.514,62 \mathrm{e}^{-7}
\end{aligned}
$$

The molecular weight, $M$, curve fit residuals are plotted in Figure 8-1. The values of $M$ calculated from the inferential correlation (Equation (8-5)), and are largely within $\pm 0.02 \%$ of the values of $M$ calculated from Equation (8-4).

\subsubsection{Inferential Correlation for Mass-Based Heating Value, $H_{m}$}

Mass-based heating value may be calculated, for correlational purposes, from the following detailed composition mixing model:

$$
H_{m}=\frac{\sum_{i=1}^{N}\left(\frac{X_{i}}{100} M_{i} H_{m, i}\right)}{M}
$$

where $\mathrm{N}$ is the number of pure gas components in the mixture, $X_{i}$ is the mole percentage of each component, $M_{i}$ is the molecular weight of each component (from GPA Standard 2145 (1994)), and $H_{m, i}$ is the mass-based heating value of each component (from GPA Standard 2145 (1994)). In the natural gas industry, it is standard practice to use chemical enthalpies (heating values) determined at standard conditions of $60^{\circ} \mathrm{F}$ and $14.696 \mathrm{psia}$, even though the volumetric basis is often converted to a pressure of 14.73 psia. The GPA Standard 2145 (1994) provides the $H_{m, i}$ data at the accepted chemical enthalpy conditions of $60^{\circ} \mathrm{F}$ and 14.696 psia. 


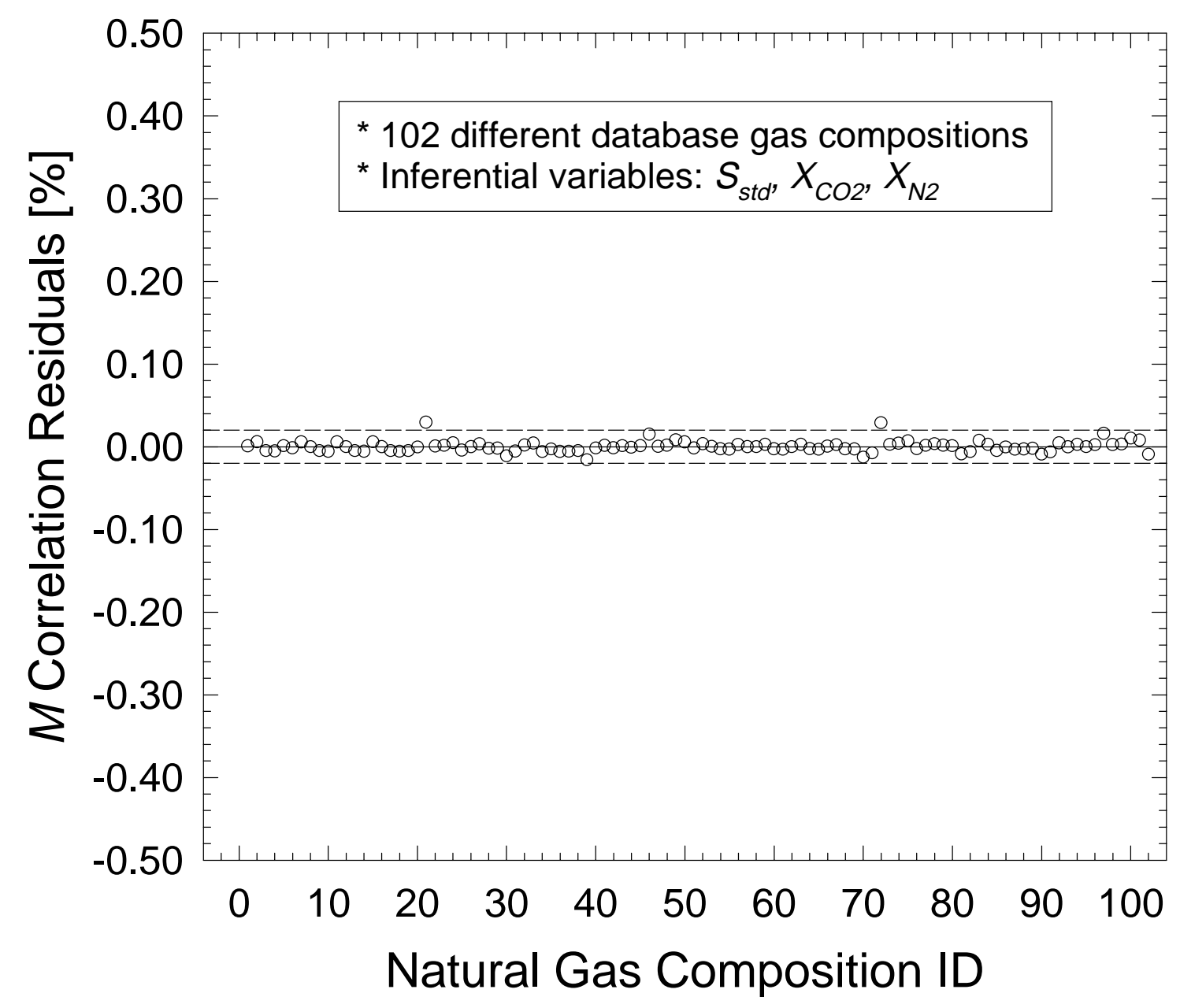

Figure 8-1. Correlation residuals for the mixture molecular weight, $M$, as a function of $S_{s t d}, X_{C O 2}$, and $X_{N 2}$.

Examination of Equation (8-6) reveals that the numerator is a function of only the hydrocarbon composition of the natural gas, since $H_{m, C O 2}=H_{m, N 2}=0$ (diluent gases have no heating value). The denominator is the mixture molecular weight, which is a function of all the gas components, and was correlated successfully to inferential properties through Equation (85). Since $H_{m}$ is, generally, a weak function of hydrocarbon composition, the numerator is fit to a linear function of the hydrocarbon molecular weight, $M_{H C}$, defined:

$$
M_{H C}=M-\left(\frac{X_{C O 2}}{100} M_{C O 2}\right)-\left(\frac{X_{N 2}}{100} M_{N 2}\right)
$$

The form of the inferential correlation is chosen to be: 


$$
H_{m}=\left(\frac{A+B M_{H C}}{M}\right)
$$

where

$$
\begin{aligned}
& B=B_{0}+B_{1} S_{\text {std }} \\
& B_{1}=B_{2}+B_{3} X_{N 2}+B_{4} X_{C O 2}
\end{aligned}
$$

A least squares curve fit of the data in the database produced values for the unknown constants:

$$
\begin{aligned}
& A=54,343.048 \\
& B_{0}=20,442.406 \\
& B_{2}=0.045,528,71 \\
& B_{3}=-0.025,238,03 \\
& B_{4}=-0.025,682,12
\end{aligned}
$$

The mass-based heating value, $H_{m}$, curve fit residuals are plotted in Figure 8-2, and are largely within $\pm 0.02 \%$.

\subsubsection{Inferential Correlation for Standard Density, $\rho_{\text {std }}$}

Even though gas density is, in general, a thermodynamic property, the standard density is a chemical property because it is evaluated at specific conditions of $60^{\circ} \mathrm{F}, 14.73 \mathrm{psia}$, and the flowing gas composition. It may be calculated from the real gas equation of state:

$$
\rho_{\text {std }}=\frac{P_{\text {std }} M}{Z R T_{\text {std }}}
$$

where $P_{\text {std }}$ and $T_{\text {std }}$ are standard pressure and temperature (absolute units), $M$ is the mixture molecular weight, $Z$ is the compressibility factor, and $R$ is the universal gas constant. Since $P_{\text {std }}, T_{\text {std }}$, and $R$ are all constants, $\rho_{\text {std }}$ is a function of only the variable ratio $M / Z$.

The form of the standard density correlation is straightforward, because $M$ has already been successfully correlated to inferential properties (Equation (8-5)), and $Z$ varies only about $0.1 \%$ across the database compositions due to the low-pressure standard condition. Therefore, the same correlation form as Equation (8-5) is used to determine unique correlation constants for standard density:

$$
\begin{aligned}
& \rho_{\text {std }}=A+B S_{\text {std }}+C S_{\text {std }}^{2} \\
& \text { where } \\
& \begin{array}{l}
A=A_{0}+A_{1} X_{N 2}+A_{2} X_{C O 2} \\
B=B_{0}+B_{1} X_{N 2}+B_{2} X_{C O 2} \\
C=C_{0}+C_{1} X_{N 2}+C_{2} X_{C O 2}
\end{array}
\end{aligned}
$$




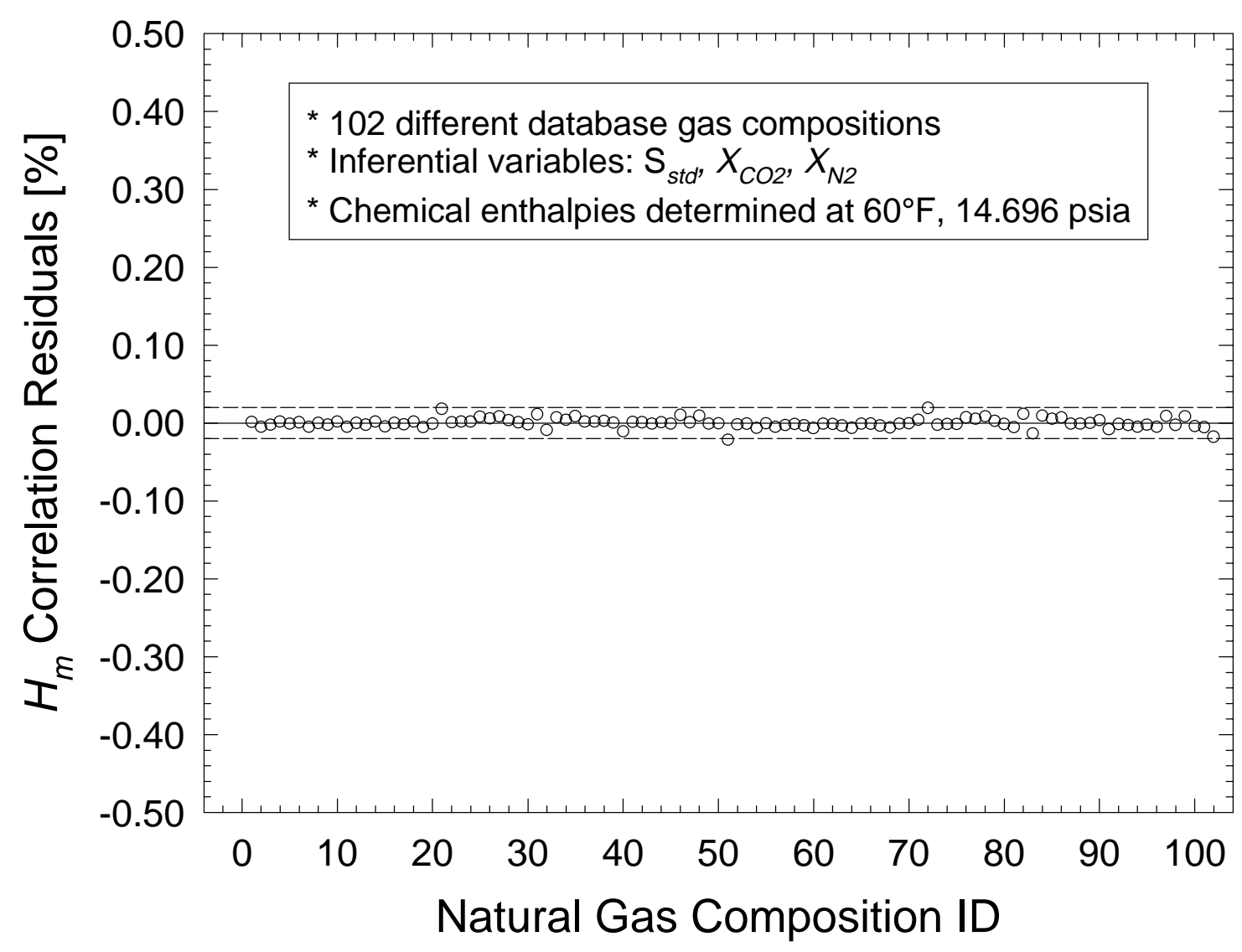

Figure 8-2. Correlation residuals for the mass-based heating value, $H_{m}$, as a function of $S_{s t d}, X_{C O 2}$, and $X_{N 2}$.

A least squares fit to the database produced values for the unknown constants:

$$
\begin{aligned}
& \mathrm{A}_{0}=0.239,514,7 \\
& \mathrm{~A}_{1}=7.067,074 \mathrm{e}^{-4} \\
& \mathrm{~A}_{2}=2.334,917 \mathrm{e}^{-3} \\
& \mathrm{~B}_{0}=-2.228,333 \mathrm{e}^{-4} \\
& \mathrm{~B}_{1}=-9.870,42 \mathrm{e}^{-7} \\
& \mathrm{~B}_{2}=-3.351,35 \mathrm{e}^{-6} \\
& \mathrm{C}_{0}=5.994,80 \mathrm{e}^{-8} \\
& \mathrm{C}_{1}=3.813,30 \mathrm{e}^{-10} \\
& \mathrm{C}_{2}=1.261,06 \mathrm{e}^{-9}
\end{aligned}
$$


The curve fit residuals for $\rho_{\text {std }}$ are plotted in Figure 8-3. As might be expected, the values of $\rho_{\text {std }}$ calculated from Equation (8-10) are largely within $\pm 0.02 \%$ of the values of $\rho_{\text {std }}$ calculated from Equation (8-9), which was implemented with the A.G.A. 8 (1994) Detail Characterization equation of state using the gas compositions of the database as input. Due to the molecular weight dependence, the residuals are very similar to those for the $M$ correlation (Figure 8-1).

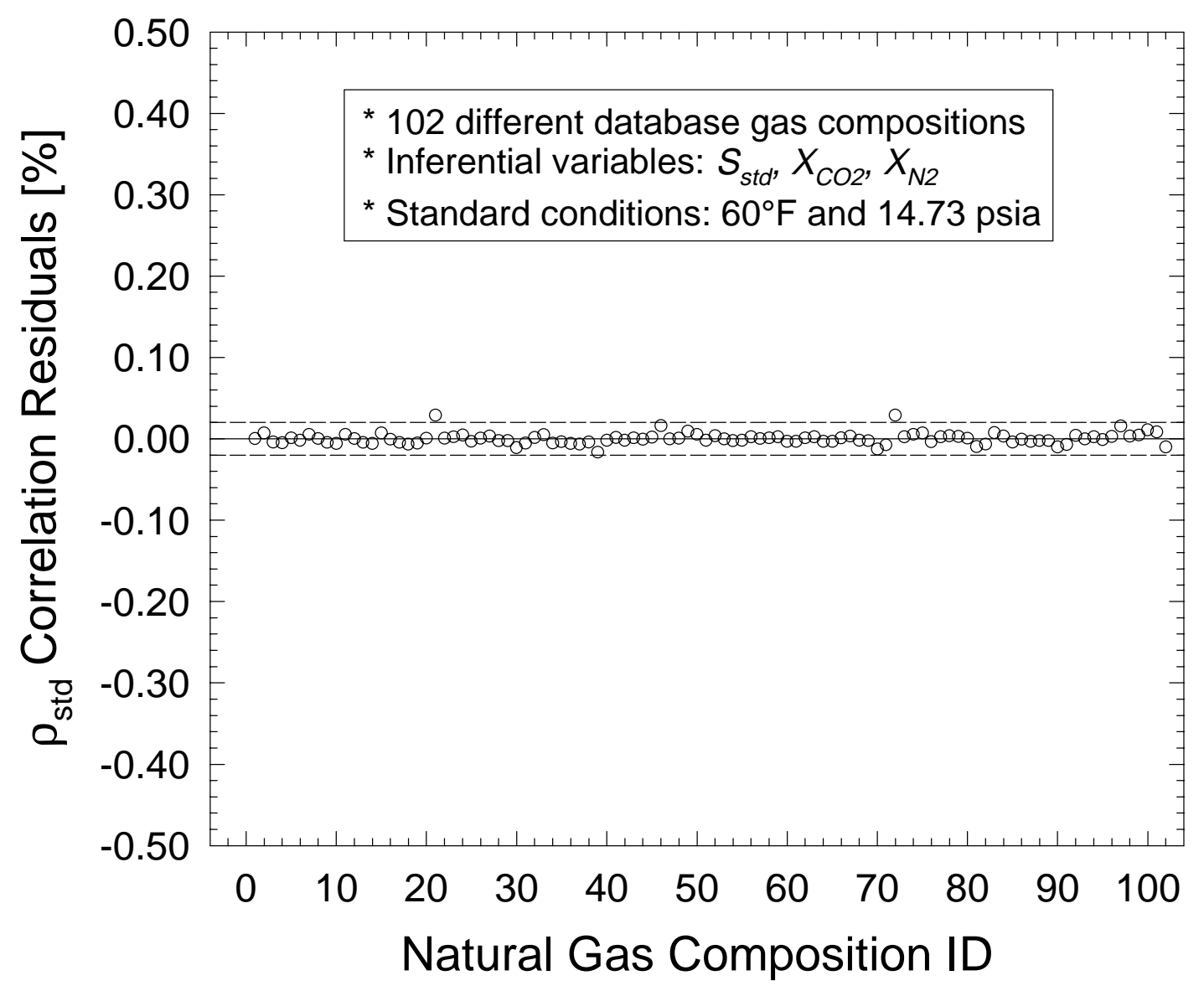

Figure 8-3. Correlation residuals for the standard density, $\rho_{\text {std }}$, as a function of $S_{s t d}, X_{C O 2}$, and $X_{N 2}$.

\subsubsection{Inferential Correlation for the Mixture Molar Ideal Gross Heating Value, $H_{n, r e f}\left[\mathrm{~kJ} / \mathrm{mol}\right.$, with chemical-enthalpies referenced to $\left.25^{\circ} \mathrm{C}, 0.101325 \mathrm{MPa}\right]$}

The molar ideal gross heating value, at $25^{\circ} \mathrm{C}$ and $0.101325 \mathrm{MPa}$ reference conditions, is important as an intermediate variable that may be used to characterize natural gas composition for density calculations. This very important application will be detailed in Section 8.2. This section, however, describes how it may be correlated to inferential variables. 
For correlation purposes, the molar ideal gross heating value, $H_{n, r e f}$, may be calculated from the database compositions:

$$
H_{n, r e f}=\sum_{i=1}^{N}\left(\frac{X_{i}}{100} H_{n, r e f, i}\right)
$$

where $X_{i}$ is the mole percentage of each pure gas component, and $H_{n, \text { ref,i }}$ is the molar ideal gross heating value (at $25^{\circ} \mathrm{C}$ and $0.101325 \mathrm{MPa}$ ) of each pure gas component (from A.G.A. 8 (1994)).

The form of the data correlation to inferential variables is the same as that for the numerator of the mass-based heating value, $H_{m}$, which is also a molar ideal gross heating value at a different reference state, and with different units:

$$
\begin{aligned}
& H_{n, r e f}=A+B M_{H C} \\
& \text { where } \\
& B=B_{0}+B_{1} S_{s t d} \\
& B_{1}=B_{2}+B_{3} X_{N 2}+B_{4} X_{C O 2}
\end{aligned}
$$

A least squares curve fit of the data in the database produced values for the unknown constants:

$$
\begin{aligned}
& \mathrm{A}=123.812,71 \\
& \mathrm{~B}_{0}=47.412,74 \\
& \mathrm{~B}_{2}=2.73,661 \mathrm{e}^{-4} \\
& \mathrm{~B}_{3}=-5.711,87 \mathrm{e}^{-5} \\
& \mathrm{~B}_{4}=-5.735,74 \mathrm{e}^{-5}
\end{aligned}
$$

The curve fit residuals for $H_{n, \text { ref }}$ are plotted in Figure 8-4. The values of $H_{n, \text { ref }}$ calculated from the inferential correlation (Equation (8-12)), agree to within about $\pm 0.02 \%$ with the values calculated from Equation (8-11). 


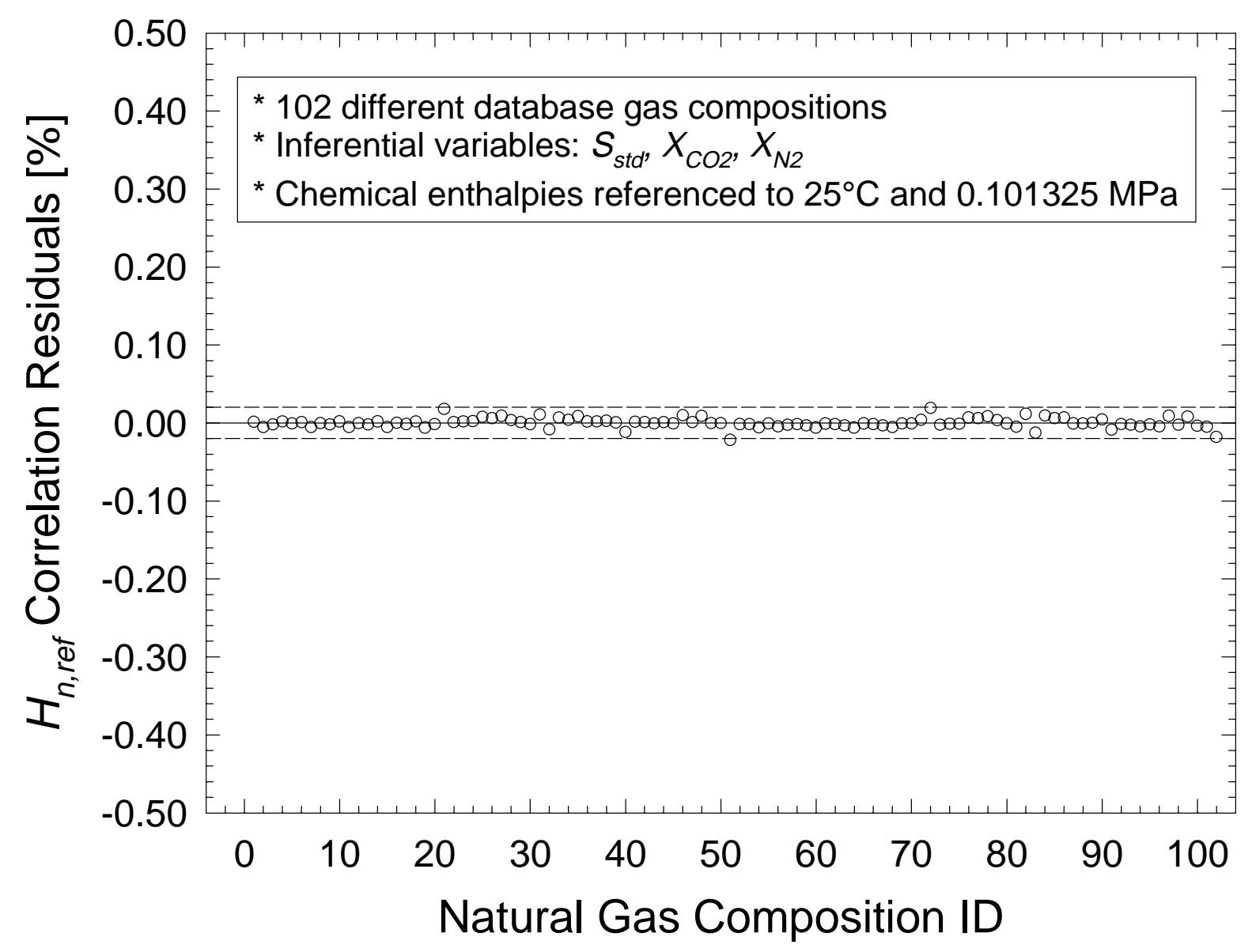

Figure 8-4. Correlation residuals for the molar ideal gross heating value, $H_{n, r e f}$, as a function of $S_{s t d}, X_{C O 2}$, and $X_{N 2}$.

\subsection{Characterizing Thermodynamic Properties}

Thermodynamic properties are more difficult to characterize than chemical properties because the chemical dependence must be modeled, not just once, but as a function of temperature and pressure. As demonstrated in Table 8-1, gas density, $\rho$, is the most important thermodynamic property related to natural gas energy flow measurement. Isentropic exponent, $\kappa$, and viscosity, $\mu$, are required for differential-based meters, but are less important because they are buried in less sensitive terms (isentropic exponent is needed for the expansion factor, and viscosity is needed for the Reynolds number). The focus of this Section is the correlation of gas density, $\rho$, to the pre-selected inferential properties of standard sound speed, $S_{\text {std }}$, carbon dioxide concentration, $X_{\mathrm{CO} 2}$, nitrogen concentration, $X_{\mathrm{N} 2}$, and, of course, temperature, $T$, and pressure, $P$.

The U.S. natural gas industry currently has two well-accepted equations of state for computing natural gas density (compressibility factor). These are contained in A.G.A. 8 (1994) as (1) the Detail Characterization Method, which requires a detailed gas composition assay to 
characterize the gas, and (2) the Gross Characterization Method, which requires inferential properties to characterize the gas. Both methods specify an uncertainty level of $0.1 \%$ over 17 $143^{\circ} \mathrm{F}, 0-1,750$ psia, and gas compositions in the "normal range" detailed in Table 8-3.

Table 8-3. "Normal range" of gas compositions for A.G.A. 8 (1994) density equations of state.

\begin{tabular}{|l|c|}
\hline \multicolumn{1}{|c|}{ Quantity } & Normal Range \\
\hline Relative Density* & $0.554-0.87$ \\
\hline Gross Heating Value**[Btu/scf] & $447-1,150$ \\
\hline Gross Heating Value***[MJ/m ${ }^{3}$ ] & $18.7-45.1$ \\
\hline Methane [mol\%] & $45.0-100.0$ \\
\hline Nitrogen [mol\%] & $0-50.0$ \\
\hline Carbon Dioxide [mol\%] & $0-30.0$ \\
\hline Ethane [mol\%] & $0-10.0$ \\
\hline Propane [mol\%] & $0-4.0$ \\
\hline Total Butanes [mol\%] & $0-1.0$ \\
\hline Total Pentanes [mol\%] & $0-0.3$ \\
\hline Hexanes Plus [mol\%] & $0-0.2$ \\
\hline Helium [mol\%] & $0-0.2$ \\
\hline Hydrogen [mol\%] & $0-10.0$ \\
\hline Carbon Monoxide [mol\%] & $0-3.0$ \\
\hline Water [mol\%] & $0-0.05$ \\
\hline Hydrogen Sulfide [mol\%] & $0-0.02$ \\
\hline
\end{tabular}

* Reference Condition: Relative density at $60^{\circ} \mathrm{F}, 14.73 \mathrm{psia}$

** Reference Conditions: Combustion at $60^{\circ} \mathrm{F}, 14.73$ psia; density at $60^{\circ} \mathrm{F}, 14.73$ psia.

*** Reference Conditions: Combustion at $25^{\circ} \mathrm{C}, 0.101325 \mathrm{MPa}$; density at $0^{\circ} \mathrm{C}, 0.101325 \mathrm{MPa}$.

The current A.G.A. 8 (1994) Gross Characterization Method allows the user to characterize the gas using one of two inferential variable sets:

Method (1): volumetric gross heating value, relative density, and carbon dioxide concentration, or

Method (2): relative density, carbon dioxide concentration, and nitrogen concentration. 
This section focuses on the development of a new third method:

Method (3): standard sound speed, $S_{s t d}$, carbon dioxide concentration, $X_{\mathrm{CO} 2}$, and nitrogen concentration, $X_{N 2}$.

The A.G.A. 8 (1994) Gross Characterization model is a virial equation of state, and is cast in terms of compressibility factor, $Z$, as a truncated expansion of molar density, $d$ :

$$
Z(T, P, \text { composition })=\frac{\rho_{\text {ideal gas }}}{\rho_{\text {real gas }}}=1+B_{\text {mix }} d+C_{m i x} d^{2}
$$

where compressibility factor, $Z$, is a dimensionless density, $d$ is the molar density (a function of $T$, $P$, and composition), and the virial coefficients, $B_{m i x}$ and $C_{m i x}$, are complicated functions of temperature and composition. Since $Z$ and $d$ are both functions of temperature, $T$, pressure, $P$, and composition, the solution of Equation (8-13) is iterative.

The Gross Characterization method determines the virial coefficients, $B_{m i x}$ and $C_{m i x}$, by modeling the natural gas as a three component mixture containing carbon dioxide, nitrogen, and an equivalent hydrocarbon component where all of the hydrocarbons are lumped together. The equivalent hydrocarbon component is then characterized by one of the two inferential variable sets, using them to determine a single hydrocarbon characterization parameter, $H_{C H}$, which is the molar ideal gross heating value of the equivalent hydrocarbon $[\mathrm{kJ} / \mathrm{mol}$ at reference conditions of $25^{\circ} \mathrm{C}$ and $0.101325 \mathrm{MPa}$ ]. $H_{C H}$ is related to $H_{n, r e f}$ :

$$
H_{C H}=\frac{H_{n, r e f}}{\left(1-\left(\frac{X_{C O 2}+X_{N 2}}{100}\right)\right)}
$$

Since $H_{n, r e f}$ was correlated to $S_{s t d}, X_{C O 2}$, and $X_{N 2}$ in the previous section (Equation (8-12)), $H_{C H}$ is now known as a function of the pre-selected inferential variables of $S_{s t d}, X_{\mathrm{CO} 2}$, and $X_{N 2}$, and can be used to characterize the equivalent hydrocarbon group for the A.G.A. 8 (1994) Gross Characterization model. This approach accounts for a third way of applying the A.G.A. 8 (1994) equation of state.

The most accurate way to determine $H_{C H}$ is from the detailed gas composition assay using Equations (8-11) and (8-14), but that, of course, defeats the purpose of gross inferential characterization. However, it is useful as a means to verify the validity of the gross inferential characterization approach for the database of natural gas compositions (Appendix A).

The A.G.A. 8 (1994) FORTRAN program subroutines for the Gross Characterization model were modified to accept, as input, either a detailed gas composition, or the Method (3) inferential variable set of $S_{s t d}, X_{C O 2}$, and $X_{N 2}$, both from the database. Natural gas density was 
then calculated using both approaches over the entire temperature and pressure ${ }^{2}$ range of the A.G.A. 8 (1994) Gross Characterization model. The comparison residuals are shown in Figure $8-5$. The majority of the data is well within $\pm 0.05 \%$.

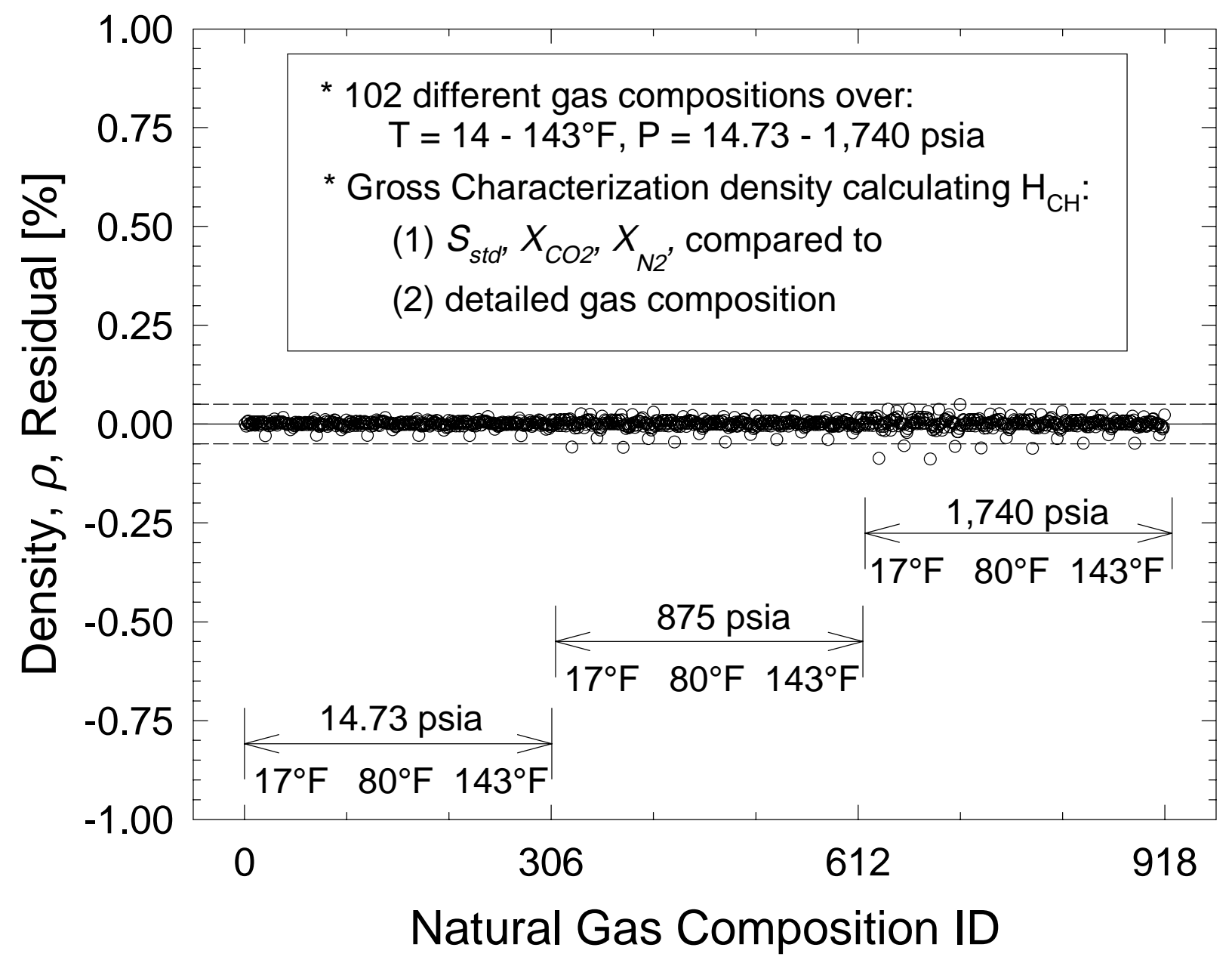

Figure 8-5. Residuals comparing density predictions from the A.G.A. 8 (1994)

Gross Characterization model, using input from (1) the inferential variables of $S_{s t d}, X_{C O 2}$, and $X_{N 2}$, and (2) the detailed gas composition database, over the full temperature and pressure application range of the model.

The modified A.G.A. 8 (1994) FORTRAN program subroutines, along with a driver program, are listed in Appendix B. Only one A.G.A 8 (1994) subroutine, CHARGS, has been modified to determine $H_{C H}$ differently. The remainder of the A.G.A. 8 (1994) subroutines,

${ }^{2}$ Note that a pressure limit of 1,740 psia is programmed into the A.G.A. 8 (1994) code, and was not exceeded, despite the A.G.A. 8 (1994) report's specification of 1,750 psia. 
including the computation and application of all interaction virial coefficient terms, are unchanged.

One additional Gross Characterization comparison was made to evaluate the relative accuracy of the A.G.A. 8 (1994) Gross Characterization state equation compared to the A.G.A. 8 (1994) Detail Characterization state equation. Detailed gas compositions from the database were applied as input to both density state equations. The comparison differences are shown in Figure 8-6. Most of the 14.73 psia and 875 psia data is within $\pm 0.05 \%$. At 1,740 psia, the differences are larger, although mostly within $\pm 0.25 \%$, with the greatest deviation of $0.6 \%$ occurring at $17^{\circ} \mathrm{F}$. It is unclear which state equation is closer to the true value.

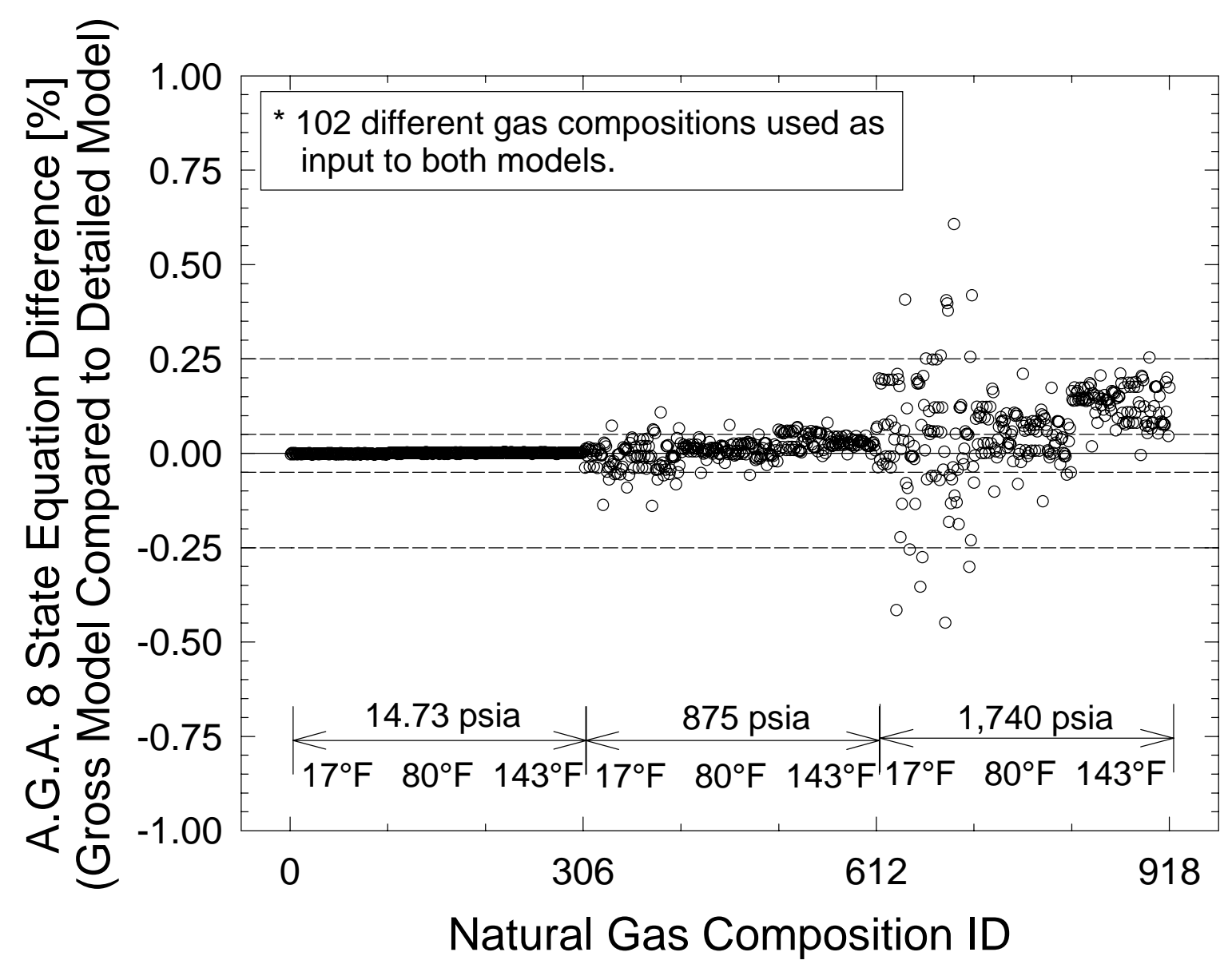

Figure 8-6. A comparison of A.G.A. 8 (1994) density state-equation predictions. The Gross Characterization model is compared to the Detail Characterization model, using detailed database gas compositions as input to both models. 


\subsection{FEASIBILITY EVALUATION OF INFERENTIAL PROPERTY-SENSING TECHNOLOGY}

Inexpensive sensor technology was identified for two of the three pre-selected inferential variables (standard sound speed, carbon dioxide concentration, and nitrogen concentration). The Siemens ultrasonic domestic gas meter sells for about \$100, and contains ultrasonic transit-time transducers and signal processing electronics. The manufacturer provides flow rate as an output variable, but not sound speed. However, the inexpensive technology appears capable of accurate sound speed measurements. Infrared absorption technology also appears capable of measuring carbon dioxide concentration. The Vaisala Model GMM11C is a complete NDIR package, that sells for about $\$ 400$. No inexpensive sensor technology has yet been identified for direct nitrogen concentration measurement.

The performance specifications of inferential sensors must be driven by the desired uncertainty in the final energy measurement result, and the sensitivity of the characterization equations to the measured inferential variable. This section, therefore, begins with a discussion of the sensitivity and uncertainty propagation of inferential variables. The sections that follow provide feasibility assessment data results for the two as-is inferential sensors that have been identified. Alternate means to determine the nitrogen concentration are also addressed.

\subsection{Uncertainty Specifications of Inferential Variables}

The gas energy measurement equations (Equations (8-1) to (8-3)) reveal three gas properties essential to energy measurement, namely, mass-based heating value, $H_{m}$, density, $\rho$, and volume-based heating value, $H_{v}$, which is the product of the first two. Standard density, $\rho_{s t d}$, and standard volumetric heating value, $H_{v, s t d}$, are the result of an arbitrarily applied reference condition that is eliminated when energy flow rate is computed.

Due to the brief nature of this technology assessment phase, there was only sufficient time to perform a detailed sensitivity analysis for $H_{m}$ as a function of $S_{s t d}, X_{C O 2}$, and $X_{N 2}$. Those results follow. The detailed sensitivity evaluation of $\rho$ and $H_{v}$ to inferential variables requires more sophisticated numerical propagation techniques, for which there was insufficient time available during this general assessment phase. However, a more general evaluation was performed for $\rho$ and $H_{v}$, as a function of $S_{s t d}, X_{C O 2}$, and $X_{N 2}$, which does provide a reasonable sense of the required uncertainty in inferential variables.

\subsubsection{Mass-Based Heating Value, $H_{m}$}

The inferential variables $\left(S_{s t d}, X_{C O 2}\right.$, and $\left.X_{N 2}\right)$ were jittered (perturbated) to determine the sensitivity of the correlation equation for $H_{m}$ (Equation 8-8) to the physical measurement of those properties. The results of that sensitivity analysis are presented in this section for all 102 gas compositions in the database. The data are presented to show the shift (required measurement uncertainty) in standard sound speed, $S_{\text {std }}$, carbon dioxide concentration, $X_{\mathrm{CO} 2}$, and nitrogen concentration, $X_{N 2}$, that would be required to produce a shift of $\pm 0.5 \%$ in massbased heating value, $H_{m}$. The $0.5 \%$ specification was arbitrarily chosen based on the general industry effort to reduce custody transfer measurements to levels below $1 \%$. 


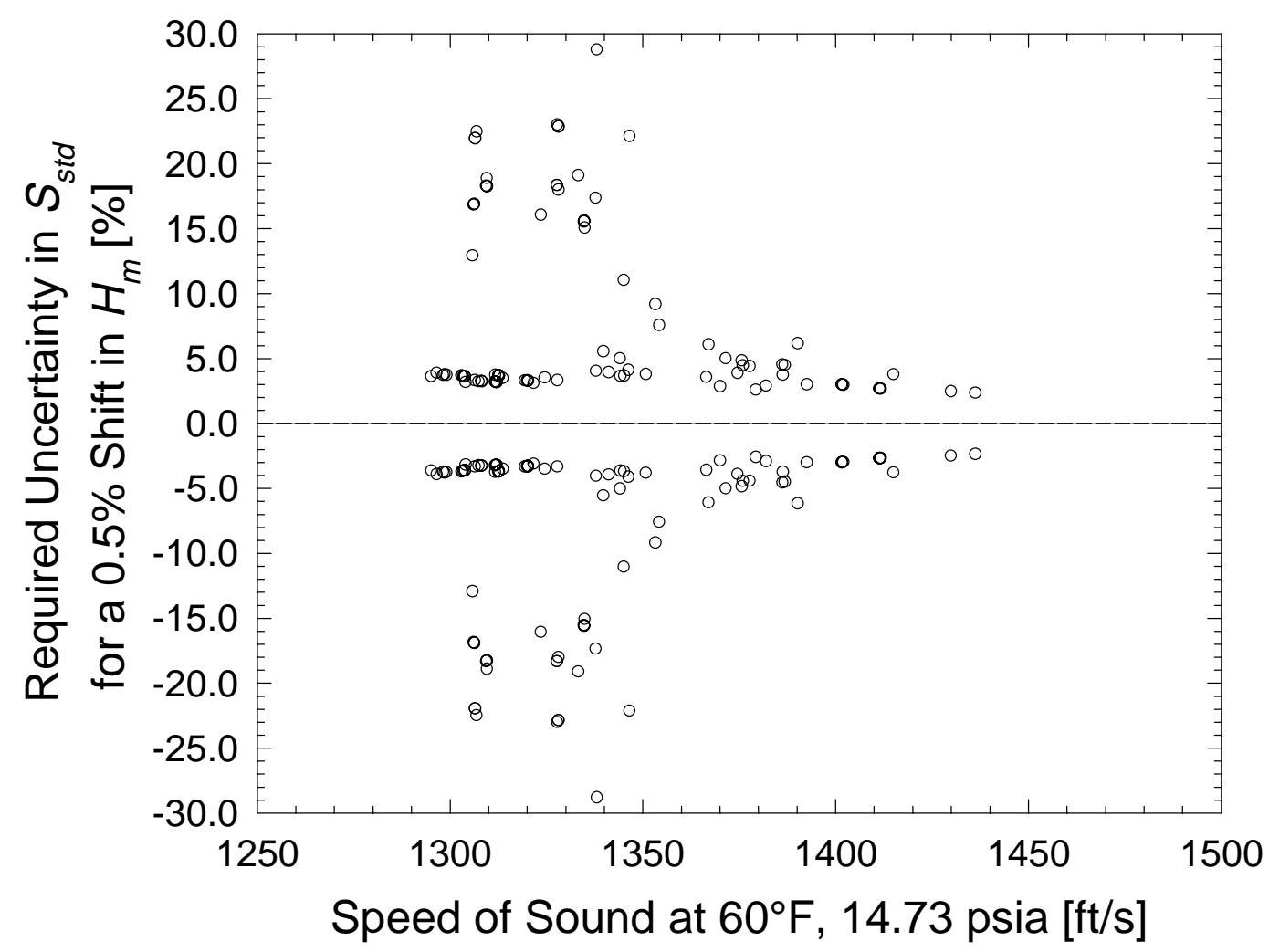

Figure 9-1. Shift in $S_{s t d}$ that would produce a $0.5 \%$ shift in $H_{m}$, for each database gas composition. Note that the scatter is a function of $X_{\mathrm{CO} 2}$ and $X_{\mathrm{N} 2}$.

Figure 9-1 shows that the required uncertainty in $S_{s t d}$ is considerably variable. This is because the sensitivity coefficient of $H_{m}$ with respect to $S_{s t d}$ (partial derivative of $H_{m}$ with respect to $S_{s t d}$ ) is a complicated function of the carbon dioxide and nitrogen concentrations. In general, however, the lowest required uncertainty in $S_{\text {std }}$ to produce a $0.5 \%$ shift in $H_{m}$ is about $2-3 \%$ of reading, depending on the operating point, for all the database compositions.

Figures 9-2 and 9-3 show that the required uncertainty in the carbon dioxide and nitrogen concentrations are strong functions of the amount present in the gas. There is some scatter in these results also because the sensitivity coefficients of $H_{m}$ with respect to $X_{\mathrm{CO} 2}$ and $X_{N 2}$ (partial derivatives of $H_{m}$ with respect to $X_{\mathrm{CO} 2}$ and $X_{N 2}$ ) are functions of the standard sound speed. The data shows that a $0.5 \%$ shift in $H_{m}$ will occur if the carbon dioxide concentration is in error by about 0.2 mole $\%$ ( $20 \%$ of reading for 1 mole $\%$ carbon dioxide), or if the nitrogen concentration, $X_{N 2}$, is in error by about 0.3 mole $\%$ (30\% of reading for 1 mole $\%$ nitrogen). The sensitivities of $H_{m}$ to all three inferential properties are summarized in Table 9-1. 


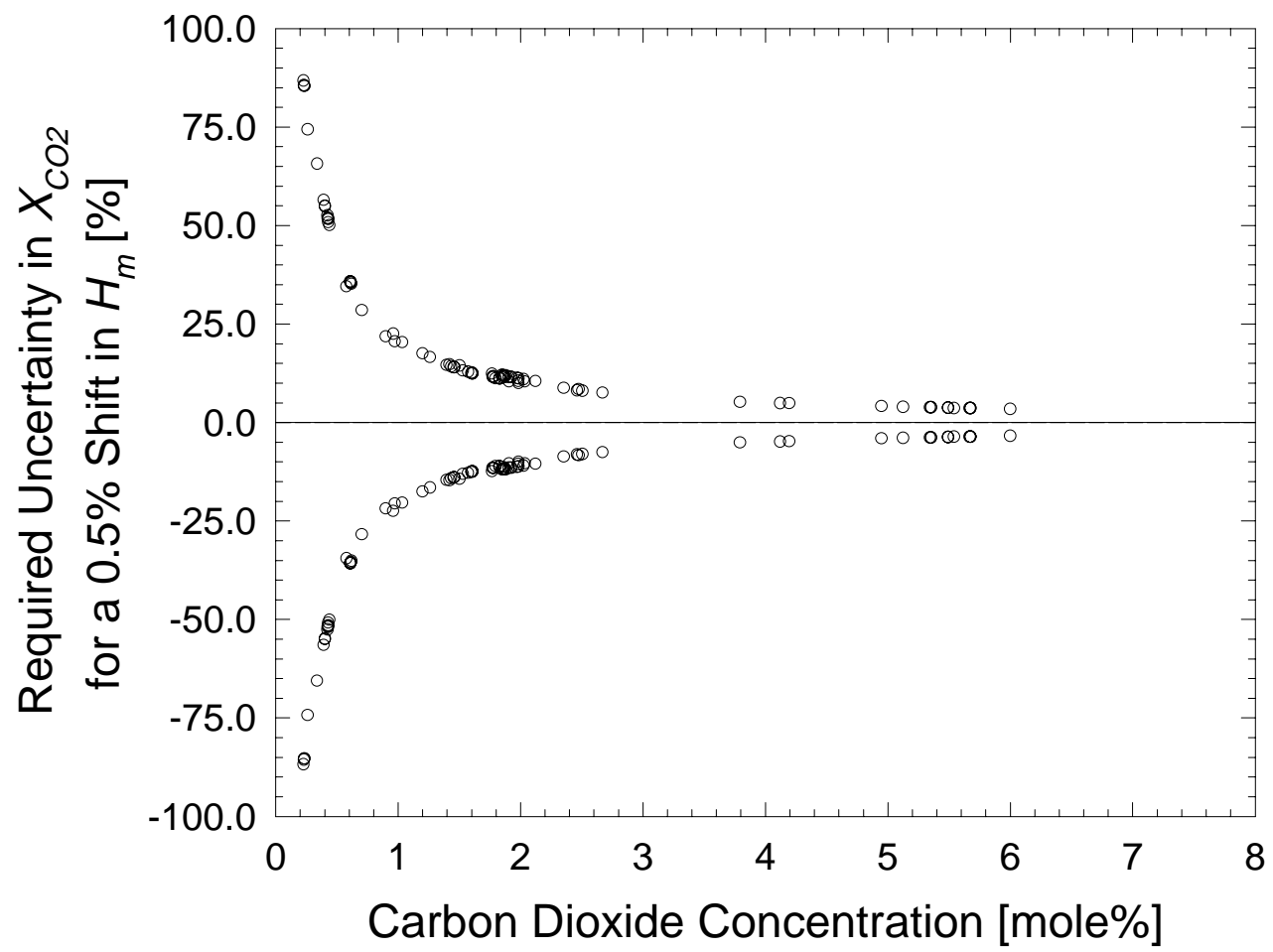

Figure 9-2. Shift in $X_{\mathrm{CO} 2}$ that would produce a $0.5 \%$ shift in $H_{m}$, for each database gas composition. Note that the scatter is a function of $S_{\text {std }}$.

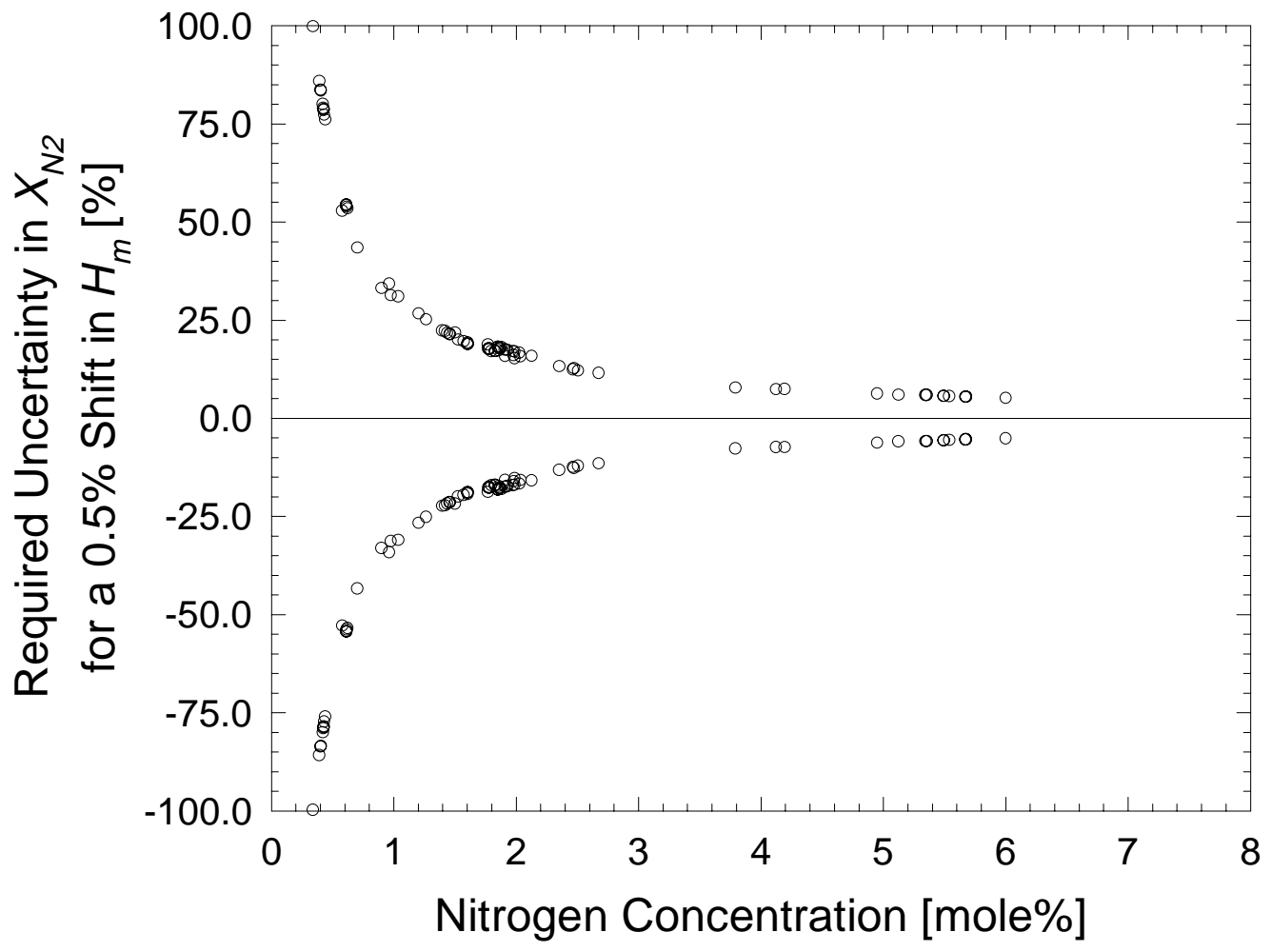

Figure 9-3. Shift in $\boldsymbol{X}_{N 2}$ that would produce a $0.5 \%$ shift in $\boldsymbol{H}_{\boldsymbol{m}}$, for each database gas composition. Note that the scatter is a function of $S_{\text {std }}$. 


\section{Table 9-1. Sensitivity of mass-based heating value, $H_{m}$, to measured inferential variables.}

\begin{tabular}{|c|c|}
\hline $\begin{array}{c}\text { Inferential } \\
\text { Variable }\end{array}$ & $\begin{array}{c}\text { Change in Inferential } \\
\text { Variable Required to Produce } \\
\text { a } \mathbf{0 . 5 \%} \text { change in } \boldsymbol{H}_{\boldsymbol{m}}\end{array}$ \\
\hline $\boldsymbol{S}_{\text {std }}$ & $\begin{array}{c}\text { 2-3\%, or greater, depending on } \\
\text { the std sound speed and total } \\
\text { diluent concentration }\end{array}$ \\
\hline $\boldsymbol{X}_{\boldsymbol{C O} 2}$ & About 0.2 mole\% \\
\hline $\boldsymbol{X}_{N 2}$ & About 0.3 mole\% \\
\hline
\end{tabular}

\subsubsection{Density, $\rho$}

As noted previously, detailed sensitivity analyses need to be performed for the thermodynamic properties of density, $\rho$, and volume-based heating value, $H_{v}$ to detail their sensitivity to inferential variables of $S_{s t d}, X_{\mathrm{CO} 2}$, and $X_{N 2}$. Since there was insufficient project time to develop the sophisticated perturbation algorithm required to perform that task, a more general discussion is presented here.

Gas density, $\rho$, in terms of traditional inferential properties of detailed mole-percentage gas component concentrations, $X_{i}$, temperature, $T$, and pressure, $P$, is given by:

$$
\rho=\frac{P \sum_{i=1}^{N}\left(\frac{X_{i}}{100} M_{i}\right)}{Z R T}
$$

where $M_{i}$ is the molecular weight of gas component $i, Z$ is the compressibility factor, and $R$ is the universal gas constant.

The change in density to any gas component concentration error may be estimated by assuming that $Z=1$, which is approximated at low-pressure conditions. The propagation of component concentration error (through density) may then be written by taking the partial derivative of Equation (9-1):

$$
\frac{1}{\rho}\left(\frac{\partial \rho}{\partial X_{i}}\right) U_{X i}=\frac{M_{i}}{M} U_{X i}
$$

where $M$ is the molecular weight of the composite gas mixture (as opposed to $M_{i}$, which is the molecular weight of a single mixture component), and $U_{x i}$ is the measurement uncertainty in $X_{i}$. 
First, consider the sensitivity of an inferential property of carbon dioxide concentration, $X_{C O 2}$. The sensitivity coefficient, $\left(M_{i} / M\right)$ for carbon dioxide, in a common natural gas mixture, is approximately $(44 / 17)=2.6$. If $U_{X C O 2}=0.2$ mole $\%$, then the resulting change in density, from Equation (9-2), is $(2.6)(0.2)=0.5 \%$. Therefore, a 0.2 mole $\%$ change in carbon dioxide concentration propagates as a $0.5 \%$ shift in mixture density. If one determines the sensitivity of density to nitrogen concentration following the same approach, a 0.3 mole $\%$ change in nitrogen concentration results in a $0.5 \%$ shift in density.

The sensitivity of density to the diluent gas concentrations is the same as was seen in Section 9.1.1 for mass-based heating value, $H_{m}$, which is not surprising. The diluent gases linearly impact the denominator of the mass-based heating value equation (Equation (8-6)), which is mixture molecular weight, $M$. If one assumes that $Z=1$ in the density equation, (Equation (9-1)), then the diluent gases linearly impact density through $M$ also. Unfortunately, previous work [Park et al. (1995)] has demonstrated that $Z$ (which was neglected in this estimate) changes the sensitivity of density to the measurement of component concentrations at higher pressures. That is why a detailed sensitivity analysis, accounting for the impact of $Z$ at high pressures, is needed.

Now consider the required uncertainty in $S_{s t d}$, for a $0.5 \%$ shift in density, $\rho$. Since hydrocarbons make up the majority of natural gas, assume that $M_{H C}=M$, and that the sensitivity coefficient of Equation (9-2) is equal to 1 . Since $S_{s t d}$ is being used to infer the hydrocarbon group concentration, one may surmise from Equation (9-2) that a $0.5 \%$ change in $S_{s t d}$ will produce an equal magnitude shift of $0.5 \%$ in density near atmospheric pressure. One may also conclude that this sensitivity will change with operating pressure as $Z$ becomes more important. The sensitivities of $\rho$ to all three inferential properties is summarized in Table 9-2.

Table 9-2. Sensitivity of density, $\rho$, to measured inferential variables.

\begin{tabular}{|c|c|}
\hline $\begin{array}{c}\text { Inferential } \\
\text { Variable }\end{array}$ & $\begin{array}{c}\text { Estimated Change in } \\
\text { Inferential Variable Required } \\
\text { to Produce a 0.5\% change in } \\
\rho\end{array}$ \\
\hline$S_{\text {std }}$ & $\begin{array}{c}\text { About 0.5\% at low pressure, } \\
\text { with changing sensitivity at } \\
\text { higher pressures }\end{array}$ \\
\hline $\boldsymbol{X}_{\boldsymbol{C O} 2}$ & $\begin{array}{c}\text { About } 0.2 \text { mole\%, with } \\
\text { changing sensitivity at higher } \\
\text { pressures }\end{array}$ \\
\hline $\boldsymbol{X}_{N 2}$ & $\begin{array}{c}\text { About } 0.3 \text { mole\%, with } \\
\text { changing sensitivity at higher } \\
\text { pressures }\end{array}$ \\
\hline
\end{tabular}




\subsubsection{Volume-Based Heating Value, $H_{v}$}

The propagation of inferential-variable measurement uncertainty through the volumebased heating value, $H_{v}$, is considerably more difficult to estimate (without a detailed analysis), because it is the product of density, $\rho$, and mass-based heating value, $H_{m}$. Sensitivities propagated through $\rho$ or $H_{m}$, may be either diminished or increased by the product of the two. However, some generalizations may be made.

The product of density, $\rho$, and mass-based heating value, $H_{m}$, may be written (from Equations (9-1) and (8-6)):

$$
H_{v}=\rho H_{m}=\left(\frac{P M}{Z R T}\right)\left(\frac{\sum_{i=1}^{N}\left(\frac{X_{i}}{100} M_{i} H_{m, i}\right)}{M}\right)=\left(\frac{P}{Z R T}\right) \sum_{i=1}^{N}\left(\frac{X_{i}}{100} M_{i} H_{m, i}\right)
$$

where $M$, the mixture molecular weight, has been canceled.

Equation (9-3) reveals that the composition-dependence of mixture molecular weight, $M$, cancels when $H_{v}$ is determined. That leaves only the composition dependence of $Z$, and the composition dependence of the second term (sensitive only to hydrocarbon composition, because the diluents have no heating value).

At low pressure conditions where $Z=1$, the volume-based heating value is insensitive to the diluent concentrations, because $Z$ is the only factor of Equation (9-3) that depends on the diluent concentrations. At higher pressures, where $Z$ becomes much more important, the diluent concentrations also become more important. That change in sensitivity is much greater for carbon dioxide, than for nitrogen. As an example, consider the change in $Z_{\mathrm{CO} 2}$ from $\left(60^{\circ}\right.$, $14.73 \mathrm{psia})$ to $\left(60^{\circ}, 1750 \mathrm{psia}\right)$. $Z_{\mathrm{CO} 2}$ changes from a value of 0.9944 to $0.8696(-13 \%)$. Over that same operating range, $Z_{N 2}$ changes from 0.9997 to $1.004(+0.43 \%)$. The implication is that carbon dioxide will change the compressibility factor of a natural gas mixture much more than nitrogen, as the operating pressure increases.

Inspection of Equation (9-3) can also reveal general expectations for sensitivity to standard sound speed, $S_{s t d}$. At low pressures, when $Z=1, H_{v}$ will have approximately a one-toone sensitivity to changes in hydrocarbon molecular weight, therefore, approximately a one-toone sensitivity to $S_{s t d}$, which is being used to characterize the hydrocarbon composition. At higher pressures, the changing sensitivity of $Z$ will change the overall sensitivity of $H_{v}$ to $S_{s t d}$. The sensitivities of $H_{v}$ to all three inferential properties is summarized in Table 9-3. 
Table 9-3. Sensitivity of volume-based heating value, $H_{v}$ to measured inferential variables.

\begin{tabular}{|c|c|}
\hline $\begin{array}{c}\text { Inferential } \\
\text { Variable }\end{array}$ & $\begin{array}{c}\text { Estimated Change in } \\
\text { Inferential Variable Required } \\
\text { to Produce a 0.5\% change in }\end{array}$ \\
\hline $\boldsymbol{H}_{\text {std }}$ & $\begin{array}{c}\text { About 0.5\% at low pressure, } \\
\text { with changing sensitivity at } \\
\text { higher pressures }\end{array}$ \\
\hline$X_{C O 2}$ & $\begin{array}{c}\text { Insensitive at low pressure, } \\
\text { with changing sensitivity at } \\
\text { higher pressures }\end{array}$ \\
\hline$X_{N 2}$ & Insensitive \\
\hline
\end{tabular}

\subsection{Feasibility Evaluation of Sound Speed Measurement}

The feasibility of measuring standard sound speed, $S_{s t d}$, with inexpensive instrumentation was investigated using the ultrasonic transducers taken from a Siemens domestic ultrasonic gas meter. The meter sells commercially for about $\$ 100$. The goal was not to optimize the performance of the as-found ultrasonic transducers. Rather, the focus of this work was to evaluate the feasibility of this inexpensive technology in a way that defines major issues for later development and application.

\subsubsection{Ultrasonic Methods}

The term ultrasound is used to describe the range of acoustic phenomena which occur at frequencies much higher than what is audible to the human ear (typically, greater than about 20 $\mathrm{kHz}$ ). It has applications in medicine, non-destructive testing of materials, and many other fields. More recently, it has gained wide acceptance within the natural gas industry as a developing means to measure the flow rate of natural gas for custody transfer.

Ultrasound provides an easy way to determine the speed of sound in a gas. However, the low densities of gases (relative to solids) provide a poor environment for ultrasonic wave propagation. Furthermore, the ultrasonic absorption (attenuation) of acoustic energy increases with frequency. Therefore, adequate generation and receipt of ultrasonic signals is limited by frequency.

Ultrasound energy is generated by an ultrasonic transducer. Ultrasonic transducers usually contain a piezoelectric element that produces mechanical vibrations when charged. The frequency of the generated waves depends on the characteristic piezoelectric element in the transducer. Transducers in commercially available natural gas ultrasonic meters tend to operate from about $125 \mathrm{kHz}$ up to several hundred $\mathrm{kHz}$.

There are two general methods applied to measure sound speed with ultrasound: (1) pulse-echo, and (2) pitch-catch. The pulse-echo method uses a single transducer as both the 
transmitter and receiver. As shown in Figure 9-4, the transducer and target are separated by a known distance, D. An ultrasound pulse is reflected by the target, and the sound speed is related to the difference in reflected transit-time through the stationary gas sample:

$$
S=\frac{2 D}{t}
$$

where $S$ is the sound speed (a thermodynamic property, hence a function of temperature, pressure, and composition), and $t$ is the time difference for detection of the reflected pulse.

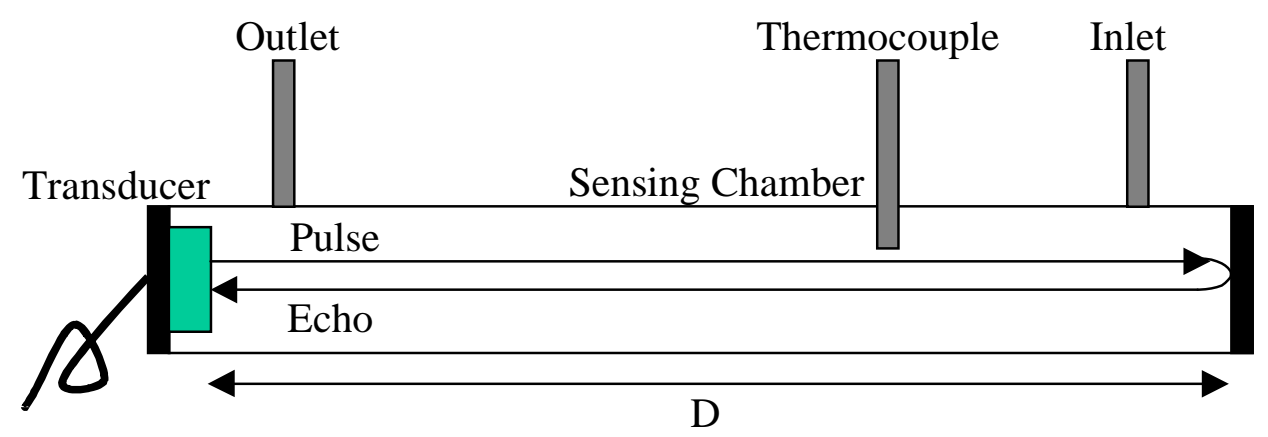

\section{Figure 9-4. Schematic diagram of a pulse-echo device that determines sound speed with a single transducer.}

The other sound speed measurement approach, the pitch-catch method, uses one transducer to transmit an acoustic pulse, and another transducer to receive it. The pitch-catch configuration is detailed in Figure 9-5. The ultrasonic pulse travels directly from the transmitting transducer to the receiving transducer without reflection. Here, the sound speed is determined using:

$$
S=\frac{D}{t}
$$




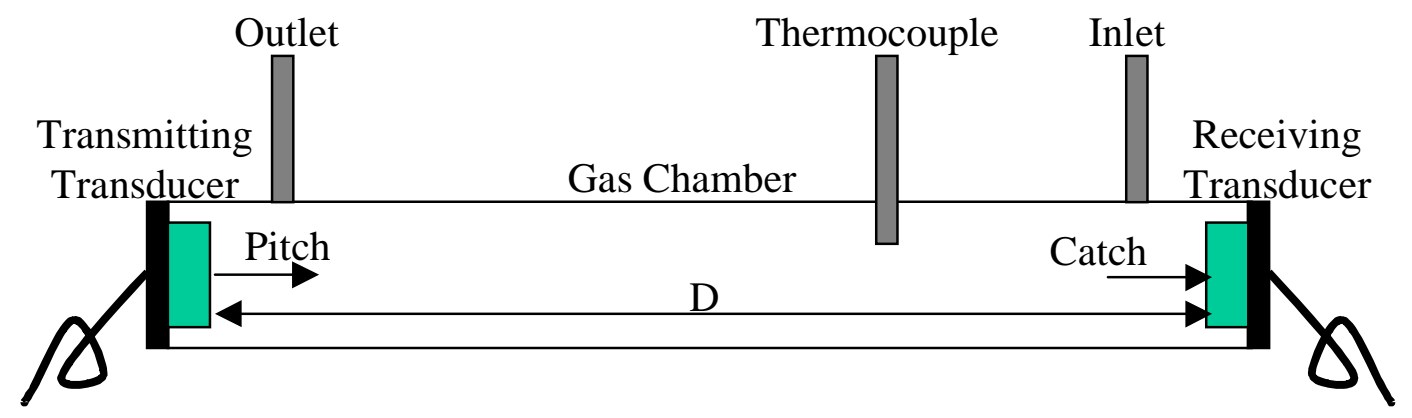

Figure 9-5. Schematic diagram of a pitch-catch device that determines sound speed using separate transmitting and receiving transducers.

There are pulse wave-form definition uncertainties associated with both methods. These uncertainties can have a significant impact on the accuracy of the sound speed measurement. However, they can be eliminated by measuring the time difference between two received signals.

\subsubsection{Exploratory Tests of Ultrasonic Technology}

The two ultrasonic transducers were removed from the Siemens domestic ultrasonic gas meter and configured in the tubular test piece shown in Figure 9-6. The piezoelectric ultrasonic transducers, Figure 9-7, had a diameter of approximately 5/8 inch. The frequency of the transducer was determined, by trial and error, to be $200-220 \mathrm{kHz}$.

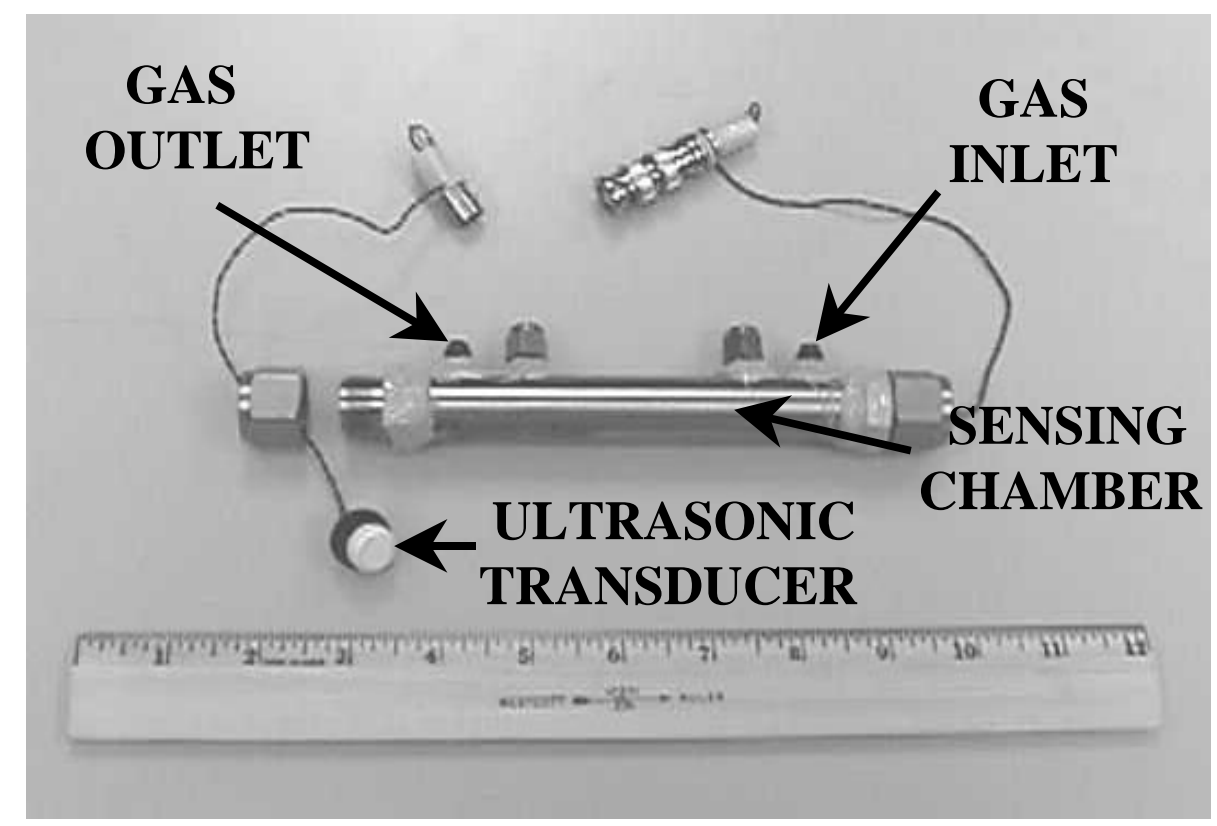

Figure 9-6. Photograph of the speed of sound test piece, showing one removed ultrasonic transducer. 


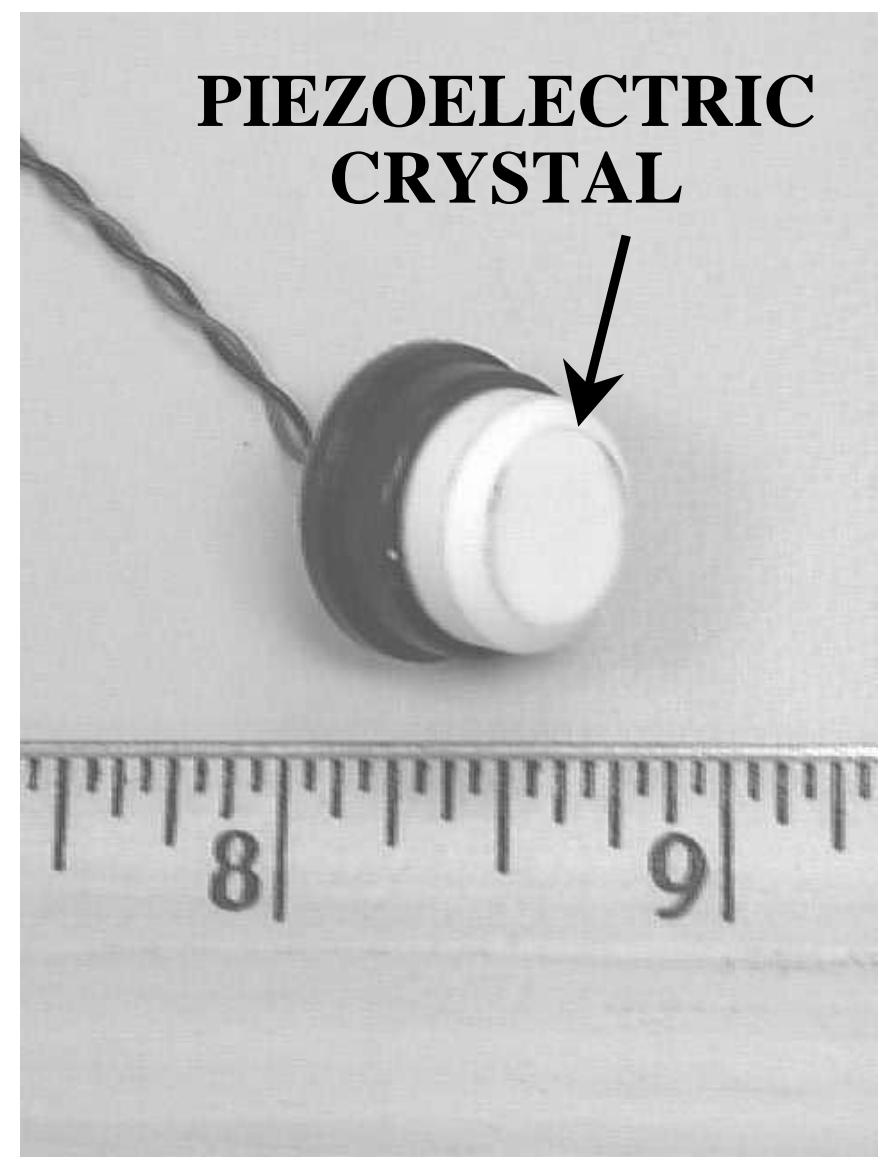

Figure 9-7. Close-up photograph of one of two ultrasonic transducers
set to evaluate inexpensive speed of sound measurement feasibility.

A field-ready sound-speed sensor would have integrated signal processing. Since a field-ready unit doesn't currently exist, more flexible laboratory instruments were used to investigate feasibility at this stage of the project. One of the transducers was connected to a tone-burst generator, which consisted of a signal generator and a gated amplifier. The frequency and gain of the narrow-band signals were controlled from a personal computer. There are a number of acoustic pulse parameters that may be controlled. For the purposes of these evaluations, pulse wave forms were produced with a frequency of $200-220 \mathrm{kHz}$, a pulse width of $9.9 \mu \mathrm{s}$, and a repetition period of $10,000 \mu \mathrm{s}$.

Gas samples were collected in a high-pressure $300 \mathrm{cc}$ sample cylinder, intended to represent a high-pressure source, such as a pipeline. The cylinder was attached to a sample delivery system consisting of a pressure regulator, 0.5 micron filter, and needle valve. The sample delivery system is shown in Figure 9-8.

Test samples were delivered to the sensing chamber at near-atmospheric pressure. Sample compositions included pure methane, pure nitrogen, and natural gas taken from the San Antonio distribution supply. A gas chromatographic analysis of the natural gas is shown in Table 9-4. 


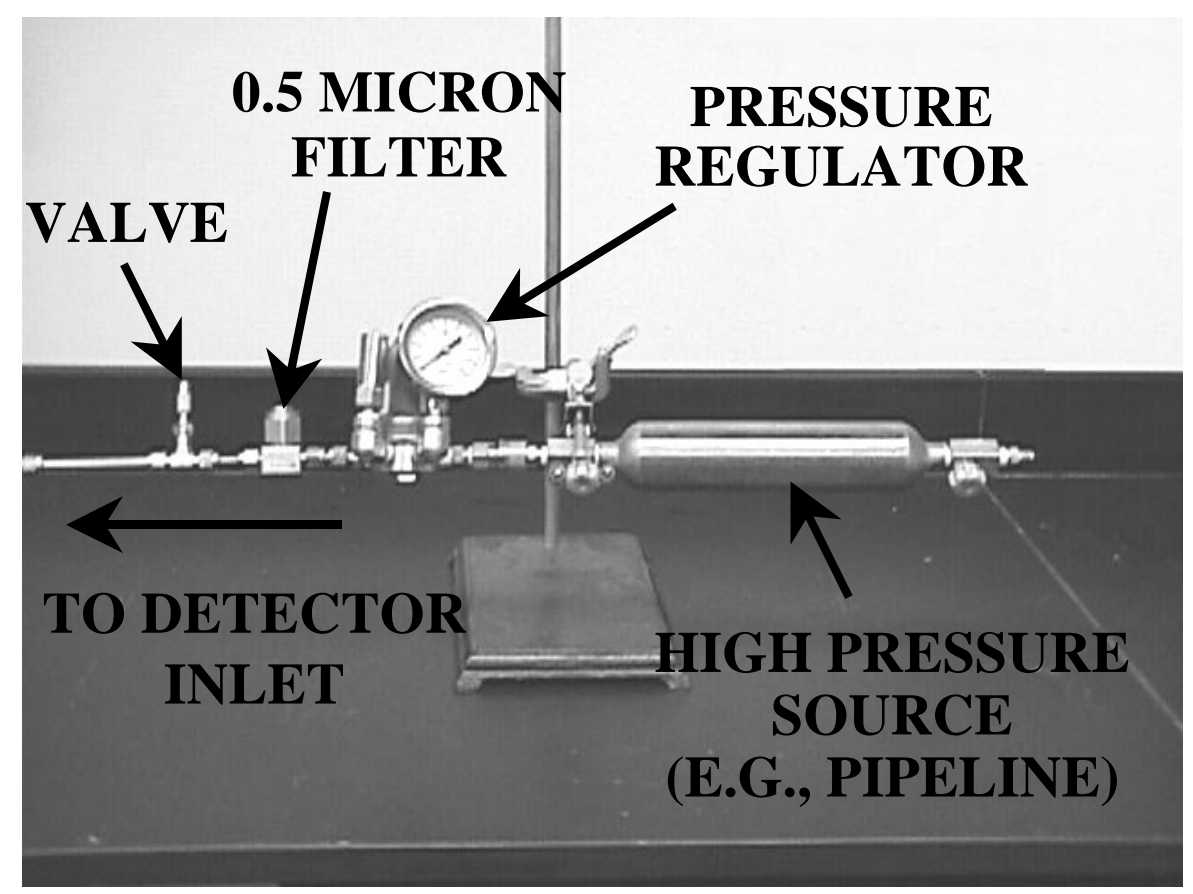

Figure 9-8. Delivery system used to provide gas samples to the speed of sound test piece.

Table 9-4. The natural gas composition used as a test gas to evaluate feasibility of the sound speed test piece.

\begin{tabular}{|c|c|}
\hline Gas Component & $\begin{array}{c}\text { Concentration } \\
\text { [mole \%] }\end{array}$ \\
\hline Methane & 96.16 \\
Ethane & 1.796 \\
Propane & 0.151 \\
i-Butane & 0.019 \\
n-Butane & 0.024 \\
i-Pentane & 0.008 \\
n-Pentane & 0.005 \\
n-Hexane & 0.006 \\
n-Heptane & 0.003 \\
n-Octane & 0.002 \\
Carbon Dioxide & 1.137 \\
Nitrogen & 0.689 \\
\cline { 2 - 2 } Total & 100.0 \\
\hline
\end{tabular}




\subsubsection{Pulse-Echo Experience}

In section 9.2.1, it was mentioned that there are pulse wave-form definition uncertainties that can have a significant impact on the accuracy of the sound speed measurement. One of the most significant is associated with measuring the starting time of both the initial pulse and received signal. There are 3 general sources of uncertainty in identifying the starting time of the initial pulse:

(1) Trigger Level: The trigger level is set to be greater than the noise level. Therefore, there can be a time difference between the actual pulse-start and the indicated start,

(2) Transducer Response: When the crystal is charged, the waves propagate through layers within the crystal before exiting. Therefore, there is a time delay between the triggering of the crystal and the time the waves exit the transducer,

(3) Synchronizing Pulse: The main pulse that drives the transducer must be synchronized with the timing electronics, which represents another electronic timing delay.

The uncertainty in the timing of the received signal is associated with the definition of the waveform. These uncertainties can be eliminated by measuring the time difference between two received signals.

From a practical standpoint, the pulse-echo sensor can be fabricated with two reflecting targets, shown in Figure 9-9. The critical distance then becomes the distance between the two targets, and the transit-time becomes the time to receive each reflection.

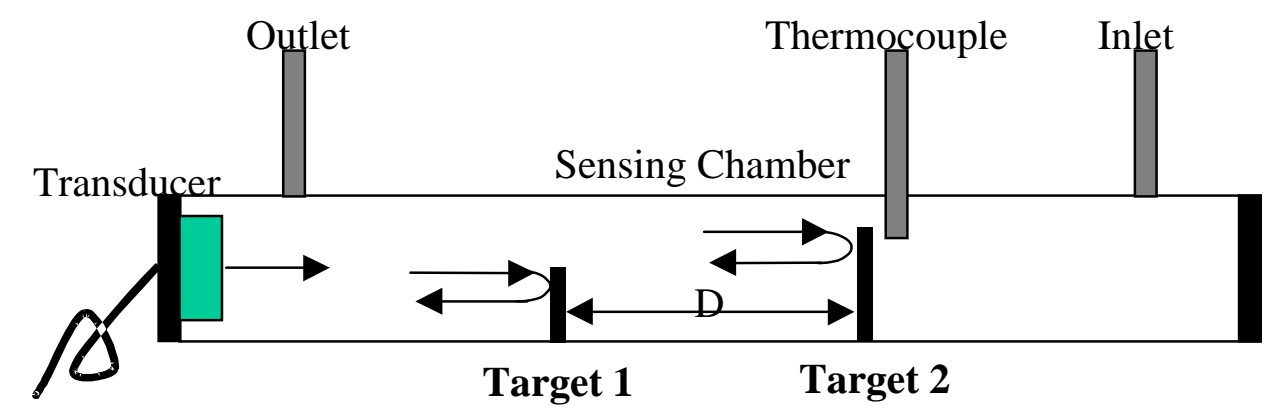

Figure 9-9. Schematic of the test piece incorporating two targets to reduce uncertainty associated with transmitted and received waveform definition/timing.

The sound speed test piece (with targets) was filled with pure nitrogen gas near atmospheric pressure, and the pulse-echo approach was investigated. Figure 9-10 shows the signal received in nitrogen gas and the transit-time used to determine the sound speed. Note the reduced amplitude in the signal received from the second target. This is indicative of the, previously noted, attenuation due to absorption of ultrasound energy. 


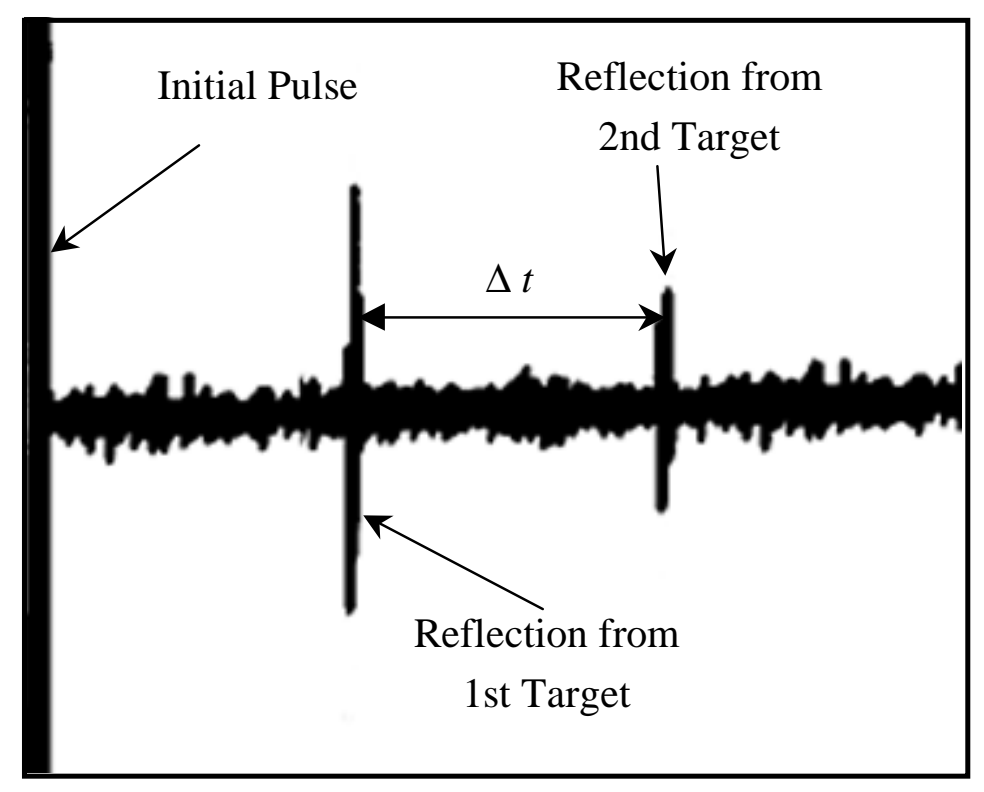

Figure 9-10. An example of the two pulse-signals seen in nitrogen gas. The low signal-tonoise ratio reveals the need to optimize the sound speed sensor design.

Since natural gas more readily absorbs ultrasound, the reflected signals were attenuated below the noise level when the test piece was filled with natural gas. It is clear from this result that pulse-echo development challenges include the enhancement of the signal-to-noise ratio through optimizing (1) chamber/reflector design, and (2) pulse signal quality (which may involve the use of different transducers and signal generation circuitry). Despite the nonoptimum test piece design, the sound speed measurement in pure nitrogen was only $0.49 \%$ lower than the value predicted by the GRI Extended Thermodynamic Properties computer program (1989).

\subsubsection{Pitch-Catch Experience}

As discussed in the previous sections, timing uncertainty is a critical issue because identification of the timing points is somewhat arbitrary. In the pitch-catch mode, the same is true, if not more critical. In an attempt to overcome these system limitations, the pitch-catch timing measurements were compared to a known reference, which was chosen to be nitrogen. The transit-time difference between the test gas and nitrogen, and the known sound speed in nitrogen, were used to determine the sound speed in the test gas.

Assuming that the transit distance for a pitch-catch pulse is simply the distance between the two transducers in the chamber, $D$, then the speed of sound, $S$, is given by:

$$
S=\frac{D}{t}
$$


where $t$ is the pulse transit time.

The pitch-catch transit time difference between any gas, $i$, and a reference gas, ref, (nitrogen, in this case) is:

$$
t_{i}-t_{r e f}=\frac{D}{S_{i}}-\frac{D}{S_{r e f}}
$$

where the only unknown is $S_{i}$, since the speed of sound in the reference gas is assumed known, and the time difference may be measured. Equation (9-6) may be solved for $S_{i}$ :

$$
S_{i}=\frac{D S_{r e f}}{D+S_{r e f}\left(t_{i}-t_{r e f}\right)}
$$

Figure 9-11 shows the transit-time difference between a received nitrogen signal, and a signal representative of a test gas. The transit-time difference arises simply because an acoustic pulse travels the distance, $D$, at a different speed in the test gas than in the reference gas. It is evident from the Figure 9-11 that improvements in the signal-to-noise ratio will improve the pulse definition, which must be used to resolve the transit-time difference.

Pitch-catch evaluations were performed by filling the test piece with pure methane in one case, then natural gas (Table 9-4) in another. Using the reference approach described by Equation (9-7), the pure methane measurements were found to be $0.87 \%$ higher than those predicted by the GRI Extended Thermodynamic Properties code (1989). The natural gas measurements were found to be $0.26 \%$ lower than the predicted value from (1989). Note that the GRI Extended Thermodynamic Properties code (1989) predictions of sound speed agree with the Lomic SonicWare (1997) predictions at these atmospheric pressure conditions.

These data suggest that the test piece, while not yet optimized, demonstrates general feasibility for inferential measurement of flow rate and energy flow rate through $S_{\text {std }}$ measurement. Recall from Section 9.1 that a specification of $2-3 \%+$ in $S_{s t d}$ is required to produce a $0.5 \%$ shift in $H_{m}$, and that a specification of about $0.5 \%$ in $S_{s t d}$ is required to produce a $0.5 \%$ shift in either $\rho$ or $H_{v}$ (at low pressure). 


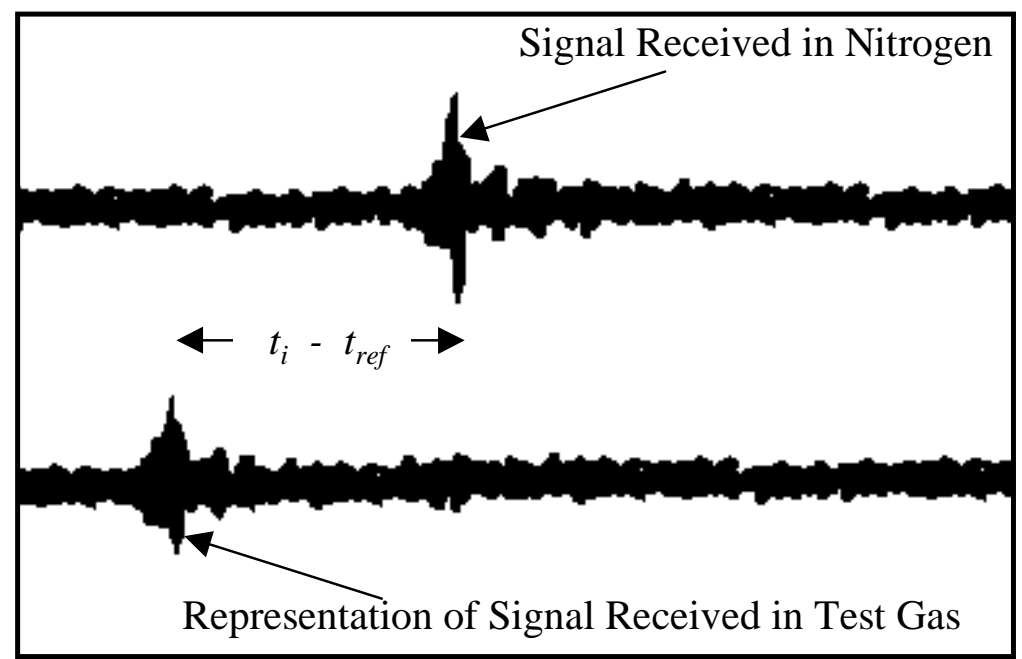

Figure 9-11. Time difference using the received signal from nitrogen, and a signal representative of a test gas.

The pitch-catch approach, in particular, demonstrated feasibility even with very low signal-to-noise ratios. Improvement of the signal-to-noise ratio during the development phase will enhance the performance of both the pitch-catch and pulse-echo approaches. Needed improvements include transducer selection (other types may produce more suitable characteristics), transducer mounting (to ensure that the acoustic energy is transmitted to the gas, rather than the mounting hardware), and physical chamber/reflector geometry.

\subsection{Feasibility Evaluation of Diluent (Carbon Dioxide and Nitrogen) Concentration Measurement}

The measurement of diluent gas concentrations make it possible to independently characterize the hydrocarbons with inferential properties like standard sound speed. Therefore, the diluent concentration measurements are important for compensation purposes. The feasibility of measuring carbon dioxide concentration, $\mathrm{X}_{\mathrm{CO} 2}$, with inexpensive instrumentation was investigated using the Vaisala GMM11 non-dispersive infrared (NDIR) instrument, which sells commercially for about $\$ 400$. As with the speed of sound evaluations, the goal was not to optimize the performance of the as-found instrument. Rather, the focus of this work was to evaluate the feasibility of this inexpensive technology in a way that defines major issues for later development and application in natural gas environments. No commercially available sensors were found to directly sense the concentration of nitrogen. Indirect measurement approaches are, however, addressed for nitrogen.

\subsubsection{Infrared Methods}

The presence of carbon dioxide in a mixture of other gases may be directly sensed by its unique infrared absorption characteristics. Infrared radiation is the region of the electromagnetic spectrum with wavelengths ranging from about $0.1 \mathrm{~cm}\left(0.039\right.$ in.) to $7.0 \times 10^{-5}$ $\mathrm{cm}\left(2.8 \times 10^{-5} \mathrm{in}\right.$.). In terms of the wavenumber, which is the inverse of wavelength, the range is from $10 \mathrm{~cm}^{-1}\left(26 \mathrm{in}^{-1}\right)$ to $14,000 \mathrm{~cm}^{-1}\left(36,000 \mathrm{in}^{-1}\right)$. The region is bounded by microwaves on 
the low end, and visible waves on the high end. Figure 9-12 shows the electromagnetic spectrum relative to other electromagnetic energy domains.

Infrared absorption characteristics, of some gases, may be exploited to measure concentration because (1) infrared signatures of some gases are unique, and (2) the level of absorption is related to the concentration present. A gas sample is exposed to infrared radiation (which may be broad-band) at one end of a sample cell, then the intensity at a particular wavelength (wavenumber) is measured by a narrow-band detector at the other end of the cell. Absorption of infrared energy occurs when molecular vibrations are resonated by a particular wavelength (wavenumber). These absorbed wavelengths provide a "signature" of the molecule in the form of an absorption spectrum. Such a spectrum is summarized in Figure 9-13 for carbon dioxide. The most prominent absorption peak occurs at a wavenumber of about 2360 $\mathrm{cm}^{-1}$. This is the principle wavenumber that is exploited by (infrared) carbon dioxide sensor manufacturers. The Vaisala GMM11 non-dispersive infrared (NDIR) carbon dioxide sensor is one such instrument.

Other gases, besides carbon dioxide, also have unique infrared absorption signatures. It may be possible to use these spectra to detect the presence and amount of other natural gas impurities, such as water vapor and hydrogen sulfide, using similar technology. However,

FREQUENCY (HZ)

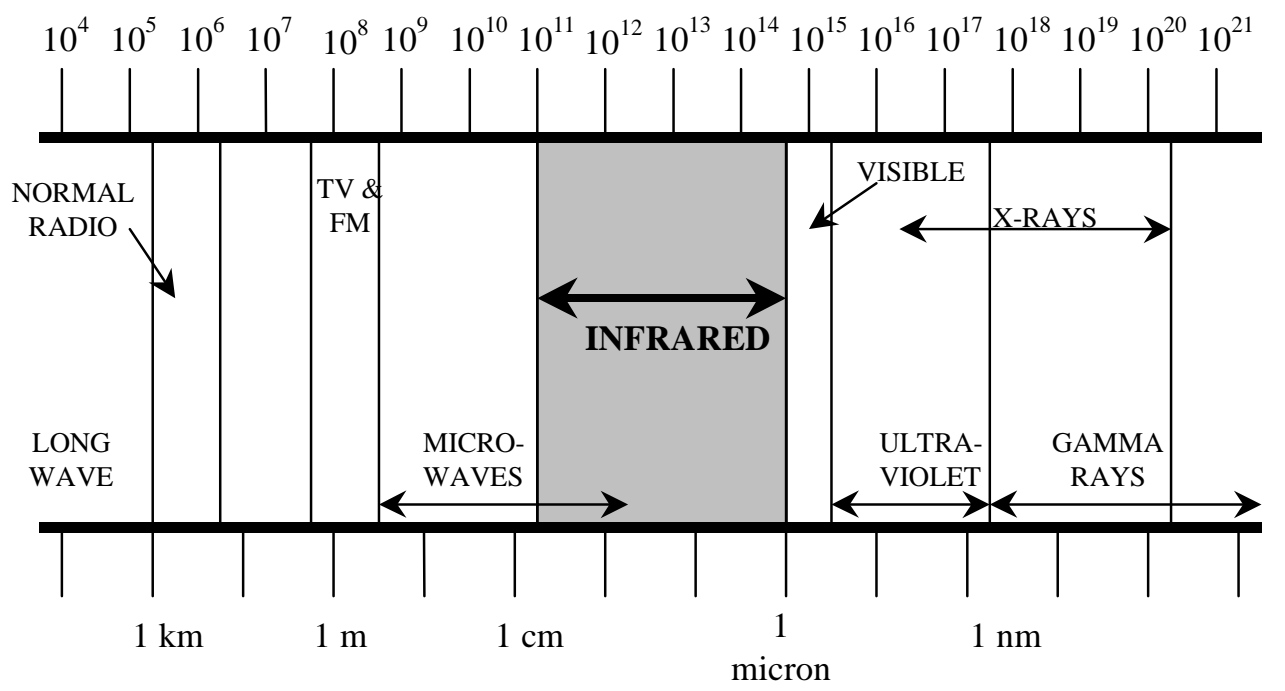

WAVELENGTH

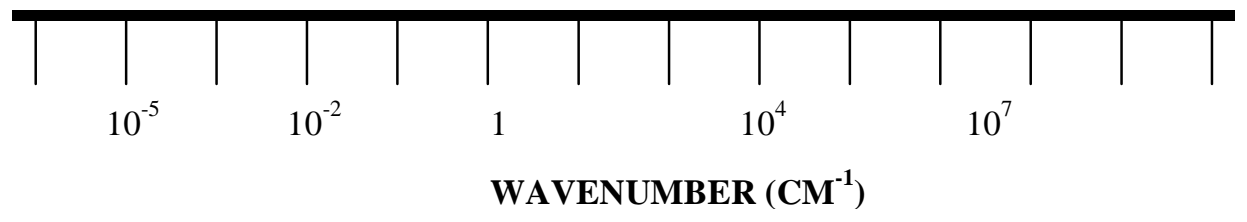

Figure 9-12. The infrared region of the electromagnetic spectrum relative to other familiar wave regions. 


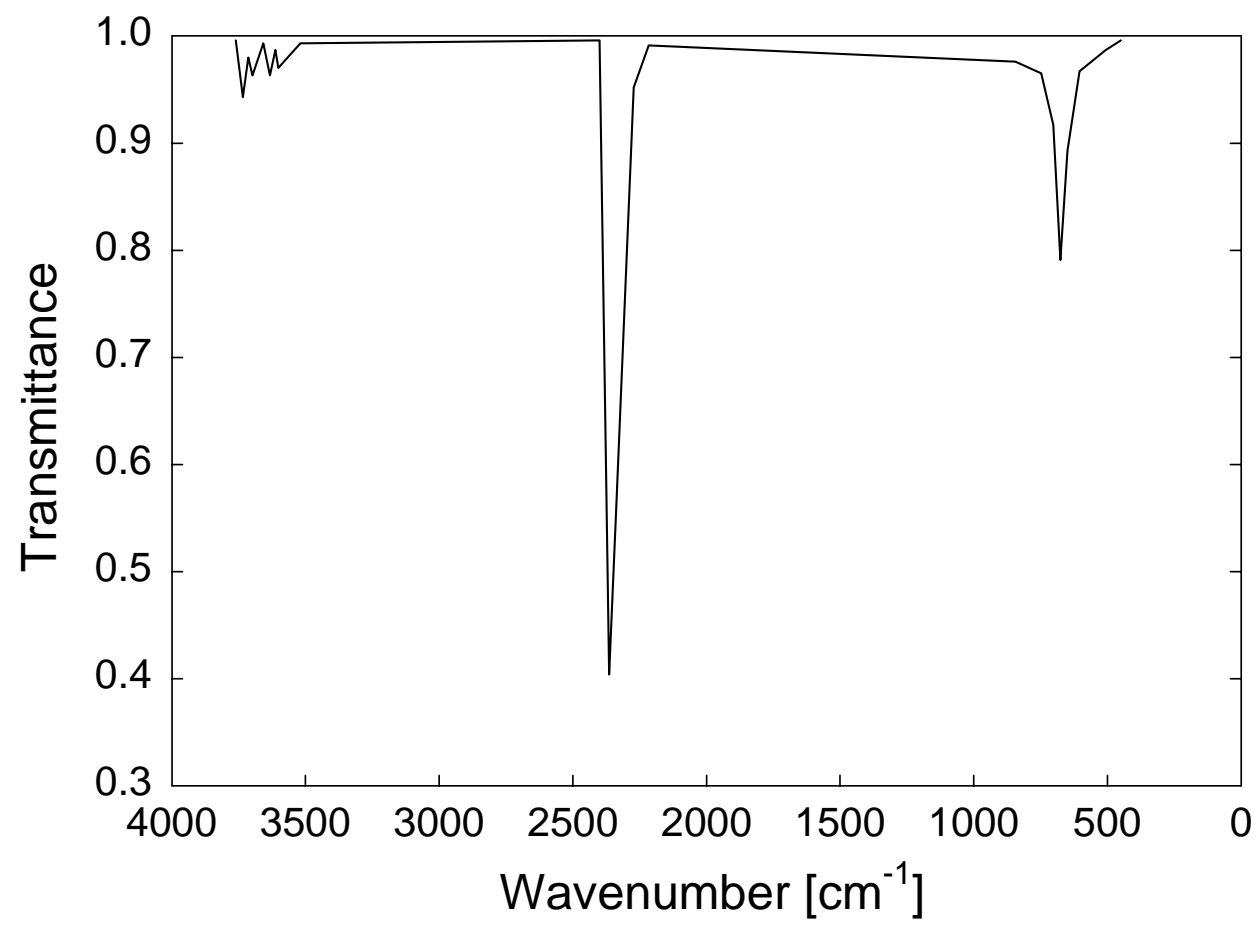

Figure 9-13. The infrared absorption (transmittance) behavior of carbon dioxide, showing unique wavenumber regions that are preferentially absorbed by the gas. (A transmittance of 1.0 means that the infrared energy passes without absorption.)

trace concentration measurements will be very dependent upon the avoidance of interference from other absorbing species at a particular infrared wavelength.

\subsubsection{Exploratory Tests of Infrared Technology}

A Vaisala model \#GMM11 NDIR carbon dioxide sensor was purchased for about $\$ 400$. This particular model has a design range of 0-10 mole\% carbon dioxide, but other ranges are also available. The commercially available sensor was designed primarily for measuring carbon dioxide concentration in atmospheric air. A photograph of the sensor is presented in Figure 9-14. The main body, which houses the infrared lamp, sample cell, and detector, is a 1.25 in. $x 1.25$ in. $x 1$ in. aluminum cube.

A critical question, that needed to be answered in this exploratory phase, was whether or not natural gas hydrocarbons would interfere with the sensor's indication at the principle carbon dioxide absorption wavelength. In other words, would the hydrocarbons also absorb infrared energy at the same wavelength to distort the instrument's interpretation of carbon dioxide concentration? To initially address that question, the U.S. National Institute of Standards and Technology (NIST) spectral-infrared absorption database (1999) was reviewed. No major interference bands were seen for the $\mathrm{n}$-Paraffin hydrocarbons from methane $\left(\mathrm{C}_{1}\right)$ to n-decane $\left(\mathrm{C}_{10}\right)$. 


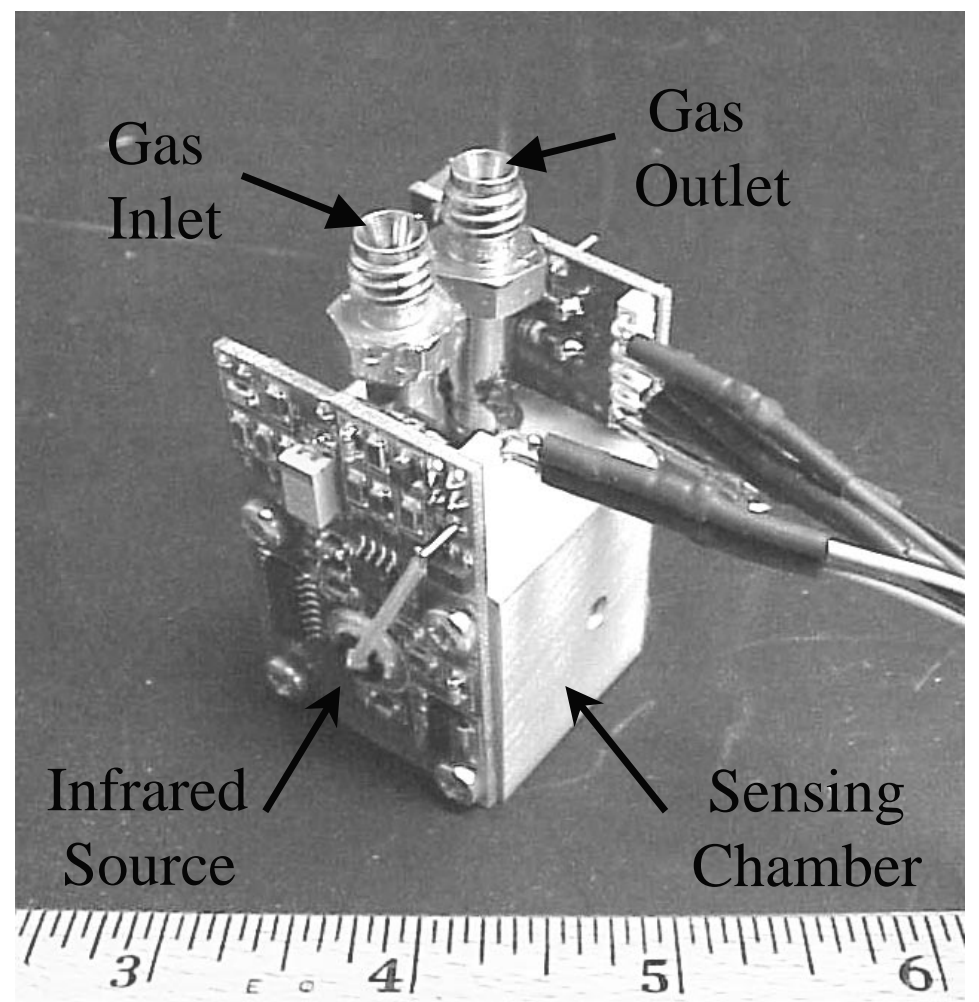

Figure 9-14. Photograph of the Vaisala model \#GMM11 non-dispersive infrared (NDIR) instrument. For scale reference, the main body is a 1.25 in. $x 1.25$ in. $x 1$ in. cube.

Natural gas mixtures of known composition were also prepared to evaluate the sensor's performance. The carbon dioxide concentration of two stock-gas mixtures, Table 9-5, was gravimetrically adjusted to provide the range of carbon dioxide concentrations shown in Table 9-6.

The infrared sensor's sample cell was flow-purged with gas samples near atmospheric pressure using the same delivery system that was developed for the ultrasonic sensor tests (Figure 9-8). Sensor readings were acquired after the upstream valve was closed, and the sample in the instrument cell had dropped to atmospheric pressure. Since nitrogen is infraredinactive, the sensor was zero-calibrated with pure nitrogen, and the span was set with a 10 mole\% mixture of carbon dioxide in nitrogen. Each natural gas sample test began with a nitrogen purge until the sensor reached it's calibrated zero reading. The natural gas sample was then introduced into the sensor. The sensor's output was monitored following at least three flow-purges per sample. 
Table 9-5. Two stock-gas mixtures that were used to prepare simulated natural gas mixtures with a range of carbon dioxide concentrations.

\begin{tabular}{|l|c|c|}
\hline Gas Component & $\begin{array}{c}\text { Stock-Gas } \\
\text { Mixture \#1 } \\
\text { [mole \%] }\end{array}$ & $\begin{array}{c}\text { Stock-Gas } \\
\text { Mixture \#2 } \\
\text { [mole\%] }\end{array}$ \\
\hline Methane & 94.462 & 75.062 \\
Ethane & 2.481 & 12.46 \\
Propane & 0.501 & 6.00 \\
i-Butane & 0.1 & 1.00 \\
n-Butane & 0.1 & 1.60 \\
i-Pentane & 0.05 & 0.181 \\
n-Pentane & 0.05 & 0.243 \\
n-Hexane & 0.025 & 0.146 \\
n-Heptane & 0.015 & 0.0692 \\
n-Octane & 0.01 & 0.0485 \\
n-Nonane & 0.000 & 0.0121 \\
n-Decane & 0.05 & 0.006 \\
Carbon Dioxide & $\mathbf{1 . 0 0 2}$ & $\mathbf{0 . 4 0 2}$ \\
Nitrogen & 1.054 & 2.77 \\
Argon & 0.1 & 0.000 \\
\hline Total & 100 & 100 \\
\hline
\end{tabular}

Table 9-6. Carbon dioxide concentrations of the simulated natural gas samples that were introduced into the infrared carbon dioxide sensor.

\begin{tabular}{|c|c|c|}
\hline Sample & $\begin{array}{c}\mathbf{C O}_{2} \\
{[\mathbf{m o l e \%} \text { ] }}\end{array}$ & Stock Gas \\
\hline $\mathbf{1}$ & 10.00 & Nitrogen \\
$\mathbf{2}$ & 9.86 & Mixture \#1 \\
$\mathbf{3}$ & 8.17 & Mixture \#1 \\
$\mathbf{4}$ & 6.30 & Mixture \#1 \\
$\mathbf{5}$ & 4.81 & Mixture \#2 \\
$\mathbf{6}$ & 4.38 & Mixture \#2 \\
$\mathbf{7}$ & 2.12 & Mixture \#1 \\
$\mathbf{8}$ & 1.00 & Mixture \#1 \\
$\mathbf{9}$ & 0.400 & Mixture \#2 \\
$\mathbf{1 0}$ & 0 & Nitrogen \\
\hline
\end{tabular}


The sensor voltage output indication is plotted in Figure 9-15, compared to the manufacturer's characterization curve. The manufacturer's characterization curve was drawn from a $5^{\text {th }}$ order polynomial equation supplied in the instrument manual. The sensor response is non-linear, due to the exponential increase in infrared absorption with carbon dioxide concentration, but it can be linearized by application of the manufacturer's characterization curve.

The sensor accuracy performance is shown in Figure 9-16. The dotted lines in the figure represent the 0.2 mole\% specification (see Section 9.1) that will produce a shift of approximately $0.5 \%$ in mass-based heating value, $H_{m}$, or density, $\rho$ (at low pressure). (Note that $H_{v}$ is insensitive to $X_{\mathrm{CO} 2}$ at low pressure.) While not all of the data is within the specification, greater controls over the unit's operating environment may reduce the variability. Vaisala also sells units with a lower design range (0-3 mole\%, for example), which may produce tighter results over that range of application. The as-is data does, however, demonstrate general technological feasibility.

The upward, apparently systematic, shift in low range may be indicative of some interference (absorption) from the hydrocarbons. If the hydrocarbons are absorbing at the sensor's design wavelength, then the sensor will indicate high because it cannot differentiate between carbon dioxide and hydrocarbon absorption. If this is the case, it may not be a severe problem for flow rate and energy flow rate determination applications, but may be a limiting issue for trace-gas quantification. The application of infrared technology (at other wavelengths) to determine trace-gas concentrations of water vapor or hydrogen sulfide, for example, is being considered. The narrow-band interference issues will be critical in that application, because small levels of interference could potentially mask trace-gas concentrations.

\subsubsection{Nitrogen}

Nitrogen is more difficult to directly measure, within a natural gas mixture, than carbon dioxide. Nitrogen has low infrared absorption characteristics, so it is unlikely that infrared sensor technology will work. It is also chemically inert, so electrochemical sensors won't work. That does not, however, imply that a nitrogen sensor can't be found, or that one can't be developed from the unique characteristics of that molecule. These are on-going issues.

Fortunately, energy measurement of natural gas is, in some cases, less demanding for nitrogen measurement, than for carbon dioxide measurement. The 0.3 mole $\%$ specification for $X_{N 2}$ was developed in Section 9.1 for a $0.5 \%$ shift in $H_{m}$ or $\rho$ (at low pressure), and $H_{v}$ is, thankfully, insensitive to $X_{N 2}$.

However, direct measurement of nitrogen may not be necessary. One indirect means to determine the nitrogen concentration arises from the definition of standard sound speed, $S_{s t d}$ :

$$
S_{s t d}=\left(\frac{\kappa_{s t d}}{\rho_{s t d}} P_{s t d}\right)^{0.5}
$$




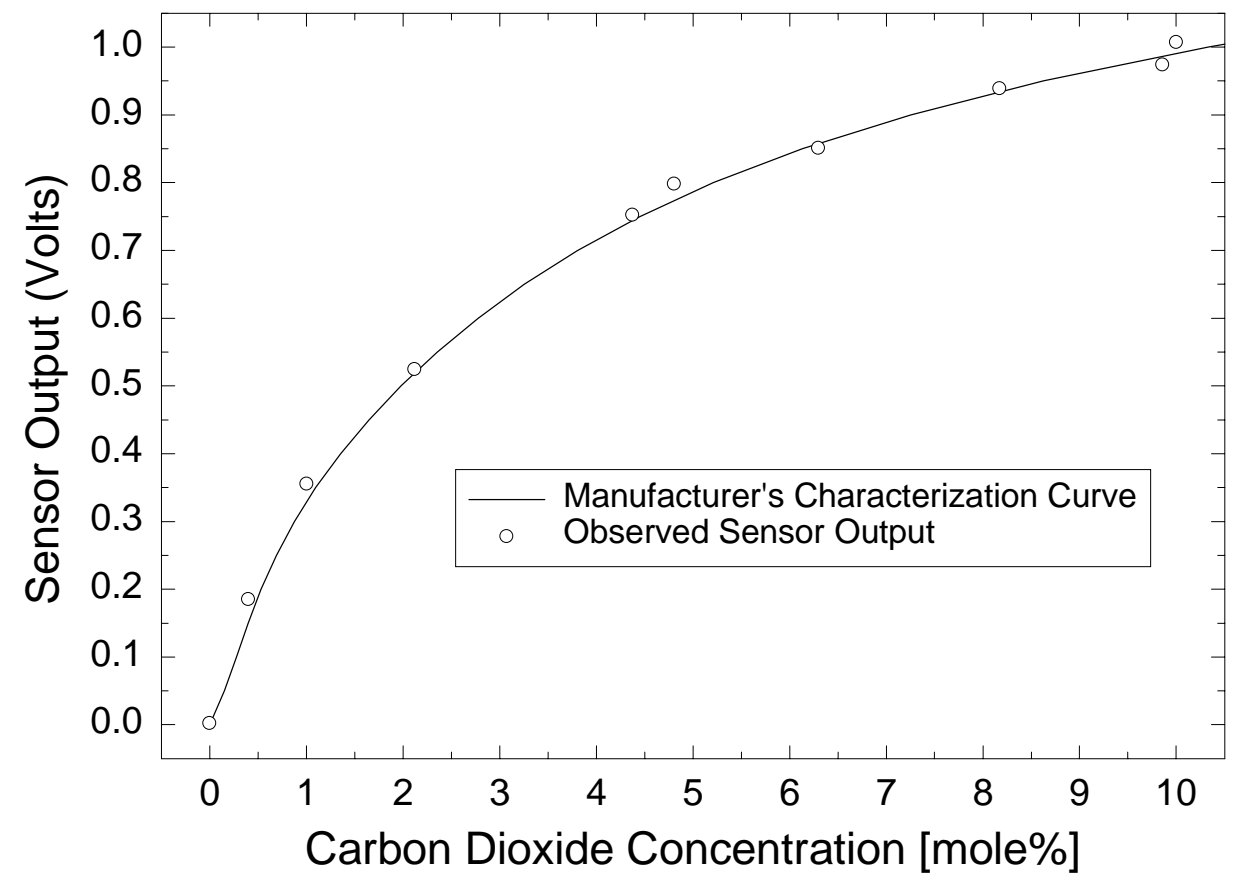

Figure 9-15. Output readings from the Vaisala model \#GMM11 carbon dioxide sensor, compared to the manufacturer's characterization curve.

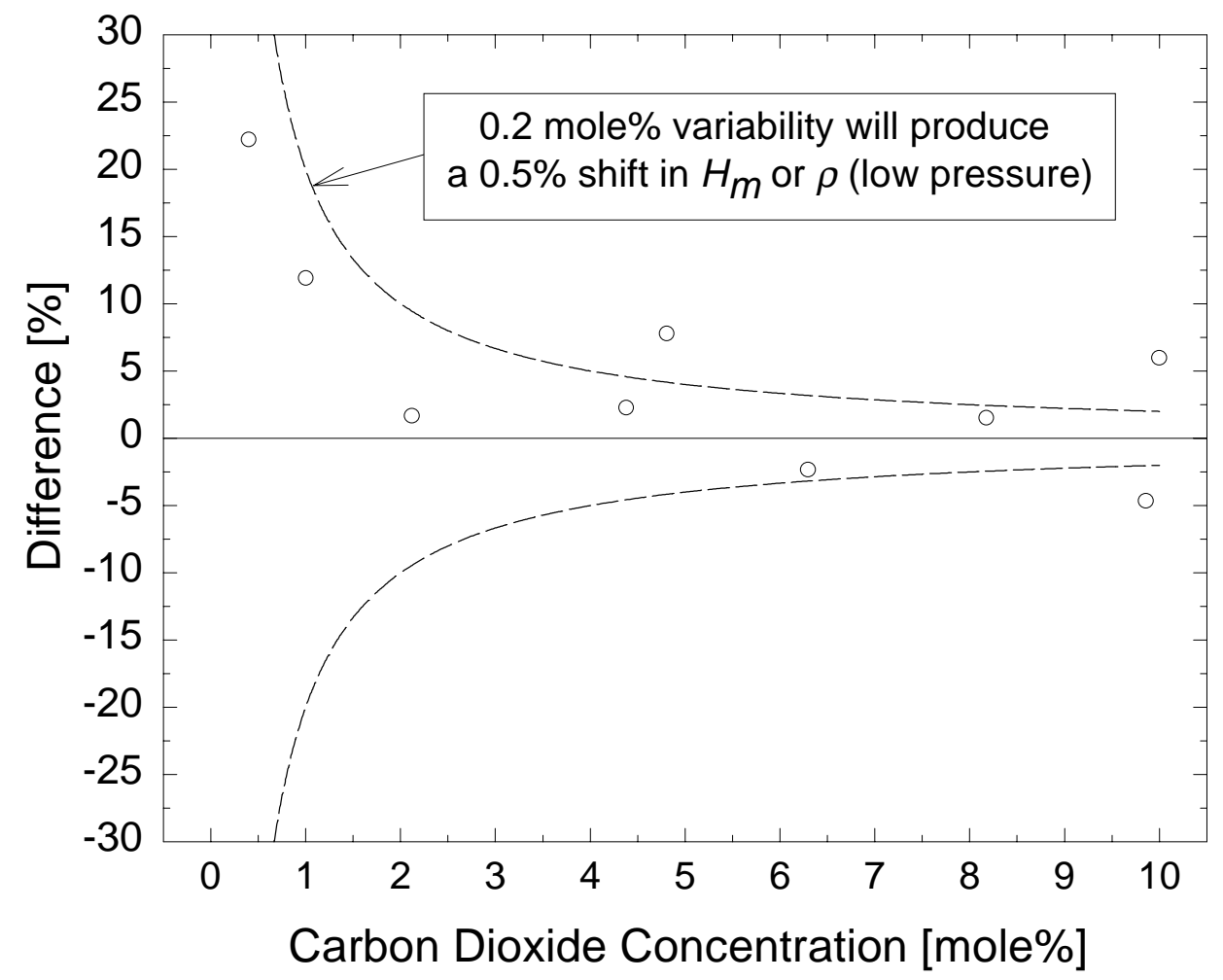

Figure 9-16. Carbon dioxide concentrations indicated from the Vaisala model \#GMM11 carbon dioxide sensor, compared to the known values. The dotted lines represent a 0.2 mole\% variability specification that will produce a $0.5 \%$ shift in $H_{m}$ or $\rho$ (low pressure). 
where $\kappa_{s t d}$ is the isentropic exponent (a thermodynamic property evaluated at standard conditions), $P_{\text {std }}=14.73$ psia, and the standard density, $\rho_{s t d}$, is given as a function of $S_{s t d}, X_{C O 2}$, and $X_{N 2}$ by the correlation equation (Equation (8-10)). If $\kappa_{s t d}$ were correlated to $X_{C O 2}, X_{N 2}$, and some other measurable inferential property (different than $\rho_{s t d}$ or $M$ ), then $X_{N 2}$ could be iteratively determined from Equation (9-8) with knowledge of $S_{s t d}, X_{\mathrm{CO} 2}$, and the correlation for $\kappa_{s t d}$. The inferential property that characterizes the hydrocarbon portion of $\kappa_{s t d}$, however, must be measurable with inexpensive and reliable instrumentation in order to be useful. Inferential property candidates for the equivalent hydrocarbon portion of $\kappa_{\text {std }}$ include thermal conductivity, specific heat, isothermal compressibility, isothermal expansion exponent, volume expansivity, Joule-Thomson coefficient, etc.

Another indirect scheme, to determine $X_{N 2}$, arises from sound speed measurements at two different operating conditions. Take, for example, the standard operating conditions of Equation (9-8), and some other arbitrary operating condition:

$$
S=\left(\frac{\kappa}{\rho} P\right)^{0.5}
$$

An iterative scheme that solves for $X_{N 2}$, may be generated between Equations (9-8) and (9-9), with knowledge of $S_{s t d}, S, X_{\mathrm{CO} 2}, T_{s t d}, T, P_{s t d}$, and $P$. However, it may require the development of a thermodynamic (a function of $T$ and $P$ ) correlation for $\kappa$ in terms of some inferential property, other than $\rho$. 


\subsection{CONCLUSIONS AND RECOMMENDATIONS}

Task A of the project identified a promising technique to characterize natural gas hydrocarbons with a single inferential property, such as standard sound speed, when the concentrations of the diluent gases (carbon dioxide and nitrogen) are known. The key advantage was the application of a few inexpensive inferential property sensors to characterize the full chemical composition of natural gas, without the expense and complexity of performing a detailed gas composition assay. Task B investigated the practical realities of such an approach, and found that it was capable of even more than was originally intended.

For an exploratory range of 102 different natural gas compositions $(987-1,150 \mathrm{Btu} / \mathrm{scf}$, 16.3 - $19.5 \mathrm{lbm} / \mathrm{lb}$-mole, 83.4 - 98.3 mole\% methane, 0.97 - 7.4 mole\% total diluent concentration, and $0.001-0.1$ mole $\% \mathrm{C}_{6}+$ ), successful natural gas property correlations were developed for the chemical and thermodynamic properties summarized in Table 10-1. These property correlations may be used to determine flow rate or energy flow rate from flow meters of all kinds (ultrasonic, orifice, turbine, rotary, Coriolis, diaphragm, etc.) with knowledge of only standard sound speed, $S_{s t d}$, carbon dioxide concentration, $X_{\mathrm{CO} 2}$, nitrogen concentration, $X_{N 2}$, temperature, $T$, and pressure, $P$.

Table 10-1. Chemical and thermodynamic properties of natural gas that were successfully correlated to gross-characterization inferential properties.

\begin{tabular}{|c|c|}
\hline $\begin{array}{l}\text { Successful Data Correlations Developed for } \\
\text { These Chemical Properties as a Function of } \\
\qquad S_{s t d}, X_{C O 2}, X_{N 2}\end{array}$ & $\begin{array}{c}\text { Successful Data Correlations Developed for } \\
\text { These Thermodynamic Properties as a } \\
\text { Function of } T, P, S_{s t d}, X_{C O 2}, X_{N 2}\end{array}$ \\
\hline Molecular Weight, $M$ & Density, $\rho$ \\
\hline Mass-Based Heating Value, $H_{m}$ & $\begin{array}{l}\text { Volume-Based heating Value, } H_{v} \\
\text { (product of } \rho \text { and } H_{m} \text { ) }\end{array}$ \\
\hline \multicolumn{2}{|l|}{ Standard Density, $\rho_{\text {std }}$} \\
\hline \multicolumn{2}{|l|}{ Molar Ideal Gross Heating Value, $H_{n, r e f}$} \\
\hline $\begin{array}{c}\text { Standard Volumetric Heating Value, } H_{v, s t d} \\
\text { (product of } \rho_{s t d} \text { and } H_{m} \text { ) }\end{array}$ & \\
\hline
\end{tabular}

The required inferential-property measurement accuracies, for less than approximately $0.5 \%$ shift in essential properties of $H_{m}, \rho$, and $H_{v}$, are summarized in Table 10-2. General technological feasibility of the required $S_{s t d}$ measurement was successfully demonstrated, relative to those specifications, with an ultrasonic transducer test piece assembled by extracting the transducers from a $\$ 100$ ultrasonic domestic gas meter. General technological feasibility of the required $X_{\mathrm{CO} 2}$ measurement was successfully demonstrated using a $\$ 400$ self-contained infrared sensor. No inexpensive and direct means to measure $X_{N 2}$ was found, but some indirect measurement approaches were presented. 
Table 10-2. Required accuracy of inferential property measurements for a $0.5 \%$ shift in $H_{m}, \rho$, and $H_{v}$.

\begin{tabular}{|c|c|c|c|}
\hline $\begin{array}{c}\text { Inferential } \\
\text { Variable }\end{array}$ & $\begin{array}{c}\text { Change in Inferential } \\
\text { Variable Required to } \\
\text { Produce a 0.5\% } \\
\text { Change in } \boldsymbol{H}_{\boldsymbol{m}}\end{array}$ & $\begin{array}{c}\text { Change in Inferential } \\
\text { Variable Required to } \\
\text { Produce a 0.5\% Change } \\
\text { in } \rho\end{array}$ & $\begin{array}{c}\text { Change in Inferential } \\
\text { Variable Required to } \\
\text { Produce a 0.5\% Change } \\
\text { in } \boldsymbol{H}_{\boldsymbol{v}}\end{array}$ \\
\hline $\boldsymbol{S}_{\text {std }}$ & $\begin{array}{c}2-3 \%, \text { or greater, } \\
\text { depending on the } \\
\text { magnitude of } S_{\text {std }}, X_{C O 2}, \\
\text { and } X_{N 2}\end{array}$ & $\begin{array}{c}\text { About } 0.5 \% \text { at low } \\
\text { pressure, with changing } \\
\text { sensitivity at higher } \\
\text { pressures }\end{array}$ & $\begin{array}{c}\text { About } 0.5 \% \text { at low } \\
\text { pressure, with changing } \\
\text { sensitivity at higher } \\
\text { pressures }\end{array}$ \\
\hline $\boldsymbol{X}_{\boldsymbol{C O} 2}$ & About 0.2 mole\% & $\begin{array}{c}\text { About } 0.2 \text { mole\%, with } \\
\text { changing sensitivity at } \\
\text { higher pressures }\end{array}$ & $\begin{array}{c}\text { Insensitive at low } \\
\text { pressure, with changing } \\
\text { sensitivity at higher } \\
\text { pressures }\end{array}$ \\
\hline $\boldsymbol{X}_{N 2}$ & About 0.3 mole\% & $\begin{array}{c}\text { About } 0.3 \text { mole\%, with } \\
\text { changing sensitivity at } \\
\text { higher pressures }\end{array}$ & Insensitive \\
\hline
\end{tabular}

If developed into a field-worthy instrument, this inferential measurement approach has the potential to dramatically reduce capital and operating costs, in an on-line energy measurement package. It will not replace the traditional gas chromatograph (GC), because there will always be a need for natural gas composition assay, but it does have the potential to reduce reliance on the $\mathrm{GC}$ at custody transfer locations.

It is recommended that the 1999 project focus on:

(1) Extension of the data correlations to a broader range of gas compositions, and determine if sound speed measured at line conditions can be easily related to sound speed at standard conditions. This would make a sound speed retrofit sensor unnecessary for ultrasonic meters,

(2) Refinement of the performance of the speed of sound measurement configuration,

(3) Refinement of the performance of the infrared carbon dioxide sensor,

(4) Development of a workable indirect approach to nitrogen measurement,

(5) Design and construction of a prototype retrofit instrument module for testing purposes,

(6) Conduction of tests with the prototype retrofit module in the GRI Metering Research Facility at varied operating conditions. 


\subsection{REFERENCES}

\subsection{Literature}

A.G.A. Transmission Measurement Committee Report No. 8, "Compressibility Factors of Natural Gas and Other Related Hydrocarbon Gases," Second Edition, American Gas Association, Arlington, Virginia, November 1992 (second printing July 1994).

Bonne, Ulrich (1998), "Microsensor Fabrication and Application," $11^{\text {th }}$ IGT Symposium on Gas Quality and Energy Measurement, St. Petersburg, FL, Feb. 2-4, 1998.

Bonne, Ulrich and Kubisiak, David (1996), "Microsensors for Fluid Properties," Scientific Honeyweller, 1996, Sensors Issue, pp. 21-28.

Bonne, Ulrich (1996), "Sensing Fuel Properties with Thermal Microsensors," Proceedings of SPIE, Vol. 2722, pp. 165-176.

Bonne, Ulrich (1995), "New Developments in Natural Gas Transducer Technology," 8th IGT Symposium on Natural Gas Quality and Energy Measurement, Feb. 20-22, 1995.

Bonne, Ulrich, Vesovic, V., and Wakeham, W. A. (1995a), "Thermophysical Properties of Natural Gases for On-Line Metering," International Journal of Thermal Physics, Vol. 16, No. 1, pp. 195-204.

Bonne, Ulrich, Vesovic, V. and Wakeham, W. A. (1995b), "Sensing Thermophysical and Transport Properties of Natural Gas With Thermal Microsensors," International Gas Research Conference, Nov. 6-9, 1995, Cannes, France, pp. 671-680.

Bonne, Ulrich, (1992), "Fully Compensated Flow Microsensor for Electronic Gas Metering," 1992 International Gas Research Conference, pp. 859-871.

Curry, Jim (1998), "New HV, SG, and Percent Inerts Field Analyzer," (unpublished) presented at Gas Measurement Research Council Meeting, Sept. 1, 1998, San Antonio, TX.

Dodds, Douglas E. (1991), "Conversion from Volume to Energy Measurement," International School of Hydrocarbon Measurement, Norman, OK, May 21-23, 1991, pp. 26-28.

Foundos, Albert P. and Kersey, A. (1985), "Energy Measurement Utilizing On-Line Chromatograph", International School of Hydrocarbon Measurement, Norman, OK, April 1618, 1985 pp. 433-435.

GPA Standard 2145-94 (1994), "Table of Physical Constants of Paraffin Hydrocarbons and Other Components of Natural Gas," Gas Processors Association, Tulsa, OK, 1994.

Haas, Arthur F. (1984), "Energy Measurement Utilizing On Line Chromatograph," International School of Hydrocarbon Measurement, Norman, OK, April 10-12, 1984, pp. 309312.

Hall, Kenneth R. and Holste, James C. (1995), "Heating Value, Relative Density and Compression Factor for Dry or Wet Natural Gas from Composition," Flow Measurement and Instrumentation, Vol. 6, No. 2, pp. 121-125.

Hall, Kenneth R. and Holste, James C. (1990), "Determination of Natural Gas Custody Transfer Properties," Flow Measurement and Instrumentation, Vol. 1, 1990, pp. 127-132. 
Jeffrey, Michael J., Maselli, Stephen, DiLoretto, Bob, McDonnell, Tom, Maclay, G. J., Pan, Li, Stetter, Joseph R., Findlay, Melvin, Vickers, William, Lukasiewicz, Michael, Gregor, John G., "Development of a Therm Factor Transmitter," 3rd International Fluid Flow Symposium, San Antonio, TX, March 20-22, 1995.

Johnson, J. E., Magott, R. J., Wood, C. M., Development of a Prototype Energy Meter, GRI Topical Report \#GRI 84/0148, the Gas Research Institute, Chicago, Illinois.

King, J. Derwin, Nicholls, Colin I., and Rollwitz, William L. (1988), "NMR Measurement of Gas Energy, Compressibility and Density," IGT Gas Quality Measurement Workshop, Chicago, IL, Jan. 1988.

King, J. Derwin, Nicholls, Colin I. (1990), "Gas Properties Measured by Magnetic Resonance," IGT Gas Quality Measurement Workshop, Chicago, IL, July 1990.

King, J. Derwin, Ni, QingWen (1996), "In-Line Measurement of Hydrocarbon Gas (CNG and LNG) Energy and Composition Using Nuclear Magnetic Resonance," Proceedings of the 8th International Conference on Flow Measurement, Beijing, October 20-24, 1996, pp. 630-635.

Kizer, Paul E. (1998), "Energy Measurement Using On-Line Chromatographs," International School of Hydrocarbon Measurement, Norman, OK, May 19-21, 1998, pp. 568-572.

Kristensen, Bard D., Lofseik, Cecilie, and Froysa, Kjell-Eivind, "An Overview of Projects Related to the KOS FMU 7006 Path Ultrasonic Gas Flow Meter," American Gas Association Gas Operations Conference, Seattle, WA, May 17-19, 1998.

Lomic (1997) “SonicWare Computer Program,” Ver. 2.0, Lomic Inc., State College, PA, 1997.

Lueptow, Richard M. and Phillips, Scott (1994), "Acoustic Sensor for Determining Combustion Properties of Natural Gas," Measurement Science and Technology, Vol. 5, pp. 1374-1381.

Park, Joel T., Behring II, Kendricks A., Krueger, Philip J., "Metering Research Facility Program: Review of Field Meter Provers," GRI Topical Report \#GRI-95/0209, December 1995.

Price, Michael D. (1998), "Energy Measurement Using Flow Computers and Chromatographs," International School of Hydrocarbon Measurement, Norman, OK, May 19-21, 1998, pp. 563567.

Sakariassen, R., "On-Line Quality Control of Ultrasonic Gas Flow Meters," $15^{\text {th }}$ North Sea Flow Measurement Workshop, Kristiansand, October 28-30, 1997.

Savidge, Jeffrey L. (1989), "GRI Extended Thermodynamic Properties Computer Program," Gas Research Institute, Chicago, IL, March, 1989.

Sharples, Richard J. and Pannill, William (1985), "Calculation of Gas Heating Value is Complicated by the Courts," International School of Hydrocarbon Measurement, Norman, OK, April 16-18, 1985, pp. 197-203.

Sowell, Thomas (1995), "A System for the Real Time, Direct Measurement of Natural Gas Flow, " 3 rd International Symposium on Fluid Flow Measurement, San Antonio, TX, March 2022, 1995 
Stern, Richard E. (1984), "Determination of Calorific Values of Natural Gas by Combustion Instruments," International School of Hydrocarbon Measurement, Norman, OK, April 10-12, 1984, pp. 424-426.

U.S. National Institute of Standards and Technology (NIST), World Wide Web-site: //webbook.nist.gov, 1998.

Vader Heyden, William H. (1991), “A Different Approach to Total Energy Metering - Final Report," International School of Hydrocarbon Measurement, Norman, OK, May 21-23, 1991, pp. 168-172.

Van Meter, Robert (1985), "Determination of Calorific Values of Natural Gas by Combustion Instruments," International School of Hydrocarbon Measurement, Norman, OK, April 16-18, 1985, pp. 154-156.

Watson, J. W., White, F. A. (1981), "Acoustic Measurement of Natural Gas BTU Content," 1981 International Gas Research Conference, Los Angeles, CA, Sept. 28- Oct. 1, 1981, pp. 1793-1802.

\subsection{Patents}

5,759,862, "Measuring Heating Value Using Catalytic Combustion," William H. Vander Heyden, Ronald Arthur Berg, assigned to Badger Meter, Inc., Milwaukee, WI, June 2, 1998.

5,707,150, "Apparatus for Computing BTU Content in a Sample of Gas," Fed C. Sittler, assigned to Rosemount Analytical Inc., La Habra, CA, Jan. 13, 1998.

5,537,854, "Acoustic Natural Gas Fuel Sensor," Scott Phillips and Richard M. Lueptow, July 23, 1996.

5,486,107, "Determination of Fuel Characteristics," Ulrich Bonne, assigned to Honeywell, Inc., Minneapolis, MN, Jan 23, 1996.

5,325,703, "Method for Identifying the Concentration of Fuels or Gases," Valentine Magori, assigned to Siemens Aktiengesellschaft, Munich, Germany, July 5, 1994.

5,311,447, "On-Line Combustionless Measurement of Gaseous Fuels Fed to Gas Consumption Devices," Ulrich Bonne, May 10, 1994.

5,235,844, "Multiple Gas Property Sensor," Ulrich Bonne, Robert J. Matthys, David Kubisiak, assigned to Niagara Mohawk Power Corporation, Syracuse, NY, August 17, 1993.

5,201,581, "Method and Apparatus for Measuring Ratio of Mass Flow Rates and Energy Flow in a Gas Pipeline," William H. Vander Heyden, William H. Clingman, Jr., assigned to Badger Meter, Inc., Milwaukee, WI, April 13, 1993. [Patent reissued RE35,639 on October 21, 1997]

5,060,507, "Method and Apparatus for Fluid Mixture Monitoring, Constituent Analysis, and Composition Control," John Urmson, Anthony Pearson and Sanjay Gidwani, October 29, 1991.

5,016,482, "Method of Taking a Proportional Sample of Flowing Gas in a Line," William H. Clingman, Jr., Lyn R. Kennedy, May 21, 1991. 
4,951,503, "Method and Apparatus for Determining the Heating Value of a Gaseous Fuel," Anselmo Fini, assigned to Niagara Mohawk Power Corporation, Syracuse, NY, Aug. 28, 1990.

4,845,976, "Method and Apparatus of Determining Energy Content of a Diluted Hydrocarbon Gas," James E. Johnson, Raymond J. Magott, Clinton, M. Wood, assigned to Gas Research Institute, Chicago, IL, July 11, 1989.

4,677,841, "Method and Apparatus for Measuring the Relative Density of Gases," Lyn R. Kennedy, assigned to Precision Measurement, Inc., Duncanville, TX, July 7, 1987.

4,596,133, "Apparatus and Methods for Measuring Fluid Flow Parameters," Jack W. Smalling, Leonard D. Braswell, Lawrence C. Lynnworth, assigned to Panametrics, Inc., Waltham, MA and to Exxon Research \& Engineering Co., Houston, TX, June 24, 1986.

4,520,654, "Method and Apparatus for Detecting Hydrogen, Oxygen and Water Vapor Concentrations in a Host Gas," James H. Terhune, assigned to General Electric Company, San Jose, CA, June 4, 1985.

4,501,144, “Flow Sensor,” Robert E. Higashi, Robert G. Johnson, Philip J. Bohrer, assigned to Honeywell Inc., Feb. 26, 1985.

4,446,748, "Proportional Flow Sampler," William H. Clingman, Kenneth R. Hall, assigned to Precision Machine Products, Inc., Dallas, TX, May 8, 1984.

4,396,299, "Method and Apparatus for Determining Total Energy Flow in a Gas Line," William H. Clingman, Jr., Lyn R. Kennedy, assigned to Precision Machine Products, Inc., Dallas, TX, August 2, 1983.

4,380,400, “Combustible Gas Analyzer,” John L. Searle, assigned to Honeywell, Inc., Apr. 19, 1983.

4,351,614, "Method of and Apparatus for Continually Monitoring the Heating Value of a Fuel Gas Using a Combustibility Meter," John J. Garnier, assigned to Eaton Corporation, Cleveland, OH, Sept. 28, 1982.

4,345,463, “On-Line Gas Measurement and Analysis System," Wayne Wilson, George Rosko, James R. Patmore, assigned to Electronic Associates, Inc., West Long Branch, NJ, Aug. 24, 1982.

4,285,245, "Method and Apparatus for Measuring and Controlling Volumetric Flow Rate of Gases in a Line," Lyn R. Kennedy, assigned to Precision Machine Products, Inc., Dallas, TX, August 25, 1981.

4,246,773, "Combustion Property of Gas Measuring Apparatus," Masao Haruta, assigned to Osaka Gas Company Ltd., Osaka, Japan, January 27, 1981.

4,125,123, "Methods of and Means for Accurately Measuring the Calorific Value of Combustible Gases," William H. Clingman, Jr., assigned to Precision Machine Products, Inc., Dallas, TX, November 14, 1978. 
4,125,108, "Method of and Means for Accurately Measuring the Calorific Value of Combustible Gases," William H. Clingman, Jr., assigned to Precision Machine Products, Inc., Dallas, TX, November 14, 1978.

4,062,236, "Method of and Means for Accurately Measuring the Calorific Value of Combustible Gases," William H. Clingman, Jr., assigned to Precision Machine Products, Inc., Dallas, TX, December 13, 1977. 


\subsection{NOMENCLATURE}

$B_{\text {mix }} \quad$ second virial coefficient [ $\left.\mathrm{vol} / \mathrm{mol}\right]$

$C \quad$ contains all orifice flow variables except density $\left(\mathrm{Q}_{\mathrm{m}, \text { orifice }} /(\rho)^{0.5}\right)$

$C_{m i x} \quad$ third virial coefficient $\left[(\mathrm{vol} / \mathrm{mol})^{2}\right]$

$\mathrm{C}_{\mathrm{pj}} \quad$ specific heat at constant pressure for a pure gas component

d molar density [mol/vol]

$D$ distance [inches]

$G_{i d} \quad$ ideal specific gravity, $\mathrm{M}_{\mathrm{i}} / \mathrm{M}_{\text {air }}$

$H_{C H}$ molar ideal gross heating value of the equivalent hydrocarbon $[\mathrm{KJ} / \mathrm{mol}]$

$H_{m} \quad$ mass-based heating value [Btu/lbm]

$H_{m, i} \quad$ component mass-based heating value [Btu/lbm]

$H_{n, \text { ref }}$ mixture molar ideal gross heating value $[\mathrm{KJ} / \mathrm{mol}]$

$H_{v} \quad$ volume-based heating value [Btu/acf]

$H_{v, s t d} \quad$ standard volumetric heating value [Btu/scf]

$\mathrm{K}_{\mathrm{j}} \quad$ thermal conductivity for a pure gas component

$M \quad$ mixture molecular weight [lbm/lb-mole]

$M_{H C} \quad$ hydrocarbon molecular weight [lbm/lb-mole]

$M_{i} \quad$ component molecular weight $[\mathrm{lbm} / \mathrm{lb}-\mathrm{mole}]$

$N \quad$ number of gas components

$P \quad$ pressure [psia]

$P_{\text {std }} \quad$ standard reference pressure (typically 14.73 psia)

$Q_{\text {energy }}$ energy flow rate [Btu/hr, Btu/day, etc.]

$Q_{m} \quad$ mass flow rate [ $[\mathrm{bm} / \mathrm{hr}, \mathrm{lbm} /$ day, etc.]

$Q_{v} \quad$ volume flow rate [actual $\mathrm{ft}^{3} / \mathrm{hr}$ (acfh), actual $\mathrm{ft}^{3} /$ day (acfd), etc. ]

$Q_{v, s t d} \quad$ standard volumetric flow rate [scfh at flowing composition, $\mathrm{T}_{\text {std }}$, and $\mathrm{P}_{\text {std }}$ ]

$R \quad$ universal gas constant (10.7316 $\mathrm{psi}^{\left.-\mathrm{ft}^{3} /(\mathrm{lb}-\mathrm{mol} * \mathrm{R})\right)}$

$S_{\text {std }} \quad$ standard sound speed [ft/s at $\left.60^{\circ} \mathrm{F}, 14.73 \mathrm{psia}\right]$

$T$ temperature [R]

$T_{\text {std }} \quad$ standard reference temperature (typically $60^{\circ} \mathrm{F}$ )

$U_{X i} \quad$ component concentration uncertainty [mole\%]

$X_{i} \quad$ component concentration [mole \%]

Z compressibility factor

$Z_{i} \quad$ component compressibility factor 


$\begin{aligned} \kappa & \text { isentropic exponent } \\ \mu & \text { viscosity }\left[\mathrm{lbm} / \mathrm{ft}_{* \mathrm{~S}}\right] \\ \rho & \text { density }\left[\mathrm{lbm} / \mathrm{ft}^{3}\right] \\ \left.\rho_{\text {std }}\right] & \text { standard density }\left[\mathrm{lbm} / \mathrm{scf} \text { at flowing composition, } \mathrm{T}_{\text {std }} \text {, and } \mathrm{P}_{\text {std }}\right]\end{aligned}$


APPENDIX A: NATURAL GAS COMPOSITION DATABASE 
APPENDIX A: NATURAL GAS COMPOSITION DATABASE

\begin{tabular}{|c|c|c|c|c|c|c|c|c|c|c|c|c|}
\hline ID\# & $\begin{array}{l}\text { nitrogen } \\
\text { [mole\%] }\end{array}$ & $\begin{array}{c}\text { carbon dioxide } \\
\text { [mole\%] }\end{array}$ & $\begin{array}{l}\text { methane } \\
\text { [mole \%] }\end{array}$ & $\begin{array}{l}\text { ethane } \\
\text { [mole\%] }\end{array}$ & $\begin{array}{l}\text { propane } \\
\text { [mole\%] }\end{array}$ & $\begin{array}{l}\text { i-butane } \\
\text { [mole \%] }\end{array}$ & $\begin{array}{l}\text { n-butane } \\
\text { [mole \%] }\end{array}$ & $\begin{array}{l}\text { i-pentane } \\
\text { [mole \%] }\end{array}$ & $\begin{array}{c}\text { n-pentane } \\
\text { [mole \%] }\end{array}$ & $\begin{array}{c}\text { n-hexane } \\
\text { [mole \%] }\end{array}$ & $\begin{array}{c}\text { n-heptane } \\
\text { [mole \%] }\end{array}$ & $\begin{array}{l}\text { n-octane } \\
\text { [mole \%] }\end{array}$ \\
\hline 1 & 0.4422 & 1.9285 & 84.3361 & 8.8946 & 3.1919 & 0.59064 & 0.39376 & 0.10950 & 0.07300 & 0.0325 & 0.0061 & 0.0012 \\
\hline 2 & 1.6004 & 0.2331 & 95.5340 & 1.8790 & 0.4926 & 0.09066 & 0.06044 & 0.03522 & 0.02348 & 0.0309 & 0.0168 & 0.0034 \\
\hline 3 & 5.6769 & 1.4546 & 85.1473 & 5.4174 & 1.5968 & 0.30438 & 0.20292 & 0.08694 & 0.05796 & 0.0391 & 0.0138 & 0.0019 \\
\hline 4 & 0.6224 & 1.8643 & 85.4814 & 8.0607 & 2.8624 & 0.52170 & 0.34780 & 0.11346 & 0.07564 & 0.0398 & 0.0096 & 0.0008 \\
\hline 5 & 5.4939 & 1.8292 & 84.3931 & 5.8857 & 1.6910 & 0.32742 & 0.21828 & 0.06942 & 0.04628 & 0.0296 & 0.0128 & 0.0033 \\
\hline 6 & 5.3551 & 1.7802 & 84.4786 & 5.8782 & 1.7778 & 0.34002 & 0.22668 & 0.07050 & 0.04700 & 0.0309 & 0.0116 & 0.0034 \\
\hline 7 & 1.6052 & 0.2339 & 95.5192 & 1.8835 & 0.4933 & 0.09108 & 0.06072 & 0.03546 & 0.02364 & 0.0326 & 0.0176 & 0.0038 \\
\hline 8 & 0.4278 & 1.8497 & 84.4678 & 8.8604 & 3.1831 & 0.58008 & 0.38672 & 0.11994 & 0.07996 & 0.0369 & 0.0068 & 0.0008 \\
\hline 9 & 5.6760 & 1.4579 & 85.1666 & 5.4022 & 1.5922 & 0.30366 & 0.20244 & 0.08706 & 0.05804 & 0.0385 & 0.0134 & 0.0020 \\
\hline 10 & 0.6122 & 1.8630 & 85.4915 & 8.0626 & 2.8576 & 0.52254 & 0.34836 & 0.11412 & 0.07608 & 0.0404 & 0.0100 & 0.0016 \\
\hline 11 & 1.6052 & 0.2339 & 95.5192 & 1.8835 & 0.4933 & 0.09108 & 0.06072 & 0.03546 & 0.02364 & 0.0326 & 0.0176 & 0.0038 \\
\hline 12 & 0.4278 & 1.8497 & 84.4678 & 8.8604 & 3.1831 & 0.58008 & 0.38672 & 0.11994 & 0.07996 & 0.0369 & 0.0068 & 0.0008 \\
\hline 13 & 5.6760 & 1.4579 & 85.1666 & 5.4022 & 1.5922 & 0.30366 & 0.20244 & 0.08706 & 0.05804 & 0.0385 & 0.0134 & 0.0020 \\
\hline 14 & 0.6122 & 1.8630 & 85.4915 & 8.0626 & 2.8576 & 0.52254 & 0.34836 & 0.11412 & 0.07608 & 0.0404 & 0.0100 & 0.0016 \\
\hline 15 & 1.6032 & 0.2299 & 95.5480 & 1.8724 & 0.4883 & 0.08982 & 0.05988 & 0.03462 & 0.02308 & 0.0312 & 0.0164 & 0.0032 \\
\hline 16 & 0.4293 & 1.8647 & 84.4333 & 8.8669 & 3.1897 & 0.58182 & 0.38788 & 0.12066 & 0.08044 & 0.0377 & 0.0072 & 0.0004 \\
\hline 17 & 5.6680 & 1.4349 & 85.1784 & 5.4163 & 1.5962 & 0.30426 & 0.20284 & 0.08706 & 0.05804 & 0.0387 & 0.0131 & 0.0022 \\
\hline 18 & 0.6137 & 1.8710 & 85.4620 & 8.0768 & 2.8634 & 0.52272 & 0.34848 & 0.11412 & 0.07608 & 0.0405 & 0.0101 & 0.0011 \\
\hline 19 & 2.3535 & 0.0401 & 92.2794 & 3.7252 & 0.9170 & 0.26166 & 0.17444 & 0.08898 & 0.05932 & 0.0654 & 0.0115 & 0.0235 \\
\hline 20 & 2.6733 & 0.0402 & 93.0357 & 3.1217 & 0.6420 & 0.16896 & 0.11264 & 0.06930 & 0.04620 & 0.0436 & 0.0229 & 0.0235 \\
\hline 21 & 2.4630 & 1.5280 & 90.8251 & 4.4050 & 0.6420 & 0.06774 & 0.04516 & 0.01386 & 0.00924 & 0.0003 & 0.0006 & 0.0000 \\
\hline 22 & 0.4040 & 1.9870 & 83.9520 & 9.1380 & 3.2590 & 0.59340 & 0.39560 & 0.12540 & 0.08360 & 0.0473 & 0.0139 & 0.0008 \\
\hline 23 & 0.4050 & 2.0270 & 83.8681 & 9.1800 & 3.2790 & 0.58560 & 0.39040 & 0.12294 & 0.08196 & 0.0459 & 0.0136 & 0.0005 \\
\hline 24 & 0.3940 & 1.9730 & 83.7500 & 9.3490 & 3.3080 & 0.58080 & 0.38720 & 0.11976 & 0.07984 & 0.0447 & 0.0133 & 0.0004 \\
\hline 25 & 1.2630 & 1.9820 & 88.9650 & 5.4550 & 1.6160 & 0.30780 & 0.20520 & 0.09780 & 0.06520 & 0.0310 & 0.0120 & 0.0000 \\
\hline 26 & 4.1950 & 1.5730 & 87.9810 & 4.8020 & 0.9080 & 0.18840 & 0.12560 & 0.09300 & 0.06200 & 0.0450 & 0.0260 & 0.0010 \\
\hline 27 & 1.9080 & 1.9860 & 92.7220 & 2.7990 & 0.3430 & 0.06180 & 0.04120 & 0.06420 & 0.04280 & 0.0150 & 0.0170 & 0.0000 \\
\hline 28 & 5.1240 & 0.5810 & 88.8020 & 4.1500 & 0.8580 & 0.17940 & 0.11960 & 0.07320 & 0.04880 & 0.0400 & 0.0220 & 0.0020 \\
\hline 29 & 4.9480 & 1.6030 & 86.6460 & 4.9600 & 1.2440 & 0.24180 & 0.16120 & 0.08640 & 0.05760 & 0.0340 & 0.0170 & 0.0010 \\
\hline 30 & 0.4230 & 2.1250 & 84.0050 & 8.7790 & 3.2380 & 0.64740 & 0.43160 & 0.16740 & 0.11160 & 0.0590 & 0.0130 & 0.0000 \\
\hline 31 & 2.4750 & 1.7790 & 87.9700 & 5.5520 & 1.5120 & 0.29520 & 0.19680 & 0.09840 & 0.06560 & 0.0360 & 0.0190 & 0.0010 \\
\hline 32 & 5.5400 & 1.7960 & 86.4450 & 4.7560 & 0.9140 & 0.19860 & 0.13240 & 0.08580 & 0.05720 & 0.0460 & 0.0260 & 0.0030 \\
\hline 33 & 2.5050 & 0.9750 & 92.3210 & 3.2850 & 0.5690 & 0.11100 & 0.07400 & 0.06000 & 0.04000 & 0.0350 & 0.0230 & 0.0020 \\
\hline 34 & 4.1230 & 0.7040 & 90.4400 & 3.5110 & 0.7500 & 0.17040 & 0.11360 & 0.07140 & 0.04760 & 0.0410 & 0.0250 & 0.0030 \\
\hline
\end{tabular}


APPENDIX A: NATURAL GAS COMPOSITION DATABASE

\begin{tabular}{|c|c|c|c|c|c|c|c|c|c|c|c|c|}
\hline ID\# & $\begin{array}{l}\text { nitrogen } \\
\text { [mole\%] }\end{array}$ & $\begin{array}{c}\text { carbon dioxide } \\
\text { [mole\%] }\end{array}$ & $\begin{array}{l}\text { methane } \\
\text { [mole \%] }\end{array}$ & $\begin{array}{l}\text { ethane } \\
\text { [mole\%] }\end{array}$ & $\begin{array}{l}\text { propane } \\
\text { [mole\%] }\end{array}$ & $\begin{array}{l}\text { i-butane } \\
\text { [mole \%] }\end{array}$ & $\begin{array}{l}\text { n-butane } \\
\text { [mole \%] }\end{array}$ & $\begin{array}{c}\text { i-pentane } \\
\text { [mole \%] }\end{array}$ & $\begin{array}{c}\text { n-pentane } \\
\text { [mole \%] }\end{array}$ & $\begin{array}{l}\text { n-hexane } \\
\text { [mole \%] }\end{array}$ & $\begin{array}{c}\text { n-heptane } \\
\text { [mole \%] }\end{array}$ & $\begin{array}{l}\text { n-octane } \\
\text { [mole \%] }\end{array}$ \\
\hline 35 & 1.0370 & 2.0360 & 88.0480 & 6.2390 & 1.8390 & 0.36780 & 0.24520 & 0.09120 & 0.06080 & 0.0260 & 0.0080 & 0.0020 \\
\hline 36 & 0.6122 & 1.8630 & 85.4915 & 8.0626 & 2.8576 & 0.52254 & 0.34836 & 0.11412 & 0.07608 & 0.0404 & 0.0100 & 0.0016 \\
\hline 37 & 0.6137 & 1.8710 & 85.4620 & 8.0768 & 2.8634 & 0.52272 & 0.34848 & 0.11412 & 0.07608 & 0.0405 & 0.0101 & 0.0011 \\
\hline 38 & 0.6178 & 1.9051 & 85.3453 & 8.1433 & 2.8692 & 0.53850 & 0.35900 & 0.10470 & 0.06980 & 0.0345 & 0.0117 & 0.0011 \\
\hline 39 & 3.7924 & 0.2609 & 94.6077 & 1.0118 & 0.2128 & 0.04572 & 0.03048 & 0.01464 & 0.00976 & 0.0086 & 0.0044 & 0.0008 \\
\hline 40 & 0.9015 & 0.0668 & 98.2722 & 0.5159 & 0.1607 & 0.03552 & 0.02368 & 0.00942 & 0.00628 & 0.0055 & 0.0016 & 0.0009 \\
\hline 41 & 0.4313 & 1.7708 & 85.4560 & 8.4983 & 2.7421 & 0.53706 & 0.35804 & 0.10038 & 0.06692 & 0.0315 & 0.0068 & 0.0008 \\
\hline 42 & 5.3551 & 1.7802 & 84.4784 & 5.8782 & 1.7780 & 0.34002 & 0.22668 & 0.07050 & 0.04700 & 0.0309 & 0.0116 & 0.0034 \\
\hline 43 & 5.4939 & 1.8292 & 84.3931 & 5.8857 & 1.6910 & 0.32742 & 0.21828 & 0.06942 & 0.04628 & 0.0296 & 0.0128 & 0.0033 \\
\hline 44 & 5.3452 & 1.7745 & 84.5143 & 5.8831 & 1.7596 & 0.33582 & 0.22388 & 0.07044 & 0.04696 & 0.0309 & 0.0119 & 0.0034 \\
\hline 45 & 5.4952 & 1.8318 & 84.3746 & 5.8795 & 1.7111 & 0.32880 & 0.21920 & 0.06906 & 0.04604 & 0.0297 & 0.0117 & 0.0033 \\
\hline 46 & 0.9617 & 1.5021 & 85.9284 & 8.4563 & 2.3022 & 0.41910 & 0.27940 & 0.07308 & 0.04872 & 0.0228 & 0.0057 & 0.0005 \\
\hline 47 & 0.4264 & 1.9201 & 84.3789 & 8.8749 & 3.1776 & 0.60132 & 0.40088 & 0.10872 & 0.07248 & 0.0310 & 0.0065 & 0.0012 \\
\hline 48 & 1.2010 & 1.8560 & 88.2210 & 6.1190 & 1.8840 & 0.35340 & 0.23560 & 0.05580 & 0.03720 & 0.0230 & 0.0130 & 0.0010 \\
\hline 49 & 0.3407 & 1.8816 & 83.4187 & 9.5284 & 3.5694 & 0.62190 & 0.41460 & 0.10968 & 0.07312 & 0.0327 & 0.0081 & 0.0011 \\
\hline 50 & 5.9990 & 1.3984 & 84.4872 & 5.9271 & 1.5364 & 0.30534 & 0.20356 & 0.06342 & 0.04228 & 0.0251 & 0.0101 & 0.0021 \\
\hline 51 & 1.4200 & 0.0330 & 93.3240 & 1.7800 & 3.2000 & 0.08700 & 0.05800 & 0.02520 & 0.01680 & 0.0560 & 0.0000 & 0.0000 \\
\hline 52 & 1.9285 & 0.4422 & 84.3361 & 8.8946 & 3.1919 & 0.59064 & 0.39376 & 0.10950 & 0.07300 & 0.0325 & 0.0061 & 0.0012 \\
\hline 53 & 0.2331 & 1.6004 & 95.5340 & 1.8790 & 0.4926 & 0.09066 & 0.06044 & 0.03522 & 0.02348 & 0.0309 & 0.0168 & 0.0034 \\
\hline 54 & 1.4546 & 5.6769 & 85.1473 & 5.4174 & 1.5968 & 0.30438 & 0.20292 & 0.08694 & 0.05796 & 0.0391 & 0.0138 & 0.0019 \\
\hline 55 & 1.8643 & 0.6224 & 85.4814 & 8.0607 & 2.8624 & 0.52170 & 0.34780 & 0.11346 & 0.07564 & 0.0398 & 0.0096 & 0.0008 \\
\hline 56 & 1.8292 & 5.4939 & 84.3931 & 5.8857 & 1.6910 & 0.32742 & 0.21828 & 0.06942 & 0.04628 & 0.0296 & 0.0128 & 0.0033 \\
\hline 57 & 1.7802 & 5.3551 & 84.4786 & 5.8782 & 1.7778 & 0.34002 & 0.22668 & 0.07050 & 0.04700 & 0.0309 & 0.0116 & 0.0034 \\
\hline 58 & 0.2339 & 1.6052 & 95.5192 & 1.8835 & 0.4933 & 0.09108 & 0.06072 & 0.03546 & 0.02364 & 0.0326 & 0.0176 & 0.0038 \\
\hline 59 & 1.8497 & 0.4278 & 84.4678 & 8.8604 & 3.1831 & 0.58008 & 0.38672 & 0.11994 & 0.07996 & 0.0369 & 0.0068 & 0.0008 \\
\hline 60 & 1.4579 & 5.6760 & 85.1666 & 5.4022 & 1.5922 & 0.30366 & 0.20244 & 0.08706 & 0.05804 & 0.0385 & 0.0134 & 0.0020 \\
\hline 61 & 1.8630 & 0.6122 & 85.4915 & 8.0626 & 2.8576 & 0.52254 & 0.34836 & 0.11412 & 0.07608 & 0.0404 & 0.0100 & 0.0016 \\
\hline 62 & 0.2339 & 1.6052 & 95.5192 & 1.8835 & 0.4933 & 0.09108 & 0.06072 & 0.03546 & 0.02364 & 0.0326 & 0.0176 & 0.0038 \\
\hline 63 & 1.8497 & 0.4278 & 84.4678 & 8.8604 & 3.1831 & 0.58008 & 0.38672 & 0.11994 & 0.07996 & 0.0369 & 0.0068 & 0.0008 \\
\hline 64 & 1.4579 & 5.6760 & 85.1666 & 5.4022 & 1.5922 & 0.30366 & 0.20244 & 0.08706 & 0.05804 & 0.0385 & 0.0134 & 0.0020 \\
\hline 65 & 1.8630 & 0.6122 & 85.4915 & 8.0626 & 2.8576 & 0.52254 & 0.34836 & 0.11412 & 0.07608 & 0.0404 & 0.0100 & 0.0016 \\
\hline 66 & 0.2299 & 1.6032 & 95.5480 & 1.8724 & 0.4883 & 0.08982 & 0.05988 & 0.03462 & 0.02308 & 0.0312 & 0.0164 & 0.0032 \\
\hline 67 & 1.8647 & 0.4293 & 84.4333 & 8.8669 & 3.1897 & 0.58182 & 0.38788 & 0.12066 & 0.08044 & 0.0377 & 0.0072 & 0.0004 \\
\hline 68 & 1.4349 & 5.6680 & 85.1784 & 5.4163 & 1.5962 & 0.30426 & 0.20284 & 0.08706 & 0.05804 & 0.0387 & 0.0131 & 0.0022 \\
\hline
\end{tabular}


APPENDIX A: NATURAL GAS COMPOSITION DATABASE

\begin{tabular}{|c|c|c|c|c|c|c|c|c|c|c|c|c|}
\hline ID\# & $\begin{array}{l}\text { nitrogen } \\
\text { [mole\%] }\end{array}$ & $\begin{array}{c}\text { carbon dioxide } \\
\text { [mole\%] }\end{array}$ & $\begin{array}{l}\text { methane } \\
\text { [mole \%] }\end{array}$ & $\begin{array}{l}\text { ethane } \\
\text { [mole\%] }\end{array}$ & $\begin{array}{l}\text { propane } \\
\text { [mole\%] }\end{array}$ & $\begin{array}{l}\text { i-butane } \\
\text { [mole \%] }\end{array}$ & $\begin{array}{l}\text { n-butane } \\
\text { [mole \%] }\end{array}$ & $\begin{array}{l}\text { i-pentane } \\
\text { [mole \%] }\end{array}$ & $\begin{array}{c}\text { n-pentane } \\
\text { [mole \%] }\end{array}$ & $\begin{array}{l}\text { n-hexane } \\
\text { [mole \%] }\end{array}$ & $\begin{array}{c}\text { n-heptane } \\
\text { [mole \%] }\end{array}$ & $\begin{array}{l}\text { n-octane } \\
\text { [mole \%] }\end{array}$ \\
\hline 69 & 1.8710 & 0.6137 & 85.4620 & 8.0768 & 2.8634 & 0.52272 & 0.34848 & 0.11412 & 0.07608 & 0.0405 & 0.0101 & 0.0011 \\
\hline 70 & 0.0401 & 2.3535 & 92.2794 & 3.7252 & 0.9170 & 0.26166 & 0.17444 & 0.08898 & 0.05932 & 0.0654 & 0.0115 & 0.0235 \\
\hline 71 & 0.0402 & 2.6733 & 93.0357 & 3.1217 & 0.6420 & 0.16896 & 0.11264 & 0.06930 & 0.04620 & 0.0436 & 0.0229 & 0.0235 \\
\hline 72 & 1.5280 & 2.4630 & 90.8251 & 4.4050 & 0.6420 & 0.06774 & 0.04516 & 0.01386 & 0.00924 & 0.0003 & 0.0006 & 0.0000 \\
\hline 73 & 1.9870 & 0.4040 & 83.9520 & 9.1380 & 3.2590 & 0.59340 & 0.39560 & 0.12540 & 0.08360 & 0.0473 & 0.0139 & 0.0008 \\
\hline 74 & 2.0270 & 0.4050 & 83.8681 & 9.1800 & 3.2790 & 0.58560 & 0.39040 & 0.12294 & 0.08196 & 0.0459 & 0.0136 & 0.0005 \\
\hline 75 & 1.9730 & 0.3940 & 83.7500 & 9.3490 & 3.3080 & 0.58080 & 0.38720 & 0.11976 & 0.07984 & 0.0447 & 0.0133 & 0.0004 \\
\hline 76 & 1.9820 & 1.2630 & 88.9650 & 5.4550 & 1.6160 & 0.30780 & 0.20520 & 0.09780 & 0.06520 & 0.0310 & 0.0120 & 0.0000 \\
\hline 77 & 1.5730 & 4.1950 & 87.9810 & 4.8020 & 0.9080 & 0.18840 & 0.12560 & 0.09300 & 0.06200 & 0.0450 & 0.0260 & 0.0010 \\
\hline 78 & 1.9860 & 1.9080 & 92.7220 & 2.7990 & 0.3430 & 0.06180 & 0.04120 & 0.06420 & 0.04280 & 0.0150 & 0.0170 & 0.0000 \\
\hline 79 & 0.5810 & 5.1240 & 88.8020 & 4.1500 & 0.8580 & 0.17940 & 0.11960 & 0.07320 & 0.04880 & 0.0400 & 0.0220 & 0.0020 \\
\hline 80 & 1.6030 & 4.9480 & 86.6460 & 4.9600 & 1.2440 & 0.24180 & 0.16120 & 0.08640 & 0.05760 & 0.0340 & 0.0170 & 0.0010 \\
\hline 81 & 2.1250 & 0.4230 & 84.0050 & 8.7790 & 3.2380 & 0.64740 & 0.43160 & 0.16740 & 0.11160 & 0.0590 & 0.0130 & 0.0000 \\
\hline 82 & 1.7790 & 2.4750 & 87.9700 & 5.5520 & 1.5120 & 0.29520 & 0.19680 & 0.09840 & 0.06560 & 0.0360 & 0.0190 & 0.0010 \\
\hline 83 & 1.7960 & 5.5400 & 86.4450 & 4.7560 & 0.9140 & 0.19860 & 0.13240 & 0.08580 & 0.05720 & 0.0460 & 0.0260 & 0.0030 \\
\hline 84 & 0.9750 & 2.5050 & 92.3210 & 3.2850 & 0.5690 & 0.11100 & 0.07400 & 0.06000 & 0.04000 & 0.0350 & 0.0230 & 0.0020 \\
\hline 85 & 0.7040 & 4.1230 & 90.4400 & 3.5110 & 0.7500 & 0.17040 & 0.11360 & 0.07140 & 0.04760 & 0.0410 & 0.0250 & 0.0030 \\
\hline 86 & 2.0360 & 1.0370 & 88.0480 & 6.2390 & 1.8390 & 0.36780 & 0.24520 & 0.09120 & 0.06080 & 0.0260 & 0.0080 & 0.0020 \\
\hline 87 & 1.8630 & 0.6122 & 85.4915 & 8.0626 & 2.8576 & 0.52254 & 0.34836 & 0.11412 & 0.07608 & 0.0404 & 0.0100 & 0.0016 \\
\hline 88 & 1.8710 & 0.6137 & 85.4620 & 8.0768 & 2.8634 & 0.52272 & 0.34848 & 0.11412 & 0.07608 & 0.0405 & 0.0101 & 0.0011 \\
\hline 89 & 1.9051 & 0.6178 & 85.3453 & 8.1433 & 2.8692 & 0.53850 & 0.35900 & 0.10470 & 0.06980 & 0.0345 & 0.0117 & 0.0011 \\
\hline 90 & 0.2609 & 3.7924 & 94.6077 & 1.0118 & 0.2128 & 0.04572 & 0.03048 & 0.01464 & 0.00976 & 0.0086 & 0.0044 & 0.0008 \\
\hline 91 & 0.0668 & 0.9015 & 98.2722 & 0.5159 & 0.1607 & 0.03552 & 0.02368 & 0.00942 & 0.00628 & 0.0055 & 0.0016 & 0.0009 \\
\hline 92 & 1.7708 & 0.4313 & 85.4560 & 8.4983 & 2.7421 & 0.53706 & 0.35804 & 0.10038 & 0.06692 & 0.0315 & 0.0068 & 0.0008 \\
\hline 93 & 1.7802 & 5.3551 & 84.4784 & 5.8782 & 1.7780 & 0.34002 & 0.22668 & 0.07050 & 0.04700 & 0.0309 & 0.0116 & 0.0034 \\
\hline 94 & 1.8292 & 5.4939 & 84.3931 & 5.8857 & 1.6910 & 0.32742 & 0.21828 & 0.06942 & 0.04628 & 0.0296 & 0.0128 & 0.0033 \\
\hline 95 & 1.7745 & 5.3452 & 84.5143 & 5.8831 & 1.7596 & 0.33582 & 0.22388 & 0.07044 & 0.04696 & 0.0309 & 0.0119 & 0.0034 \\
\hline 96 & 1.8318 & 5.4952 & 84.3746 & 5.8795 & 1.7111 & 0.32880 & 0.21920 & 0.06906 & 0.04604 & 0.0297 & 0.0117 & 0.0033 \\
\hline 97 & 1.5021 & 0.9617 & 85.9284 & 8.4563 & 2.3022 & 0.41910 & 0.27940 & 0.07308 & 0.04872 & 0.0228 & 0.0057 & 0.0005 \\
\hline 98 & 1.9201 & 0.4264 & 84.3789 & 8.8749 & 3.1776 & 0.60132 & 0.40088 & 0.10872 & 0.07248 & 0.0310 & 0.0065 & 0.0012 \\
\hline 99 & 1.8560 & 1.2010 & 88.2210 & 6.1190 & 1.8840 & 0.35340 & 0.23560 & 0.05580 & 0.03720 & 0.0230 & 0.0130 & 0.0010 \\
\hline 100 & 1.8816 & 0.3407 & 83.4187 & 9.5284 & 3.5694 & 0.62190 & 0.41460 & 0.10968 & 0.07312 & 0.0327 & 0.0081 & 0.0011 \\
\hline 101 & 1.3984 & 5.9990 & 84.4872 & 5.9271 & 1.5364 & 0.30534 & 0.20356 & 0.06342 & 0.04228 & 0.0251 & 0.0101 & 0.0021 \\
\hline 102 & 0.0330 & 1.4200 & 93.3240 & 1.7800 & 3.2000 & 0.08700 & 0.05800 & 0.02520 & 0.01680 & 0.0560 & 0.0000 & 0.0000 \\
\hline
\end{tabular}




\section{APPENDIX B: FORTRAN PROGRAM TO MODIFY \\ A.G.A. 8 (1994) SUBROUTINES FOR GENERAL INFERENTIAL CHARACTERIZATION}




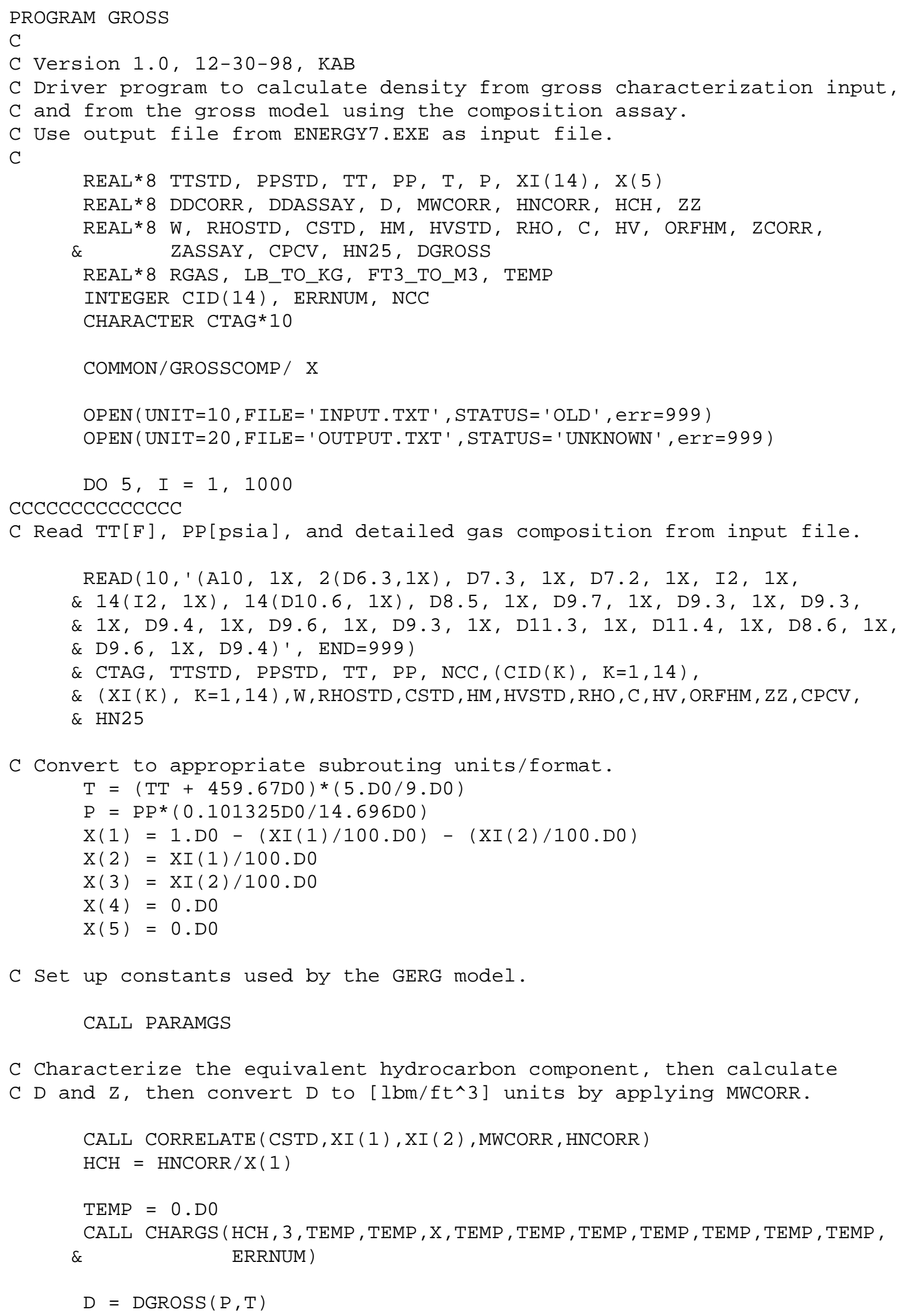




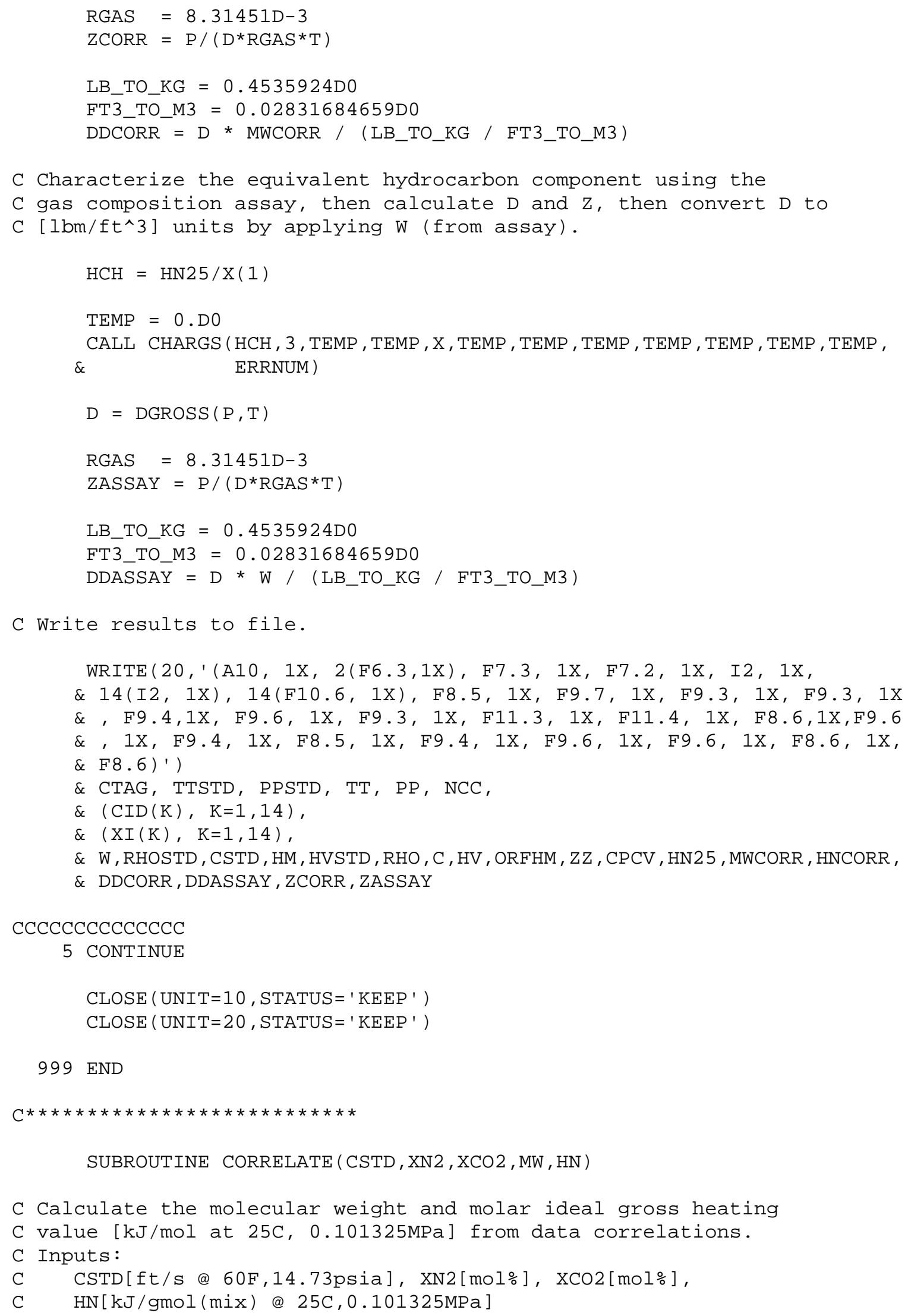


$\mathrm{REAL} * 8 \mathrm{~A} 00, \mathrm{~A} 01, \mathrm{~A} 02, \mathrm{~A} 10, \mathrm{~A} 11, \mathrm{~A} 12, \mathrm{~A} 20, \mathrm{~A} 21, \mathrm{~A} 22, \mathrm{~A} 0, \mathrm{~A} 1, \mathrm{~A} 2$

C

$\mathrm{REAL} \star 8 \mathrm{~A}, \mathrm{~B} 0, \mathrm{~B} 10, \mathrm{~B} 11, \mathrm{~B} 12, \mathrm{~B} 1, \mathrm{~B}, \mathrm{MHC}, \mathrm{CSTD}, \mathrm{XN} 2, \mathrm{XCO} 2, \mathrm{MW}, \mathrm{HN}$

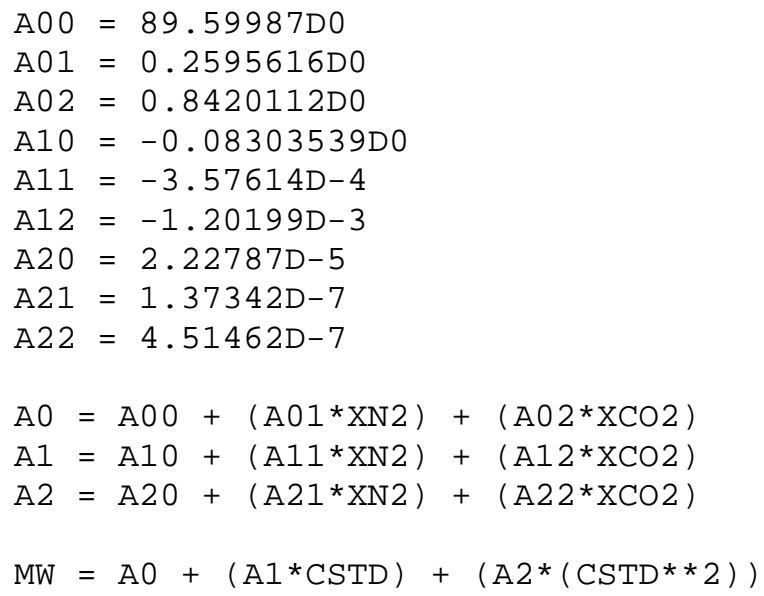




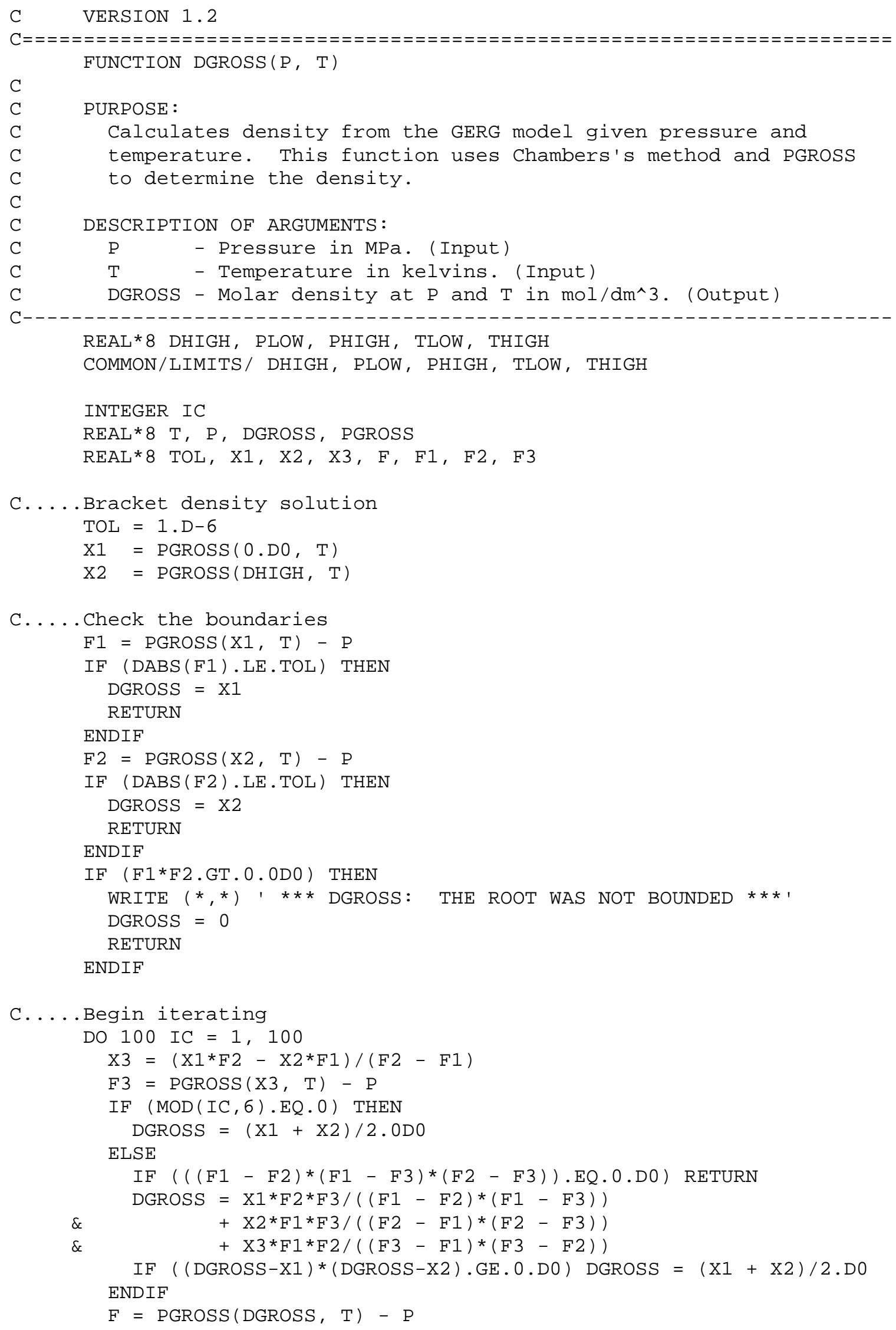




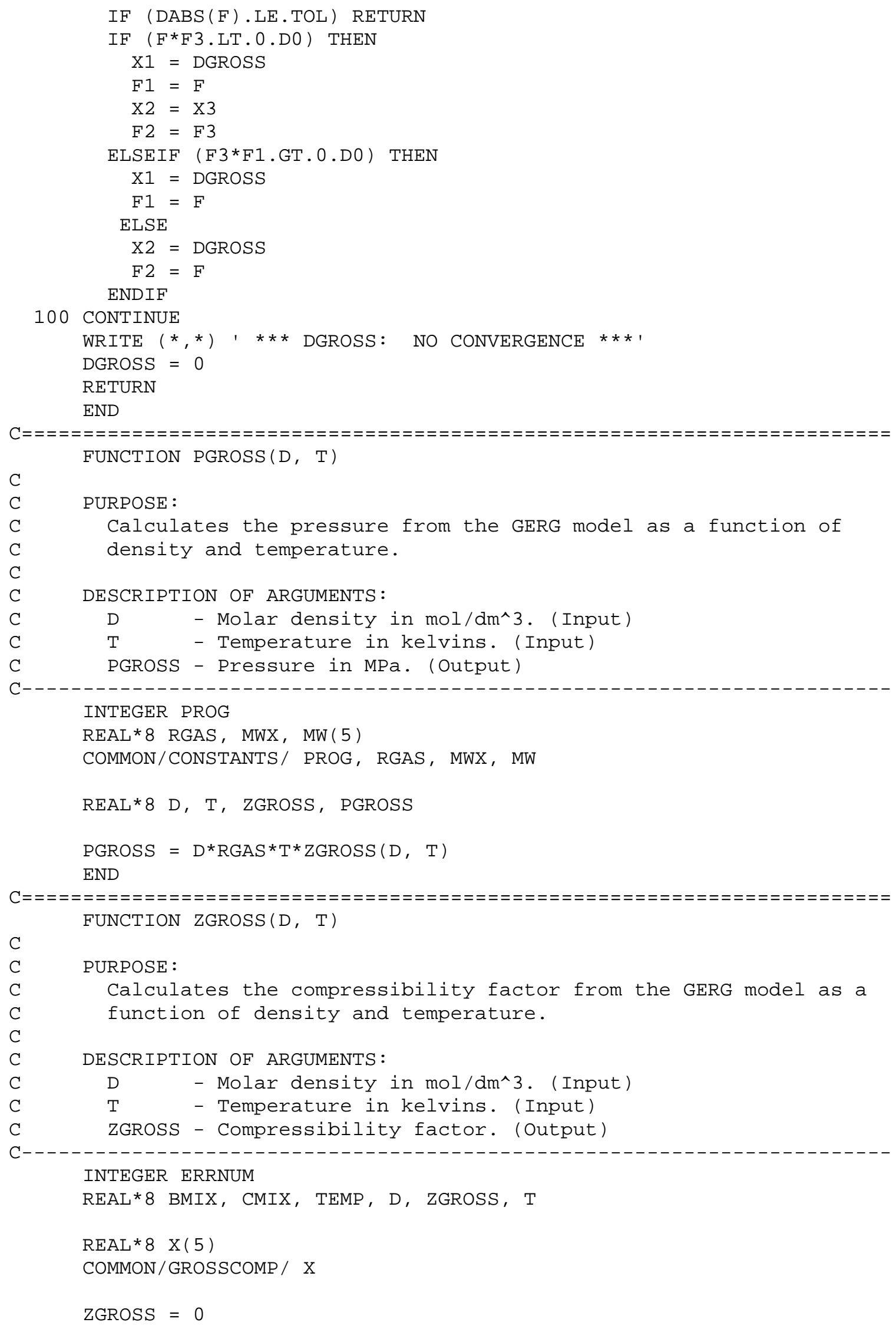


CALL VIRGS ( $\mathrm{T}, \mathrm{X}, \mathrm{BMIX}, \mathrm{CMIX}, \mathrm{TEMP}, 0, \mathrm{ERRNUM})$

IF (ERRNUM.NE.0) RETURN

ZGROSS $=1 . \mathrm{DO}+\mathrm{BMIX}{ }^{*} \mathrm{D}+\mathrm{CMIX} * \mathrm{D} * \mathrm{D}$

END

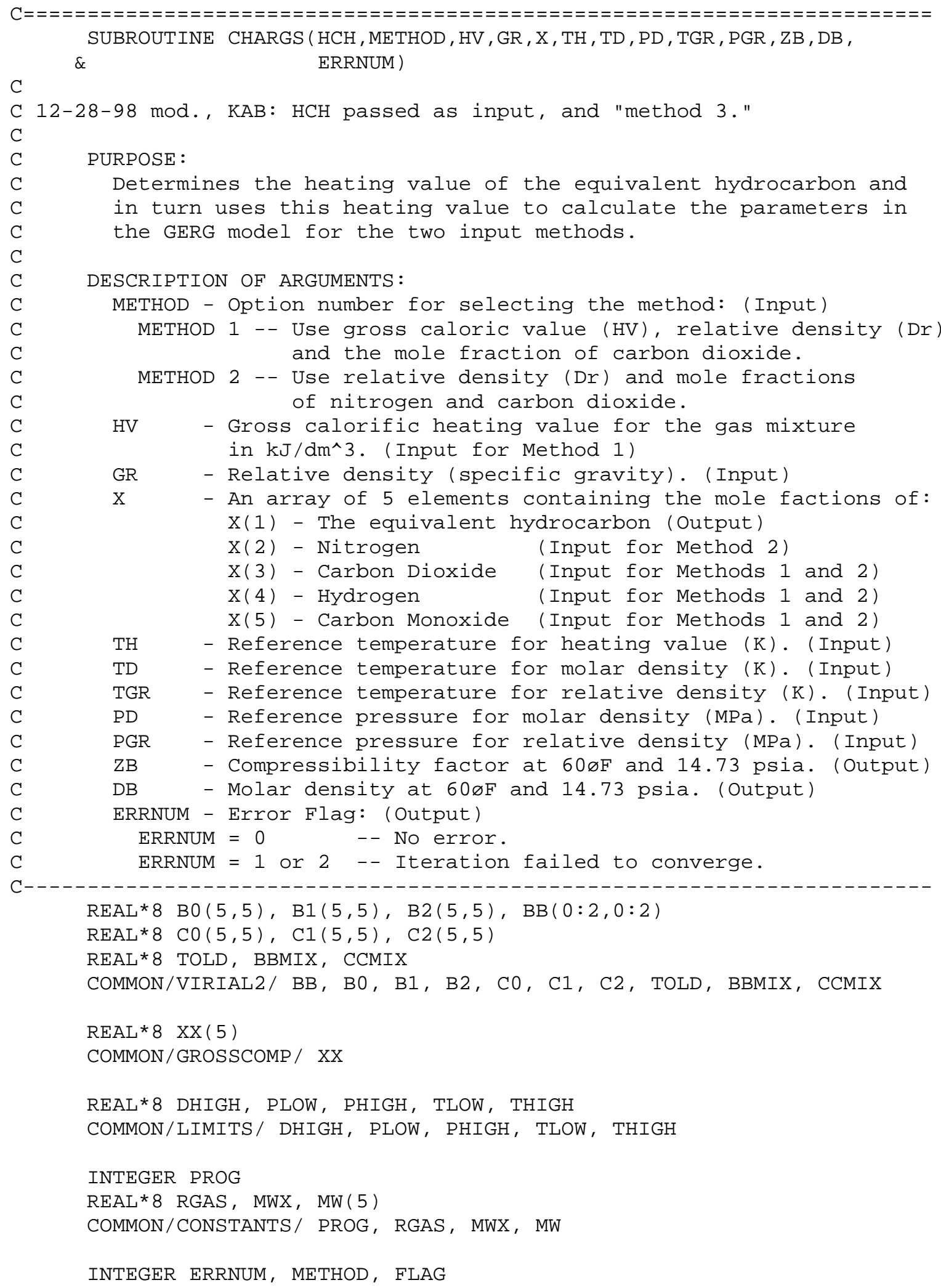




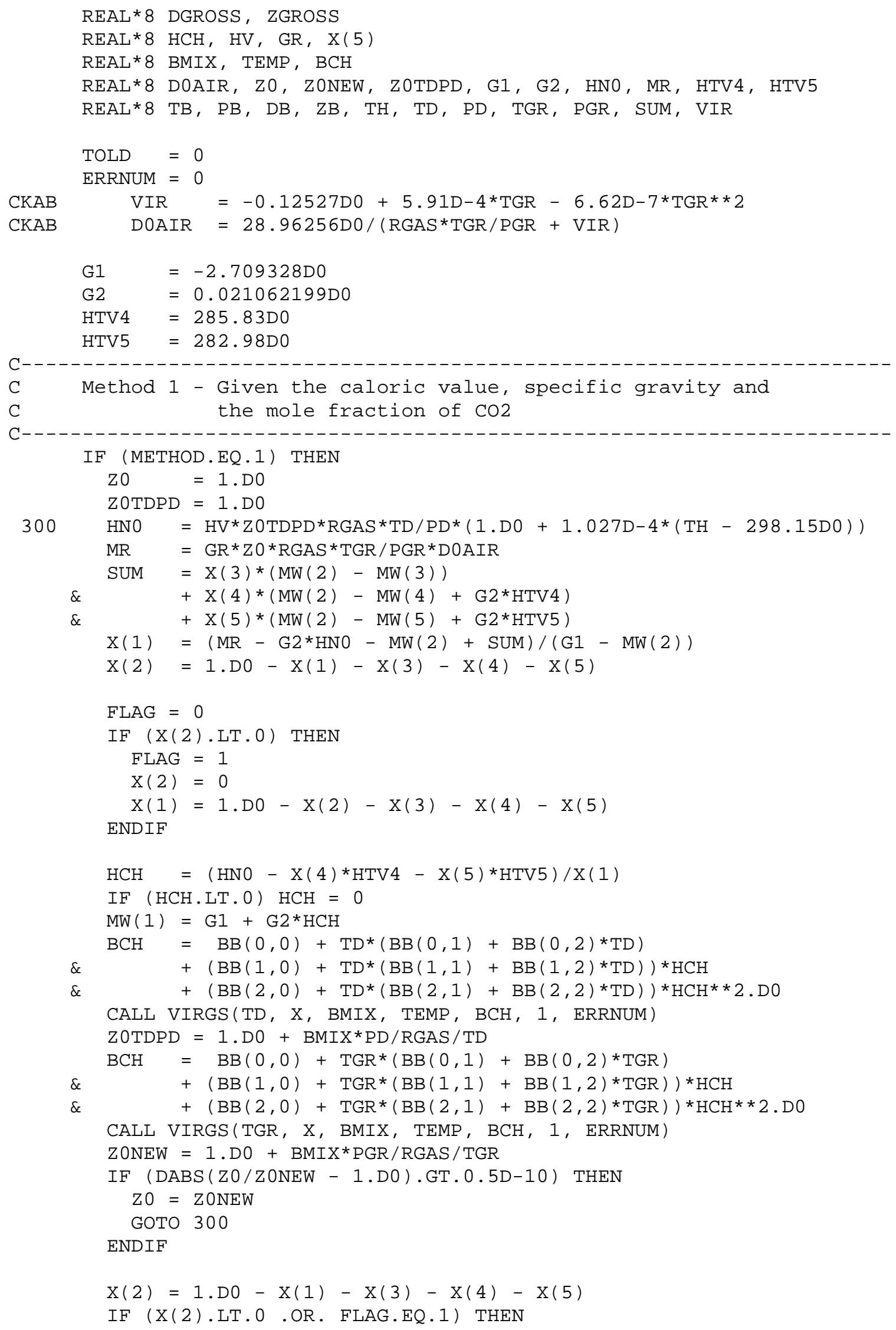




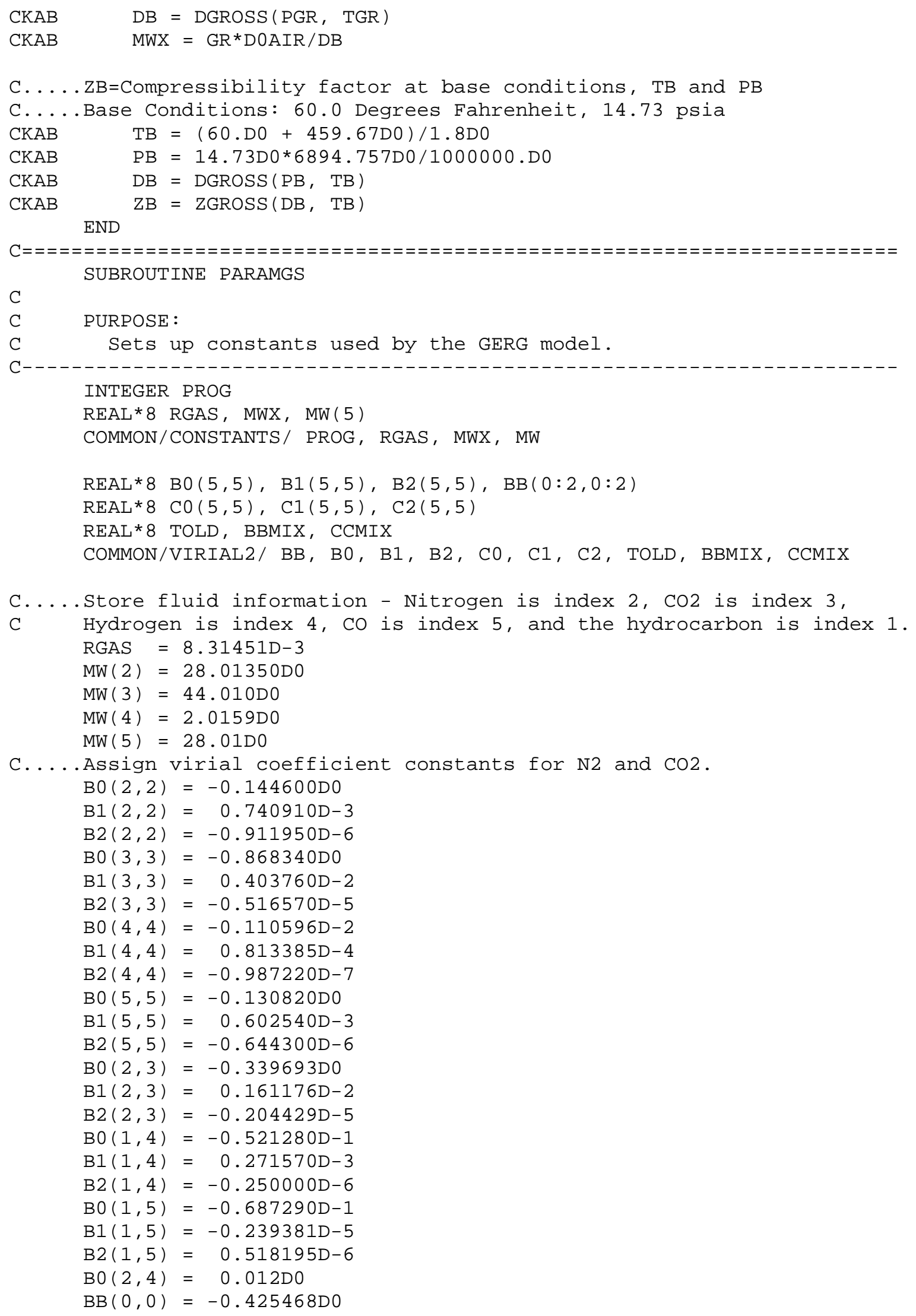




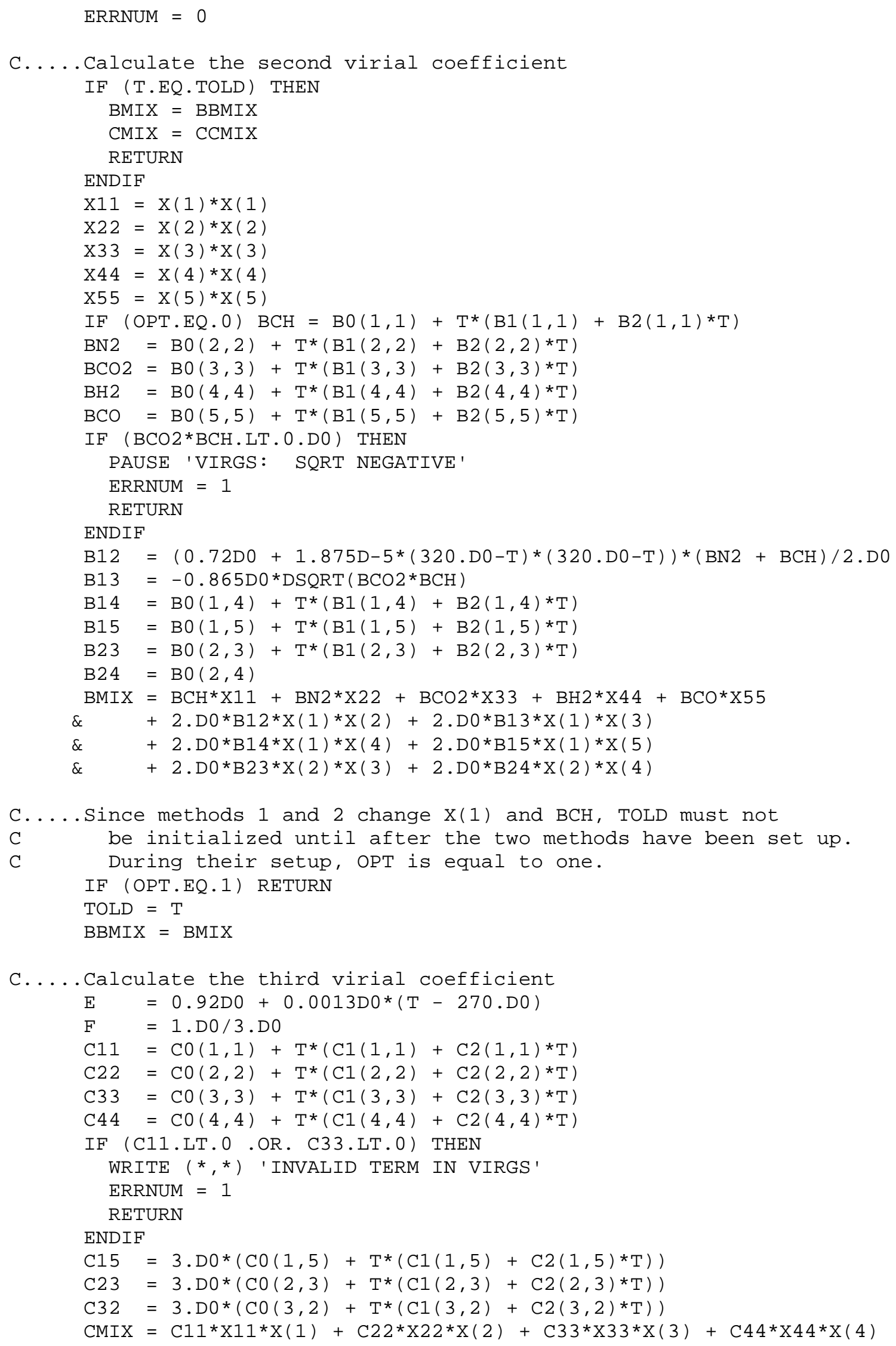




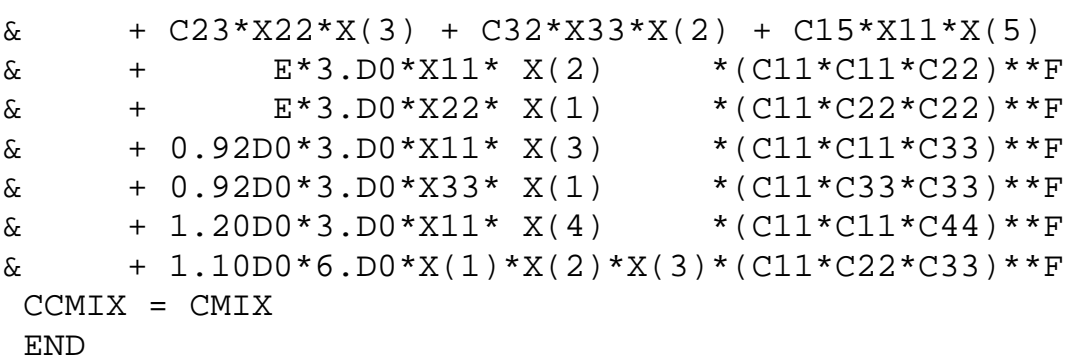

